\title{
ARTICLES
}

\section{Carbamate-Linked Lactose: Design of Clusters and Evidence for Selectivity to Block Binding of Human Lectins to (Neo)Glycoproteins with Increasing Degree of Branching and to Tumor Cells}

\author{
Sabine André, ${ }^{\dagger}$ Daniel Specker, ${ }^{\ddagger}, l$ Nicolai V. Bovin, ${ }^{\S}$ Martin Lensch, ${ }^{\dagger}$ Herbert Kaltner, ${ }^{\dagger}$ Hans-Joachim Gabius, ${ }^{*}{ }^{\dagger}$ \\ and Valentin Wittmann*\$ \\ Institut für Physiologische Chemie, Tierärztliche Fakultät, Ludwig-Maximilians-Universität, Veterinärstraße 13, \\ 80539 München, Germany, Fachbereich Chemie, Universität Konstanz, Universitätsstr. 10, 78457 Konstanz, Germany, and \\ Shemyakin and Ovchinnikov Institute of Bioorganic Chemistry, Russian Academy of Sciences, ul. Miklukho-Maklaya 16/10, \\ 117997 Moscow, Russia. Received October 29, 2008; Revised Manuscript Received June 26, 2009
}

\begin{abstract}
Various pathogenic processes are driven by protein(lectin)-glycan interactions, especially involving $\beta$-galactosides at branch ends of cellular glycans. These emerging insights fuel the interest to design potent inhibitors to block lectins. As a step toward this aim, we prepared a series of ten mono- to tetravalent glycocompounds with lactose as a common headgroup. To obtain activated carbonate for ensuing carbamate formation, conditions for the facile synthesis of pure isomers from anomerically unprotected lactose were identified. To probe for the often encountered intrafamily diversity of human lectins, we selected representative members from the three subgroups of adhesion/ growth-regulatory galectins as receptors. Diversity of the glycan display was accounted for by using four (neo)glycoproteins with different degrees of glycan branching as matrices in solid-phase assays. Cases of increased inhibitory potency of lactose clusters compared to free lactose were revealed. Extent of relative inhibition was not directly associated with valency in the glycocompound and depended on the lectin type. Of note for screening protocols, efficacy of blocking appeared to decrease with increased degree of glycan branching in matrix glycoproteins. Binding to tumor cells was impaired with selectivity for galectins-3 and -4. Representative compounds did not impair growth of carcinoma cells up to a concentration of $5 \mathrm{mM}$ of lactose moieties (valence-corrected value) per assay. The reported bioactivity and the delineation of its modulation by structural parameters of lectins and glycans set instructive examples for the further design of selective inhibitors and assay procedures.
\end{abstract}

\section{INTRODUCTION}

A salient route of biological information transfer starts from glycan determinants of cellular glycoconjugates (1). These sugarencoded signals act as ligands for target-specific receptors (lectins) $(1,2)$. Physiologically, this interaction is involved in disease manifestation, e.g., during chronic inflammation, heart failure, or malignancy. Thus, the design of glycoclusters blocking target recognition of lectins has become an active research area $(2-4)$. In view of their role as markers for unfavorable prognosis in human tumors $(5-7)$, we focus here on the family of adhesion/growth-regulatory galectins.

Galectins share the specificity for $\beta$-galactosides at branch ends of glycans so that glycoclusters can conveniently be loaded with lactose as a common headgroup (8). Of note, the spatial presentation of lectin sites differs within this family (2). Thus, it is mandatory to examine at least one member of each subgroup

\footnotetext{
* Corresponding author. H.-J.G.: e-mail gabius@tiph.vetmed.unimuenchen.de; fax (+49) 89-2180-2508.V.W.: e-mail mail@valentinwittmann.de; fax (+49) 7531-88-4573.

${ }^{\dagger}$ Ludwig-Maximilians-Universität.

*Universität Konstanz.

${ }^{\S}$ Russian Academy of Sciences.

"New address: Polymer Research - Polymer Colloids, BASF SE, 67056 Ludwigshafen, Germany.
}

in a comparative study. Hence, the following representatives were chosen: the homodimeric (prototype) galectin-1, the chimera-type galectin-3 with the ability for pentamerization in the presence of suitable ligands, the tandem-repeat-type galectin-4 with its two domains connected by a linker, and galectin-5 with its low degree of oligomer formation. Aside from the panel of lectins, it is equally important to take account of the local density of ligand. As work with different (neo)glycoproteins has revealed $(9,10)$, lectin affinity and selectivity can be modulated by glycan substitutions and branching.

In detail, four different types of binding partner for the lectins were thus tested: lactosylated bovine serum albumin (LacBSA), a neoglycoprotein with rather random and widely spaced presentation of lactose units, and three glycoproteins with either biantennary (serum amyloid P component: SAP), triantennary (asialofetuin: ASF), or tetra-antennary N-glycans $\left(\alpha_{1}\right.$-acid glycoprotein: AGP). The listed (neo)glycoproteins were adsorbed to microtiter plate wells to serve as lectin binders. With these surfaces, solid-phase assays were carried out to determine inhibition of binding of the lectins to the surfaces by lactose or synthetic lactose clusters. Natural ligands on cell surfaces are known to be present in more complex form than these lactose derivatives $(11,12)$. Since it is an open question whether the glycoclusters are capable of impairing the binding of lectins to cell surfaces, we performed fluorimetric binding assays with 
human tumor cells. In addition to the galectins, a toxic plant lectin akin to ricin, i.e., the galactoside-specific mistletoe lectin (Viscum album agglutinin, VAA) with $\beta$-trefoil folding and two fully accessible lectin sites $87 \AA$ apart in the dimer (13), was also tested.

The lactose derivatives that were tested for their potency to inhibit the lectin-matrix interaction varied in valency from one to four lactose moieties per inhibitor. However, the valency of the ligands is not the only factor that determines avidity. Case studies on selectins with a lipid anchor (i.e., 2-tetradecylhexadecyl) attached to the glycan, the cholera toxin B pentamer with spacered $p$-nitrophenyl galactopyranoside, and galectins with thiourea-linked ligands on calix $[n]$ arenes showed that the spacer portion can notably contribute to the inhibitor's performance $(14-16)$. Variations in this part can add to selectivity, because the vicinity of the lectin sites is quite divergent in galectins $(12,17)$. Therefore, we employed two series of lactose clusters differing in the absence or presence of a butene diol linker leading to varied lactose spacing. Lactosyl carbamates were conveniently synthesized by coupling an activated lactosyl carbonate to a set of amines. Therefore, we first had to resolve the problem of finding conditions to produce the glycosyl carbonate from anomerically deprotected lactose as pure isomer.

Our report, combining synthesis of ten mono- to tetravalent lactose derivatives with biochemical/cell biological testing on plant/human lectins, will answer the following questions: (1) Which conditions are suitable to gain fast and easy access to pure isomers of activated lactosyl carbonates? (2) Will the inhibitory potency of conjugated lactose relative to free lactose be enhanced? (3) How will the structure and valency of the lactose clusters and the degree of glycan branching in the (neo)glycoprotein matrix influence inhibition in solid-phase assays? (4) Will lectin binding to cells be inhibited by the lactose derivatives? (5) Will potent lactose derivatives lack cytotoxicity?

\section{EXPERIMENTAL PROCEDURES}

General Methods. Analytical thin layer chromatography was performed using silica gel $60 \mathrm{~F}_{254}$ aluminum sheets from Merck (Darmstadt, Germany); compound spots were visualized by quenching of fluorescence and/or by charring after treatment with cerium molybdophosphate. Preparative flash column chromatography (FC) was carried out on Merck silica gel 60 (40-63 $\mu \mathrm{m}) .{ }^{1} \mathrm{H}$ NMR and ${ }^{13} \mathrm{C}$ NMR spectra were recorded on a Bruker Avance DRX 600 instrument at a temperature of $300 \mathrm{~K} .{ }^{1} \mathrm{H}$ Chemical shifts are referenced to residual protic solvent $\left(\mathrm{CDCl}_{3}\right.$, $\left.\delta_{\mathrm{H}}=7.26 ; \mathrm{D}_{2} \mathrm{O}, \delta_{\mathrm{H}}=4.63\right) .{ }^{13} \mathrm{C}$ Chemical shifts are referenced to the solvent signal $\left(\mathrm{CDCl}_{3}, \delta_{\mathrm{C}}=77.0\right)$ or in the case of $\mathrm{D}_{2} \mathrm{O}$ to internal standard $\mathrm{CD}_{3} \mathrm{CN}\left(\delta_{\mathrm{C}}=1.32 \mathrm{ppm}\right)$. Assignments of proton and carbon signals were carried out by the aid of DQFCOSY, HMQC, and ROESY experiments. MALDI mass spectra were obtained on a Bruker Biflex III instrument with $\alpha$-cyano4-hydroxycinnamic acid as the matrix (positive mode). Elemental analyses were performed by the microanalytical facility at the Universität Konstanz.

4-Nitrophenyl-[2,3,4,6-tetra- $O$-acetyl- $\beta$-D-galactopyranosyl$(\mathbf{1} \rightarrow \mathbf{4})$-2,3,6-tri- $\boldsymbol{O}$-acetyl- $\alpha$-D-glucopyranosyl] Carbonate (18) $(\boldsymbol{\alpha}-\mathbf{3})$. Lactose derivative 1 (19) $(100 \mathrm{mg}, 0.16 \mathrm{mmol})$ was dissolved in $\mathrm{CH}_{3} \mathrm{CN}$ (3.5 mL). A solution of $p$-nitrophenyl chloroformate 2 (48 mg, $0.24 \mathrm{mmol})$ in $\mathrm{CH}_{3} \mathrm{CN}(0.5 \mathrm{~mL})$ and 4-(dimethylamino)-pyridine (29 mg, $0.24 \mathrm{mmol}$ ) was added and the mixture was stirred for $30 \mathrm{~min}$. The solvent was evaporated, and the remainder was dissolved in ethyl acetate and washed with water, $1 \mathrm{M} \mathrm{HCl}$, and brine. The organic layer was dried $\left(\mathrm{Na}_{2} \mathrm{SO}_{4}\right)$, concentrated, and purified by $\mathrm{FC}$ (petroleum ether/ ethyl acetate $1: 1 \rightarrow 1: 2)$ to yield $\alpha-3(122 \mathrm{mg}, 95 \%)$ as a white solid: $R_{\mathrm{f}}=0.45$ (petroleum ether/ethyl acetate $1: 2$ ). ${ }^{1} \mathrm{H}$ NMR $\left(600 \mathrm{MHz}, \mathrm{CDCl}_{3}\right): \delta=8.30-8.28$ (m, $\left.2 \mathrm{H}, \mathrm{Ar}\right), 7.43-7.42$ $(\mathrm{m}, 2 \mathrm{H}, \mathrm{Ar}), 6.20\left(\mathrm{~d}, J=3.6 \mathrm{~Hz}, 1 \mathrm{H}, \mathrm{H}-1^{\mathrm{Glc}}\right), 5.54(\mathrm{dd}, J=$ $\left.10.1 \mathrm{~Hz}, J=9.5 \mathrm{~Hz}, 1 \mathrm{H}, \mathrm{H}-3^{\mathrm{Glc}}\right), 5.35(\mathrm{dd}, J=3.3 \mathrm{~Hz}, J=$ $\left.0.7 \mathrm{~Hz}, 1 \mathrm{H}, \mathrm{H}-4^{\mathrm{Gal}}\right), 5.12(\mathrm{dd}, J=10.4 \mathrm{~Hz}, J=7.9 \mathrm{~Hz}, 1 \mathrm{H}$, $\left.\mathrm{H}-2^{\mathrm{Gal}}\right), 5.07\left(\mathrm{dd}, J=10.3 \mathrm{~Hz}, J=3.6 \mathrm{~Hz}, 1 \mathrm{H}, \mathrm{H}-2^{\mathrm{Glc}}\right), 4.96$ (dd, $\left.J=10.4 \mathrm{~Hz}, J=3.5 \mathrm{~Hz}, 1 \mathrm{H}, \mathrm{H}-3^{\mathrm{Gal}}\right), 4.53-4.51(\mathrm{~m}, 2$ $\left.\mathrm{H}, \mathrm{H}-6^{\mathrm{Glc}}, \mathrm{H}-1^{\mathrm{Gal}}\right), 4.17-4.06$ (m, $4 \mathrm{H}, \mathrm{H}-5^{\mathrm{Glc}}, \mathrm{H}-6^{\prime \mathrm{Glc}}, \mathrm{H}-6^{\mathrm{Gal}}$, H-6 $\left.{ }^{\prime \mathrm{Gal}}\right), 3.91-3.87\left(\mathrm{~m}, 2 \mathrm{H}, \mathrm{H}-4^{\mathrm{Glc}}, \mathrm{H}-5^{\mathrm{Gal}}\right), 2.15$ (s, $3 \mathrm{H}$, $\left.\mathrm{C}(\mathrm{O}) \mathrm{CH}_{3}\right), 2.13$ (s, $\left.3 \mathrm{H}, \mathrm{C}(\mathrm{O}) \mathrm{CH}_{3}\right), 2.07$ (s, $3 \mathrm{H}, \mathrm{C}(\mathrm{O}) \mathrm{CH}_{3}$ ), $2.05\left(\mathrm{~s}, 3 \mathrm{H}, \mathrm{C}(\mathrm{O}) \mathrm{CH}_{3}\right), 2.04\left(\mathrm{~s}, 3 \mathrm{H}, \mathrm{C}(\mathrm{O}) \mathrm{CH}_{3}\right), 2.04$ (s, $3 \mathrm{H}$, $\left.\mathrm{C}(\mathrm{O}) \mathrm{CH}_{3}\right), 1.95\left(\mathrm{~s}, 3 \mathrm{H}, \mathrm{C}(\mathrm{O}) \mathrm{CH}_{3}\right) .{ }^{13} \mathrm{C} \mathrm{NMR}(150 \mathrm{MHz}$, $\left.\mathrm{CDCl}_{3}\right): \delta=170.2,170.1,170.0,170.0,169.7,169.4,168.9$ $\left(C(\mathrm{O}) \mathrm{CH}_{3}\right), 154.9(\mathrm{OC}(\mathrm{O}) \mathrm{O}), 150.7,145.6,125.4,121.4(\mathrm{Ar})$, $101.0\left(\mathrm{C}-1^{\mathrm{Gal}}\right), 94.0\left(\mathrm{C}-1^{\mathrm{Glc}}\right), 75.2\left(\mathrm{C}-4^{\mathrm{Glc}}\right), 71.3\left(\mathrm{C}-5^{\mathrm{Glc}}\right), 70.9$ $\left(\mathrm{C}-3^{\mathrm{Gal}}\right), 70.7\left(\mathrm{C}-5^{\mathrm{Gal}}\right), 79.3\left(\mathrm{C}-2^{\mathrm{Glc}}\right), 69.1\left(\mathrm{C}-3^{\mathrm{Glc}}\right), 69.0\left(\mathrm{C}-2^{\mathrm{Gal}}\right)$, $66.5\left(\mathrm{C}-4^{\mathrm{Gal}}\right), 61.1\left(\mathrm{C}-6^{\mathrm{Glc}}\right), 60.7\left(\mathrm{C}-6^{\mathrm{Gal}}\right), 20.7-20.4(\mathrm{C}(\mathrm{O}) C \mathrm{H})$. MALDI-MS: calcd $\mathrm{m} / \mathrm{z} 824.2\left[\mathrm{M}+\mathrm{Na}^{+}\right], 840.2\left[\mathrm{M}+\mathrm{K}^{+}\right]$, found 824.0, 839.9. Anal. calcd for $\mathrm{C}_{33} \mathrm{H}_{39} \mathrm{NO}_{22}$ : C 49.44, $\mathrm{H}$ 4.90, N 1.75, found: C 49.24, H 4.98, N 1.76.

4-Nitrophenyl-[2,3,4,6-tetra- $\boldsymbol{O}$-acetyl- $\boldsymbol{\beta}$-D-galactopyranosyl$(1 \rightarrow 4)$-2,3,6-tri- $\boldsymbol{O}$-acetyl- $\boldsymbol{\beta}$-D-glucopyranosyl] Carbonate $(18)$ $(\boldsymbol{\beta}$-3). Lactose derivative $\mathbf{1}$ (19) $(8.6 \mathrm{~g}, 13.5 \mathrm{mmol})$ was dissolved in $\mathrm{CH}_{3} \mathrm{CN}(430 \mathrm{~mL})$ and cooled to $0{ }^{\circ} \mathrm{C}$. A solution of p-nitrophenyl chloroformate $2(2.89 \mathrm{~g}, 14.3 \mathrm{mmol})$ in $\mathrm{CH}_{3} \mathrm{CN}$ (20 mL) and 2,6-lutidine (1.66 mL, $14.3 \mathrm{mmol})$ was added, and the mixture was stirred overnight. The solvent was evaporated, and the remainder was dissolved in ethyl acetate and washed with water, $1 \mathrm{M} \mathrm{HCl}$, and brine. The organic layer was dried $\left(\mathrm{Na}_{2} \mathrm{SO}_{4}\right)$, concentrated, and crystallized from ethyl acetate/ petroleum ether to yield $\beta \mathbf{- 3}(5.40 \mathrm{~g}, 50 \%)$ as a white solid: $R_{\mathrm{f}}$ $=0.47$ (petroleum ether/ethyl acetate $1: 2) .{ }^{1} \mathrm{H}$ NMR $(600 \mathrm{MHz}$, $\left.\mathrm{CDCl}_{3}\right): \delta=8.30-8.28$ (m, $\left.2 \mathrm{H}, \mathrm{Ar}\right), 7.42-7.40$ (m, $2 \mathrm{H}, \mathrm{Ar}$ ), $5.63\left(\mathrm{~d}, J=7.8 \mathrm{~Hz}, 1 \mathrm{H}, \mathrm{H}-1^{\mathrm{Glc}}\right), 5.35(\mathrm{dd}, J=3.4 \mathrm{~Hz}, J=0.8$ $\left.\mathrm{Hz}, 1 \mathrm{H}, \mathrm{H}-4^{\mathrm{Gal}}\right), 5.26\left(\mathrm{t}, J=9.0 \mathrm{~Hz}, 1 \mathrm{H}, \mathrm{H}-3^{\mathrm{Glc}}\right), 5.15-5.10$ $\left(\mathrm{m}, 2 \mathrm{H}, \mathrm{H}-2^{\mathrm{Glc}}, \mathrm{H}-2^{\mathrm{Gal}}\right), 4.96(\mathrm{dd}, J=10.4 \mathrm{~Hz}, J=3.2 \mathrm{~Hz}, 1$ $\left.\mathrm{H}, \mathrm{H}-3^{\mathrm{Gal}}\right), 4.53-4.49$ (m, $\left.2 \mathrm{H}, \mathrm{H}-6^{\mathrm{Glc}}, \mathrm{H}-1^{\mathrm{Gal}}\right), 4.16-4.06$ (m, $\left.3 \mathrm{H}, \mathrm{H}-6^{\prime \mathrm{Glc}}, \mathrm{H}-6^{\mathrm{Gal}}, \mathrm{H}-6^{\prime \mathrm{Gal}}\right), 3.94-3.88$ (m, $\left.2 \mathrm{H}, \mathrm{H}-4^{\mathrm{Glc}}, \mathrm{H}-5^{\mathrm{Gal}}\right)$, $3.83-3.81\left(\mathrm{~m}, 1 \mathrm{H}, \mathrm{H}-5^{\mathrm{Glc}}\right), 2.16\left(\mathrm{~s}, 3 \mathrm{H}, \mathrm{C}(\mathrm{O}) \mathrm{CH}_{3}\right), 2.13$ (s, 3 $\left.\mathrm{H}, \mathrm{C}(\mathrm{O}) \mathrm{CH}_{3}\right), 2.09$ (s, $\left.3 \mathrm{H}, \mathrm{C}(\mathrm{O}) \mathrm{CH}_{3}\right), 2.07$ (s, $\left.3 \mathrm{H}, \mathrm{C}(\mathrm{O}) \mathrm{CH}_{3}\right)$, 2.05 (s, $\left.3 \mathrm{H}, \mathrm{C}(\mathrm{O}) \mathrm{CH}_{3}\right), 2.04$ (s, $\left.3 \mathrm{H}, \mathrm{C}(\mathrm{O}) \mathrm{CH}_{3}\right), 1.97$ (s, $3 \mathrm{H}$, $\left.\mathrm{C}(\mathrm{O}) \mathrm{CH}_{3}\right) .{ }^{13} \mathrm{C} \mathrm{NMR}\left(150 \mathrm{MHz}, \mathrm{CDCl}_{3}\right): \delta=170.4,170.2$, 170.1, 169.6, 169.4, $169.0\left(\mathrm{C}(\mathrm{O}) \mathrm{CH}_{3}\right), 154.7$ (OC(O)O), 150.7, 145.7, 125.4, 121.6 (Ar), 101.0 (C-1 $\left.{ }^{\mathrm{Gal}}\right), 95.7\left(\mathrm{C}-1^{\mathrm{Glc}}\right), 75.3(\mathrm{C}-$ $\left.4^{\mathrm{Glc}}\right), 73.7\left(\mathrm{C}-5^{\mathrm{Glc}}\right), 72.6\left(\mathrm{C}-3^{\mathrm{Glc}}\right), 71.0\left(\mathrm{C}-3^{\mathrm{Gal}}\right), 70.7\left(\mathrm{C}-5^{\mathrm{Gal}}\right)$, $70.2\left(\mathrm{C}-2^{\mathrm{Glc}}\right), 69.0\left(\mathrm{C}-2^{\mathrm{Gal}}\right), 66.5\left(\mathrm{C}-4^{\mathrm{Gal}}\right), 61.4\left(\mathrm{C}-6^{\mathrm{Glc}}\right), 60.8$ $\left(\mathrm{C}^{-6}{ }^{\mathrm{Gal}}\right), 20.8-20.5\left(\mathrm{C}(\mathrm{O}) \mathrm{CH}_{3}\right)$. MALDI-MS: calcd $\mathrm{m} / \mathrm{z} 824.2$ $\left[\mathrm{M}+\mathrm{Na}^{+}\right], 840.2\left[\mathrm{M}+\mathrm{K}^{+}\right]$, found 824.1, 840.0. Anal. calcd for $\mathrm{C}_{33} \mathrm{H}_{39} \mathrm{NO}_{22}$ : C 49.44, $\mathrm{H} 4.90, \mathrm{~N} \mathrm{1.75}$, found: C 48.98, H 5.22, N 1.82 .

4-Hydroxy-(Z)-but-2-enyl 2,3,4,6-tetra- $O$-acetyl- $\beta$-D-galactopyranosyl-( $1 \rightarrow 4)$-2,3,6-tri- $\boldsymbol{O}$-acetyl- $\boldsymbol{\beta}$-D-glucopyranoside (6). Under argon $\mathrm{Ag}_{2} \mathrm{CO}_{3}(2.7 \mathrm{~g}, 9.7 \mathrm{mmol}), \mathrm{CaSO}_{4} \cdot 0.5 \mathrm{H}_{2} \mathrm{O}(6.5 \mathrm{~g}$, $45 \mathrm{mmol}$ ), an iodine crystal, and (Z)-but-2-ene-1,4-diol 5 (26 $\mathrm{mL}, 322 \mathrm{mmol}$ ) were stirred for $15 \mathrm{~min}$ at room temperature. Acetobromolactose $4(20,21)(3 \mathrm{~g}, 4.3 \mathrm{mmol})$ was added and the mixture was stirred for further $24 \mathrm{~h}$. After addition of $\mathrm{CH}_{2} \mathrm{Cl}_{2}$ $(100 \mathrm{~mL})$, the mixture was filtered through Celite. To the biphasic filtrate water $(100 \mathrm{~mL})$ was added, and the aqueous phase was separated and extracted with $\mathrm{CH}_{2} \mathrm{Cl}_{2}(50 \mathrm{~mL})$. The combined organic layers were washed with water $(3 \times 100 \mathrm{~mL})$ and brine and dried over $\mathrm{Na}_{2} \mathrm{SO}_{4}$. The solvent was evaporated and the remainder purified by $\mathrm{FC}$ (petroleum ether/ethyl acetate $1: 2)$ to give $6(1.85 \mathrm{~g}, 61 \%): R_{\mathrm{f}}=0.25$ (petroleum ether/ethyl acetate $1: 2) .{ }^{1} \mathrm{H}$ NMR $\left(600 \mathrm{MHz}, \mathrm{CDCl}_{3}\right): \delta=5.85-5.81(\mathrm{~m}$, $\left.1 \mathrm{H}, \mathrm{H}^{\text {vinyl }}\right), 5.63-5.59\left(\mathrm{~m}, 1 \mathrm{H}, \mathrm{H}^{\mathrm{vinyl}}\right), 5.34(\mathrm{~d}, J=3.0 \mathrm{~Hz}, 1$ $\left.\mathrm{H}, \mathrm{H}-4^{\mathrm{Gal}}\right), 5.19\left(\mathrm{~d}, J=9.3 \mathrm{~Hz}, 1 \mathrm{H}, \mathrm{H}-3^{\mathrm{Glc}}\right), 5.10(\mathrm{dd}, J=$ $\left.10.4 \mathrm{~Hz}, J=7.9 \mathrm{~Hz}, 1 \mathrm{H}, \mathrm{H}-2^{\mathrm{Gal}}\right), 4.95(\mathrm{dd}, J=10.4 \mathrm{~Hz}, J=$ $\left.3.5 \mathrm{~Hz}, 1 \mathrm{H}, \mathrm{H}-3^{\mathrm{Gal}}\right), 4.90(\mathrm{dd}, J=9.4 \mathrm{~Hz}, J=8.0 \mathrm{~Hz}, 1 \mathrm{H}$, 
$\left.\mathrm{H}-2^{\mathrm{Glc}}\right), 4.53-4.50\left(\mathrm{~m}, 2 \mathrm{H}, \mathrm{H}-1^{\mathrm{Glc}}, \mathrm{H}-6^{\mathrm{Glc}}\right), 4.49(\mathrm{~d}, J=7.9$ $\left.\mathrm{Hz}, 1 \mathrm{H}, \mathrm{H}-1^{\mathrm{Gal}}\right), 4.28(\mathrm{ddd}, J=19.9 \mathrm{~Hz}, J=12.6 \mathrm{~Hz}, J=6.7$ $\mathrm{Hz}, 2 \mathrm{H}, \mathrm{H}^{\text {allyl }}$ ), 4.18 (bd, $J=6.2 \mathrm{~Hz}, 2 \mathrm{H}, \mathrm{H}^{\text {allyl }}$ ), 4.14-4.06 (m, $\left.3 \mathrm{H}, \mathrm{H}-6^{\prime \mathrm{Glc}}, \mathrm{H}-6^{\mathrm{Gal}}, \mathrm{H}-6^{\prime \mathrm{Gal}}\right), 3.87$ (bt, $J=6.7 \mathrm{~Hz}, 1 \mathrm{H}$, $\mathrm{H}-5^{\mathrm{Gal}}$ ), 3.79 (t, $J=9.5 \mathrm{~Hz}, 1 \mathrm{H}, \mathrm{H}-4^{\mathrm{Glc}}$ ), 3.61 (ddd, $J=9.8$ $\left.\mathrm{Hz}, J=5.0 \mathrm{~Hz}, J=2.0 \mathrm{~Hz}, 2 \mathrm{H}, \mathrm{H}-5^{\mathrm{Glc}}\right), 2.14(\mathrm{~s}, 3 \mathrm{H}$, $\left.\mathrm{C}(\mathrm{O}) \mathrm{CH}_{3}\right), 2.13$ (s, $\left.3 \mathrm{H}, \mathrm{C}(\mathrm{O}) \mathrm{CH}_{3}\right), 2.05$ (s, $\left.3 \mathrm{H}, \mathrm{C}(\mathrm{O}) \mathrm{CH}_{3}\right)$, $2.04\left(\mathrm{~s}, 9 \mathrm{H}, \mathrm{C}(\mathrm{O}) \mathrm{CH}_{3}\right), 1.96$ (s, $\left.3 \mathrm{H}, \mathrm{C}(\mathrm{O}) \mathrm{CH}_{3}\right) .{ }^{13} \mathrm{C}$ NMR $(150$ $\left.\mathrm{MHz}, \mathrm{CDCl}_{3}\right): \delta=170.4,170.3,170.1,170.0,169.7,169.7$, $169.0\left(\mathrm{C}(\mathrm{O}) \mathrm{CH}_{3}\right), 133.3,126.8\left(\mathrm{CH}^{\text {olefin }}\right), 125.3,121.7(\mathrm{Ar})$, $101.0\left(\mathrm{C}-1^{\mathrm{Gal}}\right), 99.1\left(\mathrm{C}-1^{\mathrm{Glc}}\right), 76.2\left(\mathrm{C}-4^{\mathrm{Glc}}\right), 72.8\left(\mathrm{C}-3^{\mathrm{Glc}}\right), 72.7$ $\left(\mathrm{C}-5^{\mathrm{Glc}}\right), 71.6\left(\mathrm{C}-2^{\mathrm{Glc}}\right), 71.0\left(\mathrm{C}-3^{\mathrm{Gal}}\right), 70.7\left(\mathrm{C}-5^{\mathrm{Gal}}\right), 69.1\left(\mathrm{C}-2^{\mathrm{Gal}}\right)$, $66.6\left(\mathrm{C}-4^{\mathrm{Gal}}\right), 64.3\left(\mathrm{CH}_{2}{ }^{\text {allyl }}\right), 61.9\left(\mathrm{C}-6^{\mathrm{Glc}}\right), 60.8\left(\mathrm{C}-6^{\mathrm{Gal}}\right), 58.5$ $\left(\mathrm{CH}_{2}^{\text {allyl }}\right), 20.8-20.5\left(\mathrm{C}(\mathrm{O}) \mathrm{CH}_{3}\right)$.

4-( $p$-Nitrophenoxycarbonyloxy)-(Z)-but-2-enyl $2,3,4,6$ tetra- $O$-acetyl- $\beta$-D-galactopyranosyl-(1 $\rightarrow 4)-2,3,6$-tri- $O$-acetyl$\boldsymbol{\beta}$-D-glucopyranoside (7). Compound 6 (1.72 g, $2.43 \mathrm{mmol})$ was dissolved in $\mathrm{CH}_{3} \mathrm{CN}$ (80 mL). A solution of $p$-nitrophenyl chloroformate $2(0.59 \mathrm{~g}, 2.92 \mathrm{mmol})$ in $\mathrm{CH}_{3} \mathrm{CN}(5 \mathrm{~mL})$ and pyridine $(0.24 \mathrm{~mL}, 2.92 \mathrm{mmol})$ were added, and the mixture was stirred for $1 \mathrm{~h}$. The solvent was evaporated and the remainder was dissolved in ethyl acetate and washed with water, $1 \mathrm{M} \mathrm{HCl}$, and brine. The organic layer was dried $\left(\mathrm{Na}_{2} \mathrm{SO}_{4}\right)$, concentrated, and purified by FC (petroleum ether/ethyl acetate $1: 1 \rightarrow 1: 2)$ to yield $7(1.84 \mathrm{~g}, 87 \%)$ as a white solid: $R_{\mathrm{f}}=0.50$ (petroleum ether/ethyl acetate 1:2). ${ }^{1} \mathrm{H} \mathrm{NMR}\left(600 \mathrm{MHz}, \mathrm{CDCl}_{3}\right)$ : $\delta=8.29-8.28(\mathrm{~m}, 2 \mathrm{H}, \mathrm{Ar}), 7.39-7.37(\mathrm{~m}, 2 \mathrm{H}, \mathrm{Ar})$, 5.83-5.78 (m, $\left.2 \mathrm{H}, \mathrm{H}^{\mathrm{vinyl}}\right), 5.34\left(\mathrm{~d}, J=3.0 \mathrm{~Hz}, 1 \mathrm{H}, \mathrm{H}-4^{\mathrm{Gal}}\right)$, $5.19\left(\mathrm{~d}, J=9.3 \mathrm{~Hz}, 1 \mathrm{H}, \mathrm{H}-3^{\mathrm{Glc}}\right), 5.09(\mathrm{dd}, J=10.4 \mathrm{~Hz}, J=$ $\left.7.9 \mathrm{~Hz}, 1 \mathrm{H}, \mathrm{H}-2^{\mathrm{Gal}}\right), 4.95(\mathrm{dd}, J=10.4 \mathrm{~Hz}, J=3.4 \mathrm{~Hz}, 1 \mathrm{H}$, $\left.\mathrm{H}-3^{\mathrm{Gal}}\right), 4.90\left(\mathrm{dd}, J=9.4 \mathrm{~Hz}, J=8.0 \mathrm{~Hz}, 1 \mathrm{H}, \mathrm{H}-2^{\mathrm{Glc}}\right)$, 4.87-4.79 (m, $\left.2 \mathrm{H}, \mathrm{H}^{\mathrm{allyl}}\right), 4.52\left(\mathrm{~d}, J=7.8 \mathrm{~Hz}, 1 \mathrm{H}, \mathrm{H}-1^{\mathrm{Glc}}\right)$, $4.51\left(\mathrm{dd}, J=11.8 \mathrm{~Hz}, J=2.1 \mathrm{~Hz}, 1 \mathrm{H}, \mathrm{H}-6^{\mathrm{Glc}}\right), 4.48(\mathrm{~d}, J=$ $\left.7.9 \mathrm{~Hz}, 1 \mathrm{H}, \mathrm{H}-1^{\mathrm{Gal}}\right), 4.34(\mathrm{ddd}, J=18.6 \mathrm{~Hz}, J=13.3 \mathrm{~Hz}, J=$ $\left.4.2 \mathrm{~Hz}, 2 \mathrm{H}, \mathrm{H}^{\text {allyl }}\right), 4.14-4.05$ (m, $\left.3 \mathrm{H}, \mathrm{H}-6^{\prime \text { Glc }}, \mathrm{H}-6^{\mathrm{Gal}}, \mathrm{H}-6^{\prime \mathrm{Gal}}\right)$, 3.86 (bt, $\left.J=6.9 \mathrm{~Hz}, 1 \mathrm{H}, \mathrm{H}-5^{\mathrm{Gal}}\right), 3.80(\mathrm{t}, J=9.4 \mathrm{~Hz}, 1 \mathrm{H}$, $\left.\mathrm{H}-4^{\mathrm{Glc}}\right), 3.60(\mathrm{ddd}, J=9.8 \mathrm{~Hz}, J=4.7 \mathrm{~Hz}, J=2.0 \mathrm{~Hz}, 1 \mathrm{H}$, $\left.\mathrm{H}-5^{\mathrm{Glc}}\right), 2.14\left(\mathrm{~s}, 3 \mathrm{H}, \mathrm{C}(\mathrm{O}) \mathrm{CH}_{3}\right), 2.11\left(\mathrm{~s}, 3 \mathrm{H}, \mathrm{C}(\mathrm{O}) \mathrm{CH}_{3}\right), 2.05$ $\left(\mathrm{s}, 3 \mathrm{H}, \mathrm{C}(\mathrm{O}) \mathrm{CH}_{3}\right), 2.04\left(\mathrm{~s}, 3 \mathrm{H}, \mathrm{C}(\mathrm{O}) \mathrm{CH}_{3}\right), 2.03(\mathrm{~s}, 3 \mathrm{H}$, $\left.\mathrm{C}(\mathrm{O}) \mathrm{CH}_{3}\right), 2.01\left(\mathrm{~s}, 3 \mathrm{H}, \mathrm{C}(\mathrm{O}) \mathrm{CH}_{3}\right), 1.96$ (s, $\left.3 \mathrm{H}, \mathrm{C}(\mathrm{O}) \mathrm{CH}_{3}\right)$. ${ }^{13} \mathrm{C}$ NMR $\left(150 \mathrm{MHz}, \mathrm{CDCl}_{3}\right): \delta=170.3,170.3,170.1,170.0$, 169.7, 169.6, $169.0\left(\mathrm{C}(\mathrm{O}) \mathrm{CH}_{3}\right), 155.4(\mathrm{OC}(\mathrm{O}) \mathrm{O}), 152.3,145.5$ (Ar), 130.8, 126.0 (Olefin CH), 125.3, 121.7 (Ar), 101.1 (C$\left.1^{\mathrm{Gal}}\right), 99.2\left(\mathrm{C}-1^{\mathrm{Glc}}\right), 76.2\left(\mathrm{C}-4^{\mathrm{Glc}}\right), 72.9\left(\mathrm{C}-3^{\mathrm{Glc}}\right), 72.7\left(\mathrm{C}-5^{\mathrm{Glc}}\right)$, $71.5\left(\mathrm{C}-2^{\mathrm{Glc}}\right), 70.9\left(\mathrm{C}-3^{\mathrm{Gal}}\right), 70.7\left(\mathrm{C}-5^{\mathrm{Gal}}\right), 69.1\left(\mathrm{C}-2^{\mathrm{Gal}}\right), 66.5$ $\left(\mathrm{C}-4^{\mathrm{Gal}}\right), 64.5,64.4\left(\mathrm{CH}_{2}{ }^{\text {allyl }}\right), 61.8\left(\mathrm{C}-6^{\mathrm{Glc}}\right), 60.7\left(\mathrm{C}-6^{\mathrm{Gal}}\right)$, 20.8-20.5 (C(O) $\left.\mathrm{CH}_{3}\right)$. MALDI-MS: calcd $\mathrm{m} / \mathrm{z}$ 894.2 [M + $\mathrm{Na}^{+}$], $910.2\left[\mathrm{M}+\mathrm{K}^{+}\right]$, found 894.0, 910.0. Anal. calcd for $\mathrm{C}_{37} \mathrm{H}_{45} \mathrm{NO}_{23}$ : C 50.98, H 5.20, N 1.61, found: C 50.80, H 5.23, $\mathrm{N} 1.61$.

General Procedure 1 (GP 1) for Coupling of $p$-Nitrophenyl Carbonates to Primary Amines. The amine and $i-\mathrm{Pr}_{2} \mathrm{NEt}$ (1 equiv per amino group) were added to a solution of activated carbonate $\beta$-3 or 7 (1.1-1.3 equiv per amino group) in dry $\mathrm{CH}_{2} \mathrm{Cl}_{2}$ (3-10 $\mathrm{mL}$ per mmol of activated carbonate). After complete reaction (usually after few minutes), the solvent was removed under reduced pressure and the product was purified by FC.

General Procedure 2 (GP 2) for Deacetylation with $\mathrm{NaOMe} / \mathrm{MeOH}$. The acetylated compound was dissolved in $\mathrm{MeOH}(10-30 \mathrm{~mL}$ per mmol) and a $0.5 \mathrm{M}$ solution of $\mathrm{NaOMe}$ in $\mathrm{MeOH}(0.05-0.25 \mathrm{~mL}$ per $\mathrm{mL}$ of reaction mixture) was added. After complete reaction, any precipitate formed was dissolved by addition of water or $\mathrm{MeOH}$. The solution was neutralized by addition of acidic ion-exchange resin (Dowex $50 \mathrm{~W}-\mathrm{X} 8$ or Amberlite IRC-86, $\mathrm{H}^{+}$form) and filtered. The filtrate was concentrated and lyophilized.
General Procedure 3 (GP 3) for Deacetylation with $\mathbf{E t N M e}_{2} / \mathbf{M e O H}$. The acetylated compound was stirred with a 1:5 mixture of EtNMe $2 / \mathrm{MeOH}(10-30 \mathrm{~mL}$ per mmol). After complete reaction, the mixture was concentrated and the remaining product was then dried under vacuum and lyophilized.

$(2,3,4,6$-Tetra- $O$-acetyl- $\beta$-D-galactopyranosyl- $(1 \rightarrow 4)-2,3,6$ tri- $O$-acetyl- $\beta$-D-glucopyranosyloxycarbonyl)benzylamine (AcA). According to GP $1, \beta-3$ (115 mg, $0.15 \mathrm{mmol})$ and benzylamine 8 (14 mg, $0.13 \mathrm{~mol}$ ) were reacted in $\mathrm{CH}_{2} \mathrm{Cl}_{2}$ (3 $\mathrm{mL}$ ). Purification by FC (petroleum ether/ethyl acetate 1:1) gave Ac-A $(100 \mathrm{mg}, 99 \%)$ as a white foam: $R_{\mathrm{f}}=0.45$ (petroleum ether/ethyl acetate 1:2). ${ }^{1} \mathrm{H}$ NMR $\left(600 \mathrm{MHz}, \mathrm{CDCl}_{3}\right): \delta=$ 7.35-7.27 (m, $5 \mathrm{H}, \mathrm{Ar}), 5.67$ (d, $\left.J=8.3 \mathrm{~Hz}, 1 \mathrm{H}, \mathrm{H}-1^{\mathrm{Glc}}\right), 5.35$ $\left(\mathrm{d}, J=2.3 \mathrm{~Hz}, 1 \mathrm{H}, \mathrm{H}-4^{\mathrm{Gal}}\right), 5.25\left(\mathrm{t}, J=9.0 \mathrm{~Hz}, 1 \mathrm{H}, \mathrm{H}-3^{\mathrm{Glc}}\right)$, 5.17-5.10 (m, $\left.2 \mathrm{H}, \mathrm{H}-2^{\mathrm{Gal}}, \mathrm{NHC}(\mathrm{O})\right), 5.02(\mathrm{t}, J=8.7 \mathrm{~Hz}, 1 \mathrm{H}$, $\left.\mathrm{H}-2^{\mathrm{Glc}}\right), 4.95\left(\mathrm{dd}, J=10.4 \mathrm{~Hz}, J=3.4 \mathrm{~Hz}, 1 \mathrm{H}, \mathrm{H}-3^{\mathrm{Gal}}\right)$, 4.48-4.45 (m, $\left.2 \mathrm{H}, \mathrm{H}-6^{\mathrm{Glc}}, \mathrm{H}-1^{\mathrm{Gal}}\right), 4.38-4.36\left(\mathrm{~m}, 2 \mathrm{H}, \mathrm{CH}_{2}{ }^{\mathrm{Bn}}\right.$ ), 4.17-4.07 (m, 3 H, H- $\left.6^{\prime \mathrm{Glc}}, \mathrm{H}-6^{\mathrm{Gal}}, \mathrm{H}-6^{\prime \mathrm{Gal}}\right), 3.88-3.83$ (m, 2 $\left.\mathrm{H}, \mathrm{H}-4^{\mathrm{Glc}}, \mathrm{H}-5^{\mathrm{Gal}}\right), 3.78-3.76\left(\mathrm{~m}, 1 \mathrm{H}, \mathrm{H}-5^{\mathrm{Glc}}\right), 2.16(\mathrm{~s}, 3 \mathrm{H}$, $\left.\mathrm{C}(\mathrm{O}) \mathrm{CH}_{3}\right), 2.12$ (s, $\left.3 \mathrm{H}, \mathrm{C}(\mathrm{O}) \mathrm{CH}_{3}\right), 2.07$ (s, $\left.3 \mathrm{H}, \mathrm{C}(\mathrm{O}) \mathrm{CH}_{3}\right)$, $2.05\left(\mathrm{~s}, 6 \mathrm{H}, \mathrm{C}(\mathrm{O}) \mathrm{CH}_{3}\right), 2.02\left(\mathrm{~s}, 3 \mathrm{H}, \mathrm{C}(\mathrm{O}) \mathrm{CH}_{3}\right), 1.97(\mathrm{~s}, 3 \mathrm{H}$, $\left.\mathrm{C}(\mathrm{O}) \mathrm{CH}_{3}\right), 1.97\left(\mathrm{~s}, 3 \mathrm{H}, \mathrm{C}(\mathrm{O}) \mathrm{CH}_{3}\right) .{ }^{13} \mathrm{C} \mathrm{NMR}(150 \mathrm{MHz}$, $\left.\mathrm{CDCl}_{3}\right): \delta=170.3,170.2,170.1,169.7,169.5,169.0$ $\left(C(\mathrm{O}) \mathrm{CH}_{3}\right), 153.7(\mathrm{OC}(\mathrm{O}) \mathrm{N}), 137.4,128.8,127.8,127.6(\mathrm{Ar})$, $101.0\left(\mathrm{C}-1^{\mathrm{Gal}}\right), 92.8\left(\mathrm{C}-1^{\mathrm{Glc}}\right), 75.8\left(\mathrm{C}-4^{\mathrm{Glc}}\right), 73.3\left(\mathrm{C}-5^{\mathrm{Glc}}\right), 72.6$ $\left(\mathrm{C}-3^{\mathrm{Glc}}\right), 71.0\left(\mathrm{C}-3^{\mathrm{Gal}}\right), 70.7\left(\mathrm{C}-5^{\mathrm{Gal}}\right), 70.6\left(\mathrm{C}-2^{\mathrm{Glc}}\right), 69.0\left(\mathrm{C}-2^{\mathrm{Gal}}\right)$, $66.6\left(\mathrm{C}-4^{\mathrm{Gal}}\right), 61.8\left(\mathrm{C}-6^{\mathrm{Glc}}\right), 60.8\left(\mathrm{C}-6^{\mathrm{Gal}}\right), 45.2\left(\mathrm{CH}_{2}{ }^{\mathrm{Bn}}\right)$, 20.9-20.5 $\left(\mathrm{C}(\mathrm{O}) \mathrm{CH}_{3}\right)$. MALDI-MS: calcd $\mathrm{m} / \mathrm{z} 792.2[\mathrm{M}+$ $\left.\mathrm{Na}^{+}\right]$, $808.2\left[\mathrm{M}+\mathrm{K}^{+}\right.$], found 792.4, 808.4. Anal. calcd for $\mathrm{C}_{34} \mathrm{H}_{43} \mathrm{NO}_{19}$ : C 53.05, H 5.63, N 1.82, found: C 53.03, H 5.66, $\mathrm{N} 1.83$.

$(\boldsymbol{\beta}$-D-Galactopyranosyl-( $\rightarrow 4)$ - $\boldsymbol{\beta}$-D-glucopyranosyloxycarbonyl)benzylamine (A). According to GP 2, Ac-A (100 mg, $0.13 \mathrm{mmol}$ ) was deacetylated with $0.5 \mathrm{M} \mathrm{NaOMe}$ solution $(0.25$ $\mathrm{mL})$ in $\mathrm{MeOH}(3 \mathrm{~mL})$ to give $\mathbf{A}(61 \mathrm{mg}, 99 \%)$ as a white solid. ${ }^{1} \mathrm{H}$ NMR (600 MHz, $\mathrm{D}_{2} \mathrm{O}$ ): $\delta=7.33-7.25$ (m, $\left.5 \mathrm{H}, \mathrm{Ar}\right), 5.36$ $\left(\mathrm{d}, J=8.2 \mathrm{~Hz}, 1 \mathrm{H}, \mathrm{H}-1^{\mathrm{Glc}}\right), 4.35\left(\mathrm{~d}, J=7.9 \mathrm{~Hz}, 1 \mathrm{H}, \mathrm{H}-1^{\mathrm{Gal}}\right)$, $4.26\left(\mathrm{~m}, 2 \mathrm{H}, \mathrm{CH}_{2}{ }^{\mathrm{Bn}}\right), 3.86-3.82\left(\mathrm{~m}, 2 \mathrm{H}, \mathrm{H}-4^{\mathrm{Gal}}, \mathrm{H}-6^{\mathrm{Glc}}\right)$, $3.73-3.56$ (m, 8 H, H- $3^{\mathrm{Glc}}, \mathrm{H}-3^{\mathrm{Gal}}, \mathrm{H}-4^{\mathrm{Glc}}, \mathrm{H}-5^{\mathrm{Glc}}, \mathrm{H}-5^{\mathrm{Gal}}, \mathrm{H}-6^{\prime \mathrm{Glc}}$, H-6 $\left.{ }^{\mathrm{Gal}}, \mathrm{H}-6^{\prime \mathrm{Gal}}\right), 3.47-3.40\left(\mathrm{~m}, 2 \mathrm{H}, \mathrm{H}-2^{\mathrm{Glc}}, \mathrm{H}-2^{\mathrm{Gal}}\right) .{ }^{13} \mathrm{C} \mathrm{NMR}$ $\left(150 \mathrm{MHz}, \mathrm{D}_{2} \mathrm{O}\right): \delta=156.6(\mathrm{OC}(\mathrm{O}) \mathrm{N}), 138.2,128.8,127.5$, 127.1 (Ar), $102.9\left(\mathrm{C}-1^{\mathrm{Gal}}\right), 94.8\left(\mathrm{C}-1^{\mathrm{Glc}}\right), 77.8,75.4,75.3,74.1$, $72.5\left(\mathrm{C}-3^{\mathrm{Glc}}, \mathrm{C}-3^{\mathrm{Gal}}, \mathrm{C}-4^{\mathrm{Glc}}, \mathrm{C}-5^{\mathrm{Glc}}, \mathrm{C}-5^{\mathrm{Gal}}\right), 71.7\left(\mathrm{C}-2^{\mathrm{Glc}}\right), 70.9$ $\left(\mathrm{C}-2^{\mathrm{Gal}}\right), 68.6\left(\mathrm{C}-4^{\mathrm{Gal}}\right), 61.0\left(\mathrm{C}-6^{\mathrm{Glc}}\right), 59.8\left(\mathrm{C}-6^{\mathrm{Gal}}\right), 44.2\left(\mathrm{CH}_{2}^{\mathrm{Bn}}\right)$. MALDI-MS: calcd $m / z$ 498.2 [M $\left.+\mathrm{Na}^{+}\right], 514.2\left[\mathrm{M}+\mathrm{K}^{+}\right]$, found 498.1, 514.1.

$N, N^{\prime}$-Bis-(2,3,4,6-tetra- $O$-acetyl- $\beta$-D-galactopyranosyl-( $\left.1 \rightarrow 4\right)$ $2,3,6$-tri- $O$-acetyl- $\beta$-D-glucopyranosyloxycarbonyl)- $\boldsymbol{m}$-xylylenediamine (Ac-B). According to GP 1, $\beta$-3 (123 mg, $0.15 \mathrm{mmol}$ ) and $\alpha, \alpha^{\prime}$-diamino- $m$-xylene $9(9.5 \mathrm{mg}, 0.07 \mathrm{mmol})$ were reacted in $\mathrm{CH}_{2} \mathrm{Cl}_{2}(3 \mathrm{~mL})$. Purification by $\mathrm{FC}$ (petroleum ether/ethyl acetate 1:2) gave Ac-B (102 mg, 99\%) as a white foam: $R_{\mathrm{f}}=$ 0.18 (petroleum ether/ethyl acetate $1: 2) .{ }^{1} \mathrm{H}$ NMR $(600 \mathrm{MHz}$, $\left.\mathrm{CDCl}_{3}\right): \delta=7.27-7.25$ (m, $\left.1 \mathrm{H}, \mathrm{Ar}\right), 7.15-7.11(\mathrm{~m}, 3 \mathrm{H}, \mathrm{Ar})$, $5.62\left(\mathrm{~m}, 4 \mathrm{H}, \mathrm{H}-1^{\mathrm{Glc}}, \mathrm{NHC}(\mathrm{O})\right), 5.33$ (bs, $\left.2 \mathrm{H}, \mathrm{H}-4^{\mathrm{Gal}}\right), 5.23(\mathrm{t}$, $\left.J=9.1 \mathrm{~Hz}, 2 \mathrm{H}, \mathrm{H}-3^{\mathrm{Glc}}\right), 5.09\left(\mathrm{t}, J=9.4 \mathrm{~Hz}, 2 \mathrm{H}, \mathrm{H}-2^{\mathrm{Gal}}\right), 5.00$ (t, $\left.J=8.7 \mathrm{~Hz}, 2 \mathrm{H}, \mathrm{H}-2^{\mathrm{Glc}}\right), 4.94\left(\mathrm{bd}, J=10.2 \mathrm{~Hz}, 2 \mathrm{H}, \mathrm{H}-3^{\mathrm{Gal}}\right)$, $4.49-4.38\left(\mathrm{~m}, 6 \mathrm{H}, \mathrm{H}-6^{\mathrm{Glc}}, \mathrm{H}-1^{\mathrm{Gal}}, \mathrm{CH}_{2}{ }^{\mathrm{Bn}}\right), 4.26(\mathrm{dd}, J=14.9$ $\left.\mathrm{Hz}, J=4.5 \mathrm{~Hz}, 2 \mathrm{H}, \mathrm{CH}_{2}{ }^{\mathrm{Bn}}\right), 4.18-4.03$ (m, $6 \mathrm{H}, \mathrm{H}-6^{\prime \mathrm{Glc}}, \mathrm{H}-6^{\mathrm{Gal}}$, $\left.\mathrm{H}-6^{\prime \mathrm{Gal}}\right), 3.88-3.86\left(\mathrm{~m}, 4 \mathrm{H}, \mathrm{H}-4^{\mathrm{Glc}}, \mathrm{H}-5^{\mathrm{Gal}}\right), 3.73-3.72(\mathrm{~m}, 2$ $\left.\mathrm{H}, \mathrm{H}-5^{\mathrm{Glc}}\right), 2.14$ (s, $\left.6 \mathrm{H}, \mathrm{C}(\mathrm{O}) \mathrm{CH}_{3}\right), 2.04$ (s, $\left.6 \mathrm{H}, \mathrm{C}(\mathrm{O}) \mathrm{CH}_{3}\right)$, $2.03\left(\mathrm{~s}, 18 \mathrm{H}, \mathrm{C}(\mathrm{O}) \mathrm{CH}_{3}\right), 2.00\left(\mathrm{~s}, 6 \mathrm{H}, \mathrm{C}(\mathrm{O}) \mathrm{CH}_{3}\right), 1.95$ (s, $6 \mathrm{H}$, $\left.\mathrm{C}(\mathrm{O}) \mathrm{CH}_{3}\right) .{ }^{13} \mathrm{C} \mathrm{NMR}\left(150 \mathrm{MHz}, \mathrm{CDCl}_{3}\right): \delta=170.4,170.3$, $170.1,170.0,169.8,169.5,169.0,\left(C(\mathrm{O}) \mathrm{CH}_{3}\right), 153.9(\mathrm{OC}(\mathrm{O}) \mathrm{N})$, 138.4, 129.0, 126.7, 125.7 (Ar), $100.9\left(\mathrm{C}-1^{\mathrm{Gal}}\right), 92.8\left(\mathrm{C}-1^{\mathrm{Glc}}\right)$, 75.7 (C-4 $\left.{ }^{\mathrm{Glc}}\right), 73.4\left(\mathrm{C}-5^{\mathrm{Glc}}\right), 72.7\left(\mathrm{C}-3^{\mathrm{Glc}}\right), 71.0\left(\mathrm{C}-3^{\mathrm{Gal}}\right), 70.6$ $\left(\mathrm{C}-5^{\mathrm{Gal}}\right), 70.6\left(\mathrm{C}-2^{\mathrm{Glc}}\right), 69.0\left(\mathrm{C}-2^{\mathrm{Gal}}\right), 66.5\left(\mathrm{C}-4^{\mathrm{Gal}}\right), 61.6\left(\mathrm{C}-6^{\mathrm{Glc}}\right)$, 
$60.6\left(\mathrm{C}-6^{\mathrm{Gal}}\right), 44.8\left(\mathrm{CH}_{2}{ }^{\mathrm{Bn}}\right), 20.7-20.5\left(\mathrm{C}(\mathrm{O}) \mathrm{CH}_{3}\right)$. MALDIMS: calcd $m / z$ 1483.4 $\left[\mathrm{M}+\mathrm{Na}^{+}\right], 1499.4\left[\mathrm{M}+\mathrm{K}^{+}\right]$, found 1483.4, 1499.7. Anal. calcd for $\mathrm{C}_{62} \mathrm{H}_{80} \mathrm{~N}_{2} \mathrm{O}_{38}$ : C 50.96, H 5.52, N 1.92, found: C 50.80, H 5.70, N 1.88 .

$\boldsymbol{N}, \boldsymbol{N}^{\prime}$-Bis- $(\boldsymbol{\beta}$-D-galactopyranosyl-( $1 \rightarrow 4)$ - $\boldsymbol{\beta}$-D-glucopyranosyloxycarbonyl)-m-xylylenediamine (B). According to GP 2 , Ac-B (102 mg, $0.07 \mathrm{mmol}$ ) was deacetylated with 0.5 M NaOMe solution $(0.5 \mathrm{~mL})$ in $\mathrm{MeOH}(2 \mathrm{~mL})$ to give $\mathbf{B}(61 \mathrm{mg}$, quant $)$ as a white solid. ${ }^{1} \mathrm{H}$ NMR $\left(600 \mathrm{MHz}, \mathrm{D}_{2} \mathrm{O}\right): \delta=7.30-7.28$ (m, $1 \mathrm{H}, \mathrm{Ar}), 7.18-7.16(\mathrm{~m}, 3 \mathrm{H}, \mathrm{Ar}), 5.35(\mathrm{~d}, J=8.2 \mathrm{~Hz}, 2$ $\left.\mathrm{H}, \mathrm{H}-1^{\mathrm{Glc}}\right), 4.36$ (d, $\left.J=7.7 \mathrm{~Hz}, 2 \mathrm{H}, \mathrm{H}-1^{\mathrm{Gal}}\right), 4.25$ (bs, $4 \mathrm{H}$, $\left.\mathrm{CH}_{2}{ }^{\mathrm{Bn}}\right), 3.85-3.82\left(\mathrm{~m}, 4 \mathrm{H}, \mathrm{H}-4^{\mathrm{Gal}}, \mathrm{H}-6^{\mathrm{Glc}}\right), 3.72-3.60$ (m, 14 $\mathrm{H}, \mathrm{H}-3^{\mathrm{Glc}}, \mathrm{H}-4^{\mathrm{Glc}}, \mathrm{H}-5^{\mathrm{Glc}}, \mathrm{H}-5^{\mathrm{Gal}}$, H-6 $\left.6^{\prime \mathrm{Glc}}, \mathrm{H}-6^{\mathrm{Gal}}, \mathrm{H}-6^{\prime \mathrm{Gal}}\right)$, $3.57-3.55$ (m, 2 H, H-3 ${ }^{\mathrm{Gal}}$ ), 3.46-3.40 (m, $\left.4 \mathrm{H}, \mathrm{H}-2^{\mathrm{Glc}}, \mathrm{H}-2^{\mathrm{Gal}}\right)$. ${ }^{13} \mathrm{C}$ NMR $\left(150 \mathrm{MHz}, \mathrm{D}_{2} \mathrm{O}\right): \delta=156.6(\mathrm{OC}(\mathrm{O}) \mathrm{N}), 138.6,129.1$, 126.1, 126.0 (Ar), 102.9 (C-1 $\left.{ }^{\mathrm{Gal}}\right), 94.9\left(\mathrm{C}-1^{\mathrm{Glc}}\right), 77.8,75.4,75.4$, $74.1,72.5\left(\mathrm{C}-3^{\mathrm{Glc}}, \mathrm{C}-3^{\mathrm{Gal}}, \mathrm{C}-4^{\mathrm{Glc}}, \mathrm{C}-5^{\mathrm{Glc}}, \mathrm{C}-5^{\mathrm{Gal}}\right), 71.7\left(\mathrm{C}-2^{\mathrm{Glc}}\right)$ $71.0\left(\mathrm{C}-2^{\mathrm{Gal}}\right), 68.6\left(\mathrm{C}-4^{\mathrm{Gal}}\right), 61.1\left(\mathrm{C}-6^{\mathrm{Gal}}\right), 59.8\left(\mathrm{C}-6^{\mathrm{Glc}}\right), 44.0$ $\left(\mathrm{CH}_{2}{ }^{\mathrm{Bn}}\right)$. MALDI-MS: calcd $m / z$ 895.3 [M + $\left.\mathrm{Na}^{+}\right], 911.3[\mathrm{M}$ $+\mathrm{K}^{+}$], found 895.2, 911.1.

1,4-Bis-(3-(2,3,4,6-tetra- $O$-acetyl- $\beta$-D-galactopyranosyl$(1 \rightarrow 4)$-2,3,6-tri- $O$-acetyl- $\beta$-D-glucopyranosyloxycarbonylaminopropyloxy)butane (Ac-C). According to GP 1, $\beta$-3 (148 mg $(0.188 \mathrm{mmol})$ and 1,4-bis-(3-aminopropoxy)butane $11(16 \mu \mathrm{L}$, $0.075 \mathrm{mmol})$ were reacted in $\mathrm{CH}_{2} \mathrm{Cl}_{2}(4 \mathrm{~mL})$. Purification by FC (petroleum ether/ethyl acetate 1:3, then ethyl acetate) gave Ac-C (114 mg, 99\%) as a white solid: $R_{\mathrm{f}}=0.38$ (ethyl acetate). ${ }^{1} \mathrm{H}$ NMR $\left(600 \mathrm{MHz} \mathrm{CDCl}_{3}\right): \delta=5.62(\mathrm{~d}, J=8.1 \mathrm{~Hz}, 2 \mathrm{H}$, $\left.\mathrm{H}-1^{\mathrm{Glc}}\right), 5.36-5.34\left(\mathrm{~m}, 4 \mathrm{H}, \mathrm{H}-4^{\mathrm{Gal}}, \mathrm{NHC}(\mathrm{O})\right), 5.25(\mathrm{t}, J=9.2$ $\left.\mathrm{Hz}, 2 \mathrm{H}, \mathrm{H}-3^{\mathrm{Glc}}\right), 5.09\left(\mathrm{t}, J=8.1 \mathrm{~Hz}, 2 \mathrm{H}, \mathrm{H}-2^{\mathrm{Gal}}\right), 5.00(\mathrm{t}, 2 \mathrm{H}$, $\left.J=8.8 \mathrm{~Hz}, \mathrm{H}-2^{\mathrm{Glc}}\right), 4.94(\mathrm{dd}, 2 \mathrm{H}, J=10.1 \mathrm{~Hz}, J=2.5 \mathrm{~Hz}$, $\left.\mathrm{H}-3^{\mathrm{Gal}}\right), 4.48-4.43$ (m, $\left.4 \mathrm{H}, \mathrm{H}-1^{\mathrm{Gal}}, \mathrm{H}-6^{\mathrm{Glc}}\right), 4.15-4.05$ (m, 6 $\left.\mathrm{H}, \mathrm{H}-6^{\prime \mathrm{Glc}}, \mathrm{H}-6^{\mathrm{Gal}}, \mathrm{H}-6^{\prime \mathrm{Gal}}\right), 3.87-3.83$ (m, $\left.4 \mathrm{H}, \mathrm{H}-4^{\mathrm{Glc}}, \mathrm{H}-5^{\mathrm{Gal}}\right)$, 3.75 (m, $\left.2 \mathrm{H}, \mathrm{H}-5^{\mathrm{Glc}}\right), 3.47$ (bs, $\left.4 \mathrm{H}, \mathrm{OCH}_{2} \mathrm{CH}_{2}\right), 3.41$ (bs, $4 \mathrm{H}$, $\mathrm{CH}_{2} \mathrm{CH}_{2} \mathrm{O}$ ), 3.28 (bs, $\left.4 \mathrm{H}, \mathrm{CH}_{2} \mathrm{CH}_{2} \mathrm{NH}\right), 2.15$ (s, $6 \mathrm{H}, \mathrm{C}(\mathrm{O}) \mathrm{CH}_{3}$ ), $2.11\left(\mathrm{~s}, 6 \mathrm{H}, \mathrm{C}(\mathrm{O}) \mathrm{CH}_{3}\right), 2.06\left(\mathrm{~s}, 6 \mathrm{H}, \mathrm{C}(\mathrm{O}) \mathrm{CH}_{3}\right), 2.04(\mathrm{~s}, 12 \mathrm{H}$, $\left.\mathrm{C}(\mathrm{O}) \mathrm{CH}_{3}\right), 2.02\left(\mathrm{~s}, 6 \mathrm{H}, \mathrm{C}(\mathrm{O}) \mathrm{CH}_{3}\right), 1.96$ (s, $\left.6 \mathrm{H}, \mathrm{C}(\mathrm{O}) \mathrm{CH}_{3}\right)$, 1.76 (bs, $4 \mathrm{H}, \mathrm{CH}_{2} \mathrm{CH}_{2} \mathrm{CH}_{2}$ ), 1.59 (bs, $4 \mathrm{H}, \mathrm{CH}_{2} \mathrm{CH}_{2} \mathrm{O}$ ). ${ }^{13} \mathrm{C}$ NMR (150 MHz, $\left.\mathrm{CDCl}_{3}\right): \delta=170.3,170.1,170.0,169.7,169.6$, $169.0\left(\mathrm{C}(\mathrm{O}) \mathrm{CH}_{3}\right), 153.6(\mathrm{OC}(\mathrm{O}) \mathrm{N}), 100.9\left(\mathrm{C}-1^{\mathrm{Gal}}\right), 92.6(\mathrm{C}-$ $\left.1^{\mathrm{Glc}}\right), 75.7\left(\mathrm{C}-4^{\mathrm{Glc}}\right), 73.2\left(\mathrm{C}-5^{\mathrm{Glc}}\right), 72.8\left(\mathrm{C}-3^{\mathrm{Glc}}\right), 71.0\left(\mathrm{C}-3^{\mathrm{Gal}}\right)$, $70.8\left(\mathrm{CH}_{2} \mathrm{CH}_{2} \mathrm{O}\right), 70.7\left(\mathrm{C}-5^{\mathrm{Gal}}\right), 70.6\left(\mathrm{C}-2^{\mathrm{Glc}}\right), 69.0\left(\mathrm{C}-2^{\mathrm{Gal}}\right), 68.9$ $\left(\mathrm{OCH}_{2} \mathrm{CH}_{2}\right), 66.6\left(\mathrm{C}-4^{\mathrm{Gal}}\right), 61.8\left(\mathrm{C}-6^{\mathrm{Glc}}\right), 60.8\left(\mathrm{C}-6^{\mathrm{Gal}}\right), 39.4$ $\left(\mathrm{CH}_{2} \mathrm{CH}_{2} \mathrm{NH}\right), 29.3\left(\mathrm{CH}_{2} \mathrm{CH}_{2} \mathrm{CH}_{2}\right), 26.3\left(\mathrm{CH}_{2} \mathrm{CH}_{2} \mathrm{O}\right), 20.9-20.5$ $\left(\mathrm{C}(\mathrm{O}) \mathrm{CH}_{3}\right)$. MALDI-MS: calcd $m / z, 1551.5\left[\mathrm{M}+\mathrm{Na}^{+}\right], 1567.5$ $\left[\mathrm{M}+\mathrm{K}^{+}\right]$, found 1551.2, 1567.1. Anal. calcd for $\mathrm{C}_{64} \mathrm{H}_{92} \mathrm{~N}_{2} \mathrm{O}_{40}$ : C 50.26, H 6.06, N 1.83, found: C 49.88, H 6.05, N 1.90.

1,4-Bis-(3-( $\beta$-D-galactopyranosyl- $(1 \rightarrow 4)-\beta$-D-glucopyranosyloxycarbonylaminopropyloxy)butane $(\mathbf{C})$. According to GP 2 , Ac-C (93 mg, $0.061 \mathrm{mmol})$ was deacetylated with $0.5 \mathrm{M}$ $\mathrm{NaOMe}$ solution $(0.1 \mathrm{~mL})$ in $\mathrm{MeOH}(2 \mathrm{~mL})$ to give $\mathbf{C}(58 \mathrm{mg}$, quant) as a white solid. ${ }^{1} \mathrm{H}$ NMR $\left(600 \mathrm{MHz}, \mathrm{D}_{2} \mathrm{O}\right): \delta=5.31$ $\left(\mathrm{d}, J=8.2 \mathrm{~Hz}, 2 \mathrm{H}, \mathrm{H}-1^{\mathrm{Glc}}\right), 4.35\left(\mathrm{~d}, J=7.8 \mathrm{~Hz}, 2 \mathrm{H}, \mathrm{H}-1^{\mathrm{Gal}}\right)$, 3.85-3.81 (m, $\left.4 \mathrm{H}, \mathrm{H}-4^{\mathrm{Gal}}, \mathrm{H}-6^{\mathrm{Glc}}\right), 3.74-3.60$ (m, $14 \mathrm{H}, \mathrm{H}-3^{\mathrm{Glc}}$, $\left.\mathrm{H}-4^{\mathrm{Glc}}, \mathrm{H}-5^{\mathrm{Glc}}, \mathrm{H}-5^{\mathrm{Gal}}, \mathrm{H}-6^{\prime \mathrm{Glc}}, \mathrm{H}-6^{\mathrm{Gal}}, \mathrm{H}-6^{\prime \mathrm{Gal}}\right), 3.55$ (dd, $J=$ $\left.10.0 \mathrm{~Hz}, J=3.3 \mathrm{~Hz}, 2 \mathrm{H}, \mathrm{H}-3^{\mathrm{Gal}}\right), 3.46-3.38\left(\mathrm{~m}, 12 \mathrm{H}, \mathrm{H}-2^{\mathrm{Glc}}\right.$, $\left.\mathrm{H}-2^{\mathrm{Gal}}, \mathrm{OCH}_{2} \mathrm{CH}_{2}\right), 3.16-3.10\left(\mathrm{~m}, 4 \mathrm{H}, \mathrm{CH}_{2} \mathrm{CH}_{2} \mathrm{NH}\right), 1.71-1.66$ (m, $4 \mathrm{H}, \mathrm{CH}_{2} \mathrm{CH}_{2} \mathrm{CH}_{2}$ ), 1.51 (bs, $4 \mathrm{H}, \mathrm{OCH}_{2} \mathrm{CH}_{2}$ ). ${ }^{13} \mathrm{C} \mathrm{NMR}$ $\left(150 \mathrm{MHz}, \mathrm{D}_{2} \mathrm{O}\right): \delta=156.4(\mathrm{OC}(\mathrm{O}) \mathrm{N}), 102.9\left(\mathrm{C}-1^{\mathrm{Gal}}\right), 94.7$ $\left(\mathrm{C}-1^{\mathrm{Glc}}\right), 77.8,75.4,75.3\left(\mathrm{C}-4^{\mathrm{Glc}}, \mathrm{C}-5^{\mathrm{Glc}}, \mathrm{C}-5^{\mathrm{Gal}}\right), 74.1\left(\mathrm{C}-3^{\mathrm{Glc}}\right)$, $72.5\left(\mathrm{C}-3^{\mathrm{Gal}}\right), 71.7\left(\mathrm{C}-2^{\mathrm{Glc}}\right), 71.0\left(\mathrm{C}-2^{\mathrm{Gal}}\right), 70.4\left(\mathrm{OCH}_{2} \mathrm{CH}_{2}\right), 68.6$ $\left(\mathrm{C}-4^{\mathrm{Gal}}\right), 67.7\left(\mathrm{OCH}_{2} \mathrm{CH}_{2}\right), 61.1\left(\mathrm{C}-6^{\mathrm{Gal}}\right), 59.8\left(\mathrm{C}-6^{\mathrm{Glc}}\right), 37.6$ $\left(\mathrm{CH}_{2} \mathrm{CH}_{2} \mathrm{NH}\right), 28.6\left(\mathrm{CH}_{2} \mathrm{CH}_{2} \mathrm{CH}_{2}\right), 25.3\left(\mathrm{OCH}_{2} \mathrm{CH}_{2}\right)$. MALDIMS: calcd $m / z, 963.4\left[\mathrm{M}+\mathrm{Na}^{+}\right], 979.3\left[\mathrm{M}+\mathrm{K}^{+}\right]$, found 963.4, 979.1 .
$N, N^{\prime}$-Bis-(2,3,4,6-tetra- $O$-acetyl- $\beta$-D-galactopyranosyl-( $\left.1 \rightarrow 4\right)$ $2,3,6$-tri- $O$-acetyl- $\beta$-D-glucopyranosyloxycarbonyl)-4,7,10-trioxa-1,13-tridecanediamine (Ac-D). According to GP $1, \beta-3$ (150 $\mathrm{mg}(0.190 \mathrm{mmol})$ and 4,7,10-trioxa-1,13-tridecanediamine $12(17 \mu \mathrm{L}, 0.078 \mathrm{mmol})$ were reacted in $\mathrm{CH}_{2} \mathrm{Cl}_{2}(4 \mathrm{~mL})$. Purification by FC (ethyl acetate) gave Ac-D (106 mg, 89\%) as a white solid. $R_{\mathrm{f}}=0.36$ (ethyl acetate). ${ }^{1} \mathrm{H}$ NMR $(600 \mathrm{MHz}$, $\left.\mathrm{CDCl}_{3}\right): \delta=5.62\left(\mathrm{~d}, J=8.2 \mathrm{~Hz}, 2 \mathrm{H}, \mathrm{H}-1^{\mathrm{Glc}}\right), 5.54(\mathrm{t}, J=5.3$ $\mathrm{Hz}, 2 \mathrm{H}, \mathrm{NHC}(\mathrm{O})), 5.35$ (bs, $\left.2 \mathrm{H}, \mathrm{H}-4^{\mathrm{Gal}}\right), 5.24$ (t, $J=9.4 \mathrm{~Hz}$, $\left.2 \mathrm{H}, \mathrm{H}-3^{\mathrm{Glc}}\right), 5.10\left(\mathrm{t}, J=8.2 \mathrm{~Hz}, 2 \mathrm{H}, \mathrm{H}-2^{\mathrm{Gal}}\right), 5.00$ (t, $2 \mathrm{H}, J$ $\left.=8.8 \mathrm{~Hz}, \mathrm{H}-2^{\mathrm{Glc}}\right), 4.94(\mathrm{dd}, 2 \mathrm{H}, J=10.0 \mathrm{~Hz}, J=2.9 \mathrm{~Hz}$, $\left.\mathrm{H}-3^{\mathrm{Gal}}\right), 4.48-4.44\left(\mathrm{~m}, 4 \mathrm{H}, \mathrm{H}-1^{\mathrm{Gal}}, \mathrm{H}-6^{\mathrm{Glc}}\right), 4.15-4.07$ (m, 6 $\left.\mathrm{H}, \mathrm{H}-6^{\prime \mathrm{Glc}}, \mathrm{H}-6^{\mathrm{Gal}}, \mathrm{H}-6^{\prime \mathrm{Gal}}\right), 3.88-3.84$ (m, $4 \mathrm{H}, \mathrm{H}-4^{\mathrm{Glc}}, \mathrm{H}-5^{\mathrm{Gal}}$ ), 3.76-3.75 (m, $2 \mathrm{H}, \mathrm{H}-5^{\mathrm{Glc}}$ ), 3.61 (bs, $4 \mathrm{H}, \mathrm{OCH}_{2} \mathrm{CH}_{2} \mathrm{O}$ ), 3.58 (bs, $4 \mathrm{H}, \mathrm{OCH}_{2} \mathrm{CH}_{2} \mathrm{O}$ ), 3.54 (bs, $4 \mathrm{H}, \mathrm{OCH}_{2} \mathrm{CH}_{2}$ ), 3.29 (bs, 4 $\left.\mathrm{H}, \mathrm{CH}_{2} \mathrm{CH}_{2} \mathrm{NH}\right), 2.15\left(\mathrm{~s}, 6 \mathrm{H}, \mathrm{C}(\mathrm{O}) \mathrm{CH}_{3}\right), 2.11(\mathrm{~s}, 6 \mathrm{H}$, $\left.\mathrm{C}(\mathrm{O}) \mathrm{CH}_{3}\right), 2.06\left(\mathrm{~s}, 6 \mathrm{H}, \mathrm{C}(\mathrm{O}) \mathrm{CH}_{3}\right), 2.04\left(\mathrm{~s}, 12 \mathrm{H}, \mathrm{C}(\mathrm{O}) \mathrm{CH}_{3}\right)$, 2.03 (s, $\left.6 \mathrm{H}, \mathrm{C}(\mathrm{O}) \mathrm{CH}_{3}\right), 1.96$ (s, $\left.6 \mathrm{H}, \mathrm{C}(\mathrm{O}) \mathrm{CH}_{3}\right), 1.79$ (bs, $4 \mathrm{H}$, $\left.\left.\mathrm{CH}_{2} \mathrm{CH}_{2} \mathrm{CH}_{2}\right) .{ }^{13} \mathrm{C} \mathrm{NMR} \mathrm{(150} \mathrm{MHz,} \mathrm{CDCl}_{3}\right): \delta=170.3,170.1$, 170.1, 169.7, 169.6, $169.0\left(\mathrm{C}(\mathrm{O}) \mathrm{CH}_{3}\right), 153.7(\mathrm{OC}(\mathrm{O}) \mathrm{N}), 100.9$ $\left(\mathrm{C}-1^{\mathrm{Gal}}\right), 92.5\left(\mathrm{C}-1^{\mathrm{Glc}}\right), 75.7\left(\mathrm{C}-4^{\mathrm{Glc}}\right), 73.2\left(\mathrm{C}-5^{\mathrm{Glc}}\right), 72.8\left(\mathrm{C}-3^{\mathrm{Glc}}\right)$, $71.0\left(\mathrm{C}-3^{\mathrm{Gal}}\right), 70.7\left(\mathrm{C}-5^{\mathrm{Gal}}\right), 70.6\left(\mathrm{C}-2^{\mathrm{Glc}}\right), 70.5\left(\mathrm{OCH}_{2} \mathrm{CH}_{2} \mathrm{O}\right)$, $70.2\left(\mathrm{OCH}_{2} \mathrm{CH}_{2} \mathrm{O}\right), 69.4\left(\mathrm{OCH}_{2} \mathrm{CH}_{2}\right), 69.0\left(\mathrm{C}-2^{\mathrm{Gal}}\right), 66.6(\mathrm{C}-$ $\left.4^{\mathrm{Gal}}\right), 61.8\left(\mathrm{C}-6^{\mathrm{Glc}}\right), 60.8\left(\mathrm{C}-6^{\mathrm{Gal}}\right), 39.3\left(\mathrm{CH}_{2} \mathrm{CH}_{2} \mathrm{NH}\right), 29.1$ $\left(\mathrm{CH}_{2} \mathrm{CH}_{2} \mathrm{CH}_{2}\right), 20.8-20.5\left(\mathrm{C}(\mathrm{O}) \mathrm{CH}_{3}\right)$. MALDI-MS: calcd $\mathrm{m} / \mathrm{z}$ $1567.5\left[\mathrm{M}+\mathrm{Na}^{+}\right], 1583.5\left[\mathrm{M}+\mathrm{K}^{+}\right]$, found 1567.9, 1583.9. Anal. calcd for $\mathrm{C}_{64} \mathrm{H}_{92} \mathrm{~N}_{2} \mathrm{O}_{41}$ : C 49.74, H 6.00, N 1.81, found: C 49.58, H 6.18, N 1.81 .

$\boldsymbol{N}, \boldsymbol{N}$ '-Bis-( $\boldsymbol{\beta}$-D-galactopyranosyl-( $\rightarrow 4)$ - $\boldsymbol{\beta}$-D-glucopyranosyloxycarbonyl)-4,7,10-trioxa-1,13-tridecanediamine (D). According to GP 2, Ac-D (100 mg, $0.065 \mathrm{mmol})$ was deacetylated with $0.5 \mathrm{M} \mathrm{NaOMe}$ solution $(0.5 \mathrm{~mL})$ in $\mathrm{MeOH}(2 \mathrm{~mL})$ to give D $(58 \mathrm{mg}, 94 \%)$ as a white solid. ${ }^{1} \mathrm{H}$ NMR $\left(600 \mathrm{MHz}, \mathrm{D}_{2} \mathrm{O}\right)$ : $\delta=5.33\left(\mathrm{~d}, J=8.3 \mathrm{~Hz}, 2 \mathrm{H}, \mathrm{H}-1^{\mathrm{Glc}}\right), 4.36(\mathrm{~d}, J=7.8 \mathrm{~Hz}, 2$ $\left.\mathrm{H}, \mathrm{H}-1^{\mathrm{Gal}}\right), 3.86-3.83$ (m, $\left.4 \mathrm{H}, \mathrm{H}-4^{\mathrm{Gal}}, \mathrm{H}-6^{\mathrm{Glc}}\right), 3.74-3.56$ (m, $24 \mathrm{H}, \mathrm{H}-3^{\mathrm{Glc}}, \mathrm{H}-3^{\mathrm{Gal}}, \mathrm{H}-4^{\mathrm{Glc}}, \mathrm{H}-5^{\mathrm{Glc}}, \mathrm{H}-5^{\mathrm{Gal}}, \mathrm{H}-6^{\prime \mathrm{Glc}}, \mathrm{H}-6^{\mathrm{Gal}}$, H-6 $\left.{ }^{\prime \text { Gal }}, \mathrm{OCH}_{2} \mathrm{CH}_{2} \mathrm{O}, \mathrm{OCH}_{2} \mathrm{CH}_{2} \mathrm{O}\right), 3.51-3.44\left(\mathrm{~m}, 6 \mathrm{H}, \mathrm{H}-2^{\mathrm{Gal}}\right.$, $\left.\mathrm{OCH}_{2} \mathrm{CH}_{2}\right), 3.40\left(\mathrm{t}, J=8.6 \mathrm{~Hz}, 2 \mathrm{H}, \mathrm{H}-2^{\mathrm{Glc}}\right), 3.15(\mathrm{bs}, 4 \mathrm{H}$, $\left.\mathrm{CH}_{2} \mathrm{CH}_{2} \mathrm{NH}\right), 1.73-1.69$ (m, $\left.4 \mathrm{H}, \mathrm{CH}_{2} \mathrm{CH}_{2} \mathrm{CH}_{2}\right) .{ }^{13} \mathrm{C} \mathrm{NMR}(150$ $\left.\mathrm{MHz}, \mathrm{D}_{2} \mathrm{O}\right): \delta=156.4(\mathrm{OC}(\mathrm{O}) \mathrm{N}), 102.9\left(\mathrm{C}-1^{\mathrm{Gal}}\right), 94.7(\mathrm{C}-$ $\left.1^{\mathrm{Glc}}\right), 77.8,75.4,75.3,74.1,72.5\left(\mathrm{C}-3^{\mathrm{Glc}}, \mathrm{C}-3^{\mathrm{Gal}}, \mathrm{C}-4^{\mathrm{Glc}}, \mathrm{C}-5^{\mathrm{Glc}}\right.$, $\left.\mathrm{C}-5^{\mathrm{Gal}}\right), 71.7\left(\mathrm{C}-2^{\mathrm{Glc}}\right), 70.9\left(\mathrm{C}-2^{\mathrm{Gal}}\right), 69.6\left(\mathrm{OCH}_{2} \mathrm{CH}_{2} \mathrm{O}\right)$, 69.3 $\left(\mathrm{OCH}_{2} \mathrm{CH}_{2} \mathrm{O}\right), 68.6\left(\mathrm{C}-4^{\mathrm{Gal}}\right), 68.3\left(\mathrm{OCH}_{2} \mathrm{CH}_{2}\right), 61.1\left(\mathrm{C}-6^{\mathrm{Gal}}\right)$, $59.8(\mathrm{C}-6 \mathrm{Glc}), 37.6\left(\mathrm{CH}_{2} \mathrm{CH}_{2} \mathrm{NH}\right), 28.5\left(\mathrm{CH}_{2} \mathrm{CH}_{2} \mathrm{CH}_{2}\right)$. MALDIMS: calcd $m / z$, $979.4\left[\mathrm{M}+\mathrm{Na}^{+}\right], 995.4\left[\mathrm{M}+\mathrm{K}^{+}\right]$, found 979.4 , 995.3.

1,7-Bis-(2,3,4,6-tetra- $O$-acetyl- $\beta$-D-galactopyranosyl- $(1 \rightarrow 4)$ 2,3,6-tri- $O$-acetyl- $\beta$-D-glucopyranosyloxycarbonyl)diethylenetriamine (Ac-E). According to GP 1, $\beta$-3 (202 mg, $0.252 \mathrm{mmol}$ ) and diethylenetriamine $\mathbf{1 3}(11 \mu \mathrm{L}, 0.102 \mathrm{mmol})$ were reacted in $\mathrm{CH}_{2} \mathrm{Cl}_{2}(2 \mathrm{~mL})$. Purification by $\mathrm{FC}\left(\mathrm{CH}_{2} \mathrm{Cl}_{2} / \mathrm{MeOH} 15: 1\right)$ gave Ac-E (105 mg, 71\%) as a colorless syrup. ${ }^{1} \mathrm{H}$ NMR $(600 \mathrm{MHz}$, $\left.\mathrm{CDCl}_{3}\right): \delta=5.76(\mathrm{t}, J=5.1 \mathrm{~Hz}, 2 \mathrm{H}, \mathrm{NHC}(\mathrm{O})), 5.58(\mathrm{~d}, J=$ $\left.8.3 \mathrm{~Hz}, 2 \mathrm{H}, \mathrm{H}-1^{\mathrm{Glc}}\right), 5.31\left(\mathrm{~d}, J=2.8 \mathrm{~Hz}, 2 \mathrm{H}, \mathrm{H}-4^{\mathrm{Gal}}\right), 5.21(\mathrm{t}$, $\left.J=9.1 \mathrm{~Hz}, 2 \mathrm{H}, \mathrm{H}-3^{\mathrm{Glc}}\right), 5.06(\mathrm{dd}, J=9.9 \mathrm{~Hz}, J=8.3 \mathrm{~Hz}, 2$ $\left.\mathrm{H}, \mathrm{H}-2^{\mathrm{Gal}}\right), 4.98\left(\mathrm{t}, J=8.9 \mathrm{~Hz}, 2 \mathrm{H}, \mathrm{H}-2^{\mathrm{Glc}}\right), 4.91(\mathrm{dd}, J=10.4$ $\left.\mathrm{Hz}, J=2.9 \mathrm{~Hz}, 2 \mathrm{H}, \mathrm{H}-3^{\mathrm{Gal}}\right), 4.48-4.42$ (m, $\left.4 \mathrm{H}, \mathrm{H}-1^{\mathrm{Gal}}, \mathrm{H}-6^{\mathrm{Glc}}\right)$, 4.11-4.09 (m, 2 H, H-6 $\left.{ }^{\text {Glc }}, \mathrm{H}^{-} 6^{\mathrm{Gal}}\right), 4.05-4.02$ (m, $2 \mathrm{H}, \mathrm{H}-6^{\prime \mathrm{Gal}}$ ), 3.86-3.84 (m, $\left.4 \mathrm{H}, \mathrm{H}-4^{\mathrm{Glc}}, \mathrm{H}-5^{\mathrm{Gal}}\right), 3.73-3.71$ (m, $\left.2 \mathrm{H}, \mathrm{H}-5^{\mathrm{Glc}}\right)$, $3.40-3.18\left(\mathrm{~m}, 4 \mathrm{H}, \mathrm{CH}_{2} \mathrm{CH}_{2} \mathrm{NH}\right), 2.76-2.71(\mathrm{~m}, 4 \mathrm{H}$, $\left.\mathrm{CH}_{2} \mathrm{CH}_{2} \mathrm{NH}\right), 2.11\left(\mathrm{~s}, 6 \mathrm{H}, \mathrm{C}(\mathrm{O}) \mathrm{CH}_{3}\right), 2.07$ (s, $\left.6 \mathrm{H}, \mathrm{C}(\mathrm{O}) \mathrm{CH}_{3}\right)$, $2.02\left(\mathrm{~s}, 6 \mathrm{H}, \mathrm{C}(\mathrm{O}) \mathrm{CH}_{3}\right), 2.01\left(\mathrm{~s}, 6 \mathrm{H}, \mathrm{C}(\mathrm{O}) \mathrm{CH}_{3}\right), 2.00(\mathrm{~s}, 6 \mathrm{H}$, $\left.\mathrm{C}(\mathrm{O}) \mathrm{CH}_{3}\right), 1.99$ (s, $\left.6 \mathrm{H}, \mathrm{C}(\mathrm{O}) \mathrm{CH}_{3}\right), 1.95\left(\mathrm{~s}, 6 \mathrm{H}, \mathrm{C}(\mathrm{O}) \mathrm{CH}_{3}\right)$. ${ }^{13} \mathrm{C}$ NMR $\left(150 \mathrm{MHz}, \mathrm{CDCl}_{3}\right): \delta=170.3,170.2,170.0,170.0$, 169.5, $168.9\left(\mathrm{C}(\mathrm{O}) \mathrm{CH}_{3}\right), 154.0(\mathrm{OC}(\mathrm{O}) \mathrm{N}), 100.8\left(\mathrm{C}-1^{\mathrm{Gal}}\right), 92.6$ $\left(\mathrm{C}-1^{\mathrm{Glc}}\right), 75.5\left(\mathrm{C}-4^{\mathrm{Glc}}\right), 73.2\left(\mathrm{C}-5^{\mathrm{Glc}}\right), 72.6\left(\mathrm{C}-3^{\mathrm{Glc}}\right), 70.9\left(\mathrm{C}-3^{\mathrm{Gal}}\right)$, $70.5\left(\mathrm{C}-5^{\mathrm{Gal}}\right), 70.5\left(\mathrm{C}-2^{\mathrm{Glc}}\right), 68.9\left(\mathrm{C}-2^{\mathrm{Gal}}\right), 66.5\left(\mathrm{C}-4^{\mathrm{Gal}}\right), 61.6$ 
$\left(\mathrm{C}-6^{\mathrm{Glc}}\right), 60.6\left(\mathrm{C}-6^{\mathrm{Gal}}\right), 48.0\left(\mathrm{CH}_{2} \mathrm{CH}_{2} \mathrm{NH}\right), 40.3\left(\mathrm{CH}_{2} \mathrm{CH}_{2} \mathrm{NH}\right)$, 20.8-20.5 $\left(\mathrm{C}(\mathrm{O}) \mathrm{CH}_{3}\right)$. MALDI-MS: calcd $\mathrm{m} / \mathrm{z}$ 1450.5 [M + $\left.\mathrm{Na}^{+}\right], 1466.5\left[\mathrm{M}+\mathrm{K}^{+}\right]$, found 1449.6, 1466.0.

1,7-Bis- $(\boldsymbol{\beta}$-D-galactopyranosyl-( $\boldsymbol{1} \rightarrow \mathbf{4})$ - $\boldsymbol{\beta}$-D-glucopyranosyloxycarbonyl)diethylenetriamine (E). According to GP 3, Ac-E (67 $\mathrm{mg}, 0.047 \mathrm{mmol}$ ) was deacetylated in $\mathrm{EtNMe}_{2} / \mathrm{MeOH}$ 1:5 (2.4 $\mathrm{mL})$ to give $\mathbf{E}(39 \mathrm{mg}, 99 \%)$ as a white solid. ${ }^{1} \mathrm{H}$ NMR (600 $\left.\mathrm{MHz}, \mathrm{D}_{2} \mathrm{O}\right): \delta=5.34\left(\mathrm{~d}, J=8.2 \mathrm{~Hz}, 2 \mathrm{H}, \mathrm{H}-1^{\mathrm{Glc}}\right), 4.35(\mathrm{~d}, J$ $\left.=7.5 \mathrm{~Hz}, 2 \mathrm{H}, \mathrm{H}-1^{\mathrm{Gal}}\right), 3.85-3.82\left(\mathrm{~m}, 4 \mathrm{H}, \mathrm{H}-4^{\mathrm{Gal}}, \mathrm{H}-6^{\mathrm{Glc}}\right)$, $3.72-3.54\left(\mathrm{~m}, 16 \mathrm{H}, \mathrm{H}-3^{\mathrm{Glc}}, \mathrm{H}-3^{\mathrm{Gal}}, \mathrm{H}-4^{\mathrm{Glc}}, \mathrm{H}-5^{\mathrm{Glc}}, \mathrm{H}-5^{\mathrm{Gal}}\right.$, H-6 $\left.{ }^{\text {'Glc }}, \mathrm{H}-6^{\mathrm{Gal}}, \mathrm{H}-6^{\text {'Gal }}\right), 3.45-3.39$ (m, $\left.4 \mathrm{H}, \mathrm{H}-2^{\mathrm{Gal}}, \mathrm{H}-2^{\mathrm{Glc}}\right)$, 3.20-3.13 (bs, $4 \mathrm{H}, \mathrm{CH}_{2} \mathrm{CH}_{2} \mathrm{NH}$ ), 2.78 (bs, $4 \mathrm{H}, \mathrm{CH}_{2} \mathrm{CH}_{2} \mathrm{NH}$ ). ${ }^{13} \mathrm{C}$ NMR $\left(150 \mathrm{MHz}, \mathrm{D}_{2} \mathrm{O}\right): \delta=156.6(\mathrm{OC}(\mathrm{O}) \mathrm{N}), 102.9(\mathrm{C}-$ $\left.1^{\mathrm{Gal}}\right), 94.8\left(\mathrm{C}-1^{\mathrm{Glc}}\right), 77.8,75.4,75.3,74.1\left(\mathrm{C}-3^{\mathrm{Glc}}, \mathrm{C}-4^{\mathrm{Glc}}, \mathrm{C}-5^{\mathrm{Glc}}\right.$, $\left.\mathrm{C}-5^{\mathrm{Gal}}\right), 72.6\left(\mathrm{C}-3^{\mathrm{Gal}}\right), 71.6\left(\mathrm{C}-2^{\mathrm{Glc}}\right), 71.0\left(\mathrm{C}-2^{\mathrm{Gal}}\right), 68.6\left(\mathrm{C}-4^{\mathrm{Gal}}\right)$, $61.1 \quad\left(\mathrm{C}-6^{\mathrm{Gal}}\right), \quad 59.7 \quad\left(\mathrm{C}-6^{\mathrm{Glc}}\right), \quad 47.2 \quad\left(\mathrm{CH}_{2} \mathrm{CH}_{2} \mathrm{NH}\right), \quad 38.9$ $\left(\mathrm{CH}_{2} \mathrm{CH}_{2} \mathrm{NH}\right)$.

Tris-(2-(2,3,4,6-tetra- $O$-acetyl- $\beta$-D-galactopyranosyl- $(1 \rightarrow 4)$ $2,3,6$-tri- $\boldsymbol{O}$-acetyl- $\boldsymbol{\beta}$-D-glucopyranosyloxycarbonylamino)ethyl)amine (Ac-F). According to GP 1, $\beta$-3 (144 mg, 0.18 $\mathrm{mmol})$ and tris-(2-aminoethyl)amine $14(8 \mu \mathrm{L}, 0.053 \mathrm{mmol})$ were reacted in $\mathrm{CH}_{2} \mathrm{Cl}_{2}$ (4 mL). Purification by $\mathrm{FC}$ (petroleum ether/ethyl acetate $1: 1$, then ethyl acetate) gave Ac-F $(111 \mathrm{mg}$, $97 \%)$ as a white solid. $R_{\mathrm{f}}=0.32$ (ethyl acetate). ${ }^{1} \mathrm{H}$ NMR (600 $\left.\mathrm{MHz}, \mathrm{CDCl}_{3}\right): \delta=5.61\left(\mathrm{~d}, J=8.0 \mathrm{~Hz}, 3 \mathrm{H}, \mathrm{H}-1^{\mathrm{Glc}}\right), 5.49(\mathrm{bs}$, $3 \mathrm{H}, \mathrm{NHC}(\mathrm{O})), 5.34\left(\mathrm{~s}, 3 \mathrm{H}, \mathrm{H}-4^{\mathrm{Gal}}\right), 5.25(\mathrm{t}, J=9.1 \mathrm{~Hz}, 3 \mathrm{H}$, $\left.\mathrm{H}-3^{\mathrm{Glc}}\right), 5.10\left(\mathrm{t}, J=9.2 \mathrm{~Hz}, 3 \mathrm{H}, \mathrm{H}-2^{\mathrm{Gal}}\right), 5.03-4.94(\mathrm{~m}, 6 \mathrm{H}$, $\left.\mathrm{H}-2^{\mathrm{Glc}}, \mathrm{H}-3^{\mathrm{Gal}}\right), 4.50-4.45$ (m, $\left.6 \mathrm{H}, \mathrm{H}-1^{\mathrm{Gal}}, \mathrm{H}-6^{\mathrm{Glc}}\right), 4.15-4.05$ (m, 9 H, H-6 $\left.{ }^{\prime \mathrm{Glc}}, \mathrm{H}-6^{\mathrm{Gal}}, \mathrm{H}-6^{\prime \mathrm{Gal}}\right), 3.89-3.84$ (m, $6 \mathrm{H}, \mathrm{H}-4^{\mathrm{Glc}}$, $\mathrm{H}-5^{\mathrm{Gal}}$ ), 3.75 (m, $3 \mathrm{H}, \mathrm{H}-5^{\mathrm{Glc}}$ ), 3.33 (bs, $\left.3 \mathrm{H}, \mathrm{CH}_{2} \mathrm{CH}_{2} \mathrm{NH}\right), 3.23$ (bs, $3 \mathrm{H}, \mathrm{CH}_{2} \mathrm{CH}_{2} \mathrm{NH}$ ), 2.77 (bs, $6 \mathrm{H}, \mathrm{CH}_{2} \mathrm{CH}_{2} \mathrm{NH}$ ), 2.15 (s, 9 $\left.\mathrm{H}, \mathrm{C}(\mathrm{O}) \mathrm{CH}_{3}\right), 2.11\left(\mathrm{~s}, 18 \mathrm{H}, \mathrm{C}(\mathrm{O}) \mathrm{CH}_{3}\right), 2.06\left(\mathrm{~s}, 9 \mathrm{H}, \mathrm{C}(\mathrm{O}) \mathrm{CH}_{3}\right)$, $2.05\left(\mathrm{~s}, 9 \mathrm{H}, \mathrm{C}(\mathrm{O}) \mathrm{CH}_{3}\right), 2.04\left(\mathrm{~s}, 9 \mathrm{H}, \mathrm{C}(\mathrm{O}) \mathrm{CH}_{3}\right), 1.96(\mathrm{~s}, 9 \mathrm{H}$, $\left.\mathrm{C}(\mathrm{O}) \mathrm{CH}_{3}\right) .{ }^{13} \mathrm{C} \mathrm{NMR}\left(150 \mathrm{MHz}, \mathrm{CDCl}_{3}\right): \delta=170.4,170.1$, $170.1,169.8,169.6,169.0\left(C(\mathrm{O}) \mathrm{CH}_{3}\right), 154.0(\mathrm{OC}(\mathrm{O}) \mathrm{N}), 100.9$ $\left(\mathrm{C}-1^{\mathrm{Gal}}\right), 92.7\left(\mathrm{C}-1^{\mathrm{Glc}}\right), 75.6\left(\mathrm{C}-4^{\mathrm{Glc}}\right), 73.3\left(\mathrm{C}-5^{\mathrm{Glc}}\right), 72.7\left(\mathrm{C}-3^{\mathrm{Glc}}\right)$, $71.0\left(\mathrm{C}-3^{\mathrm{Gal}}\right), 70.7\left(\mathrm{C}-5^{\mathrm{Gal}}\right), 70.6\left(\mathrm{C}-2^{\mathrm{Glc}}\right), 69.0\left(\mathrm{C}-2^{\mathrm{Gal}}\right), 66.6$ $\left(\mathrm{C}-4^{\mathrm{Gal}}\right), 61.8\left(\mathrm{C}-6^{\mathrm{Glc}}\right), 60.7\left(\mathrm{C}-6^{\mathrm{Gal}}\right), 48.2\left(\mathrm{CH}_{2} \mathrm{CH}_{2} \mathrm{NH}\right), 40.6$ $\left(\mathrm{CH}_{2} \mathrm{CH}_{2} \mathrm{NH}\right), 20.9-20.5\left(\mathrm{C}(\mathrm{O}) \mathrm{CH}_{3}\right)$. MALDI-MS: calcd $\mathrm{m} / \mathrm{z}$ 2155.7 [M $\left.+\mathrm{Na}^{+}\right]$, found 2155.2. Anal. calcd for $\mathrm{C}_{87} \mathrm{H}_{120} \mathrm{~N}_{4} \mathrm{O}_{57}$ : C 48.97, H 5.67, N 2.63, found: C 49.14, H 5.84, N 2.59 .

Tris-(2-( $\boldsymbol{\beta}$-D-galactopyranosyl-( $\boldsymbol{1} \rightarrow \mathbf{4})$ - $\boldsymbol{\beta}$-D-glucopyranosyloxycarbonylamino)ethyl)amine (F). According to GP 3, Ac-F (67 $\mathrm{mg}, 0.031 \mathrm{mmol})$ was deacetylated in $\mathrm{EtNMe}_{2} / \mathrm{MeOH}$ 1:5 (1.8 $\mathrm{mL})$ to give $\mathbf{F}(38 \mathrm{mg}, 97 \%)$ as a white solid. ${ }^{1} \mathrm{H}$ NMR $(600$ $\left.\mathrm{MHz}, \mathrm{D}_{2} \mathrm{O}\right): \delta=5.33\left(\mathrm{~d}, J=8.2 \mathrm{~Hz}, 3 \mathrm{H}, \mathrm{H}-1^{\mathrm{Glc}}\right), 4.34(\mathrm{~d}, J$ $\left.=7.8 \mathrm{~Hz}, 3 \mathrm{H}, \mathrm{H}-1^{\mathrm{Gal}}\right), 3.85-3.81\left(\mathrm{~m}, 6 \mathrm{H}, \mathrm{H}-4^{\mathrm{Gal}}\right.$, H-6 $\left.6^{\mathrm{Glc}}\right)$, $3.72-3.60\left(\mathrm{~m}, 21 \mathrm{H}, \mathrm{H}-3^{\mathrm{Glc}}, \mathrm{H}-4^{\mathrm{Glc}}, \mathrm{H}-5^{\mathrm{Glc}}, \mathrm{H}-5^{\mathrm{Gal}}, \mathrm{H}-6^{\prime \mathrm{Glc}}\right.$, H-6 $\left.{ }^{\mathrm{Gal}}, \mathrm{H}-6^{\prime \mathrm{Gal}}\right), 3.55$ (dd, $\left.J=10.0 \mathrm{~Hz}, J=3.4 \mathrm{~Hz}, 3 \mathrm{H}, \mathrm{H}-3^{\mathrm{Gal}}\right)$, $3.43\left(\mathrm{dd}, J=9.7 \mathrm{~Hz}, J=8.1 \mathrm{~Hz}, 3 \mathrm{H}, \mathrm{H}-2^{\mathrm{Gal}}\right), 3.40(\mathrm{t}, J=8.1$ $\mathrm{Hz}, 3 \mathrm{H}, \mathrm{H}-2^{\mathrm{Glc}}$ ), 3.20-3.13 (bs, $6 \mathrm{H}, \mathrm{CH}_{2} \mathrm{CH}_{2} \mathrm{NH}$ ), 2.63 (bs, 6 $\left.\mathrm{H}, \mathrm{CH}_{2} \mathrm{CH}_{2} \mathrm{NH}\right) .{ }^{13} \mathrm{C}$ NMR $\left(150 \mathrm{MHz}, \mathrm{D}_{2} \mathrm{O}\right): \delta=156.4$ $(\mathrm{OC}(\mathrm{O}) \mathrm{N}), 102.9\left(\mathrm{C}-1^{\mathrm{Gal}}\right), 94.7\left(\mathrm{C}-1^{\mathrm{Glc}}\right), 77.7,75.4,75.3,74.1$ $\left(\mathrm{C}-3^{\mathrm{Glc}}, \mathrm{C}-4^{\mathrm{Glc}}, \mathrm{C}-5^{\mathrm{Glc}}, \mathrm{C}-5^{\mathrm{Gal}}\right), 72.5\left(\mathrm{C}-3^{\mathrm{Gal}}\right), 71.6\left(\mathrm{C}-2^{\mathrm{Glc}}\right), 70.9$ $\left(\mathrm{C}-2^{\mathrm{Gal}}\right), 68.5\left(\mathrm{C}-4^{\mathrm{Gal}}\right), 61.0\left(\mathrm{C}-6^{\mathrm{Gal}}\right), 59.7\left(\mathrm{C}-6^{\mathrm{Glc}}\right), 52.5$ $\left(\mathrm{CH}_{2} \mathrm{CH}_{2} \mathrm{NH}\right), 38.1\left(\mathrm{CH}_{2} \mathrm{CH}_{2} \mathrm{NH}\right)$. MALDI-MS: calcd $\mathrm{m} / \mathrm{z}$ $1273.4\left[\mathrm{M}+\mathrm{Na}^{+}\right], 1289.4\left[\mathrm{M}+\mathrm{K}^{+}\right]$, found 1273.4 , 1289.4.

$\boldsymbol{N}, \boldsymbol{N}^{\prime}$-Bis-(4-(2,3,4,6-tetra- $\boldsymbol{O}$-acetyl- $\boldsymbol{\beta}$-D-galactopyranosyl$(1 \rightarrow 4)-2,3,6$-tri- $O$-acetyl- $\beta$-D-glucopyranosyloxy)-( $Z$ )-but-2enyloxycarbonyl)- $m$-xylylenediamine (Ac-G). According to GP 1, 7 (171 mg, $0.196 \mathrm{mmol})$ and $\alpha, \alpha^{\prime}$-diamino- $m$-xylene 9 (12 mg, $0.088 \mathrm{mmol}$ ) were reacted in $\mathrm{CH}_{2} \mathrm{Cl}_{2}(3 \mathrm{~mL})$. Purification by FC (petroleum ether/ethyl acetate $1: 2 \rightarrow 1: 3$ ) gave Ac-G (135 $\mathrm{mg}, 95 \%)$ as a white foam. $R_{\mathrm{f}}=0.15$ (petroleum ether/ ethyl acetate $1: 2) .{ }^{1} \mathrm{H}$ NMR $\left(600 \mathrm{MHz}, \mathrm{CDCl}_{3}\right): \delta=7.33-7.30$ (m, $1 \mathrm{H}, \mathrm{Ar}), 7.21-7.18(\mathrm{~m}, 3 \mathrm{H}, \mathrm{Ar}), 5.75-5.64(\mathrm{~m}, 4 \mathrm{H}$, $\left.\mathrm{H}^{\text {vinyl }}\right), 5.35\left(\mathrm{dd}, J=3.3 \mathrm{~Hz}, J=0.7 \mathrm{~Hz}, 2 \mathrm{H}, \mathrm{H}-4^{\mathrm{Gal}}\right), 5.20(\mathrm{bs}$,
$2 \mathrm{H}, \mathrm{NHC}(\mathrm{O})), 5.16\left(\mathrm{t}, J=9.3 \mathrm{~Hz}, 2 \mathrm{H}, \mathrm{H}-3^{\mathrm{Glc}}\right), 5.10(\mathrm{dd}, J=$ $\left.10.4 \mathrm{~Hz}, J=7.9 \mathrm{~Hz}, 2 \mathrm{H}, \mathrm{H}-2^{\mathrm{Gal}}\right), 4.95(\mathrm{dd}, J=10.4 \mathrm{~Hz}, J=$ $\left.3.5 \mathrm{~Hz}, 2 \mathrm{H}, \mathrm{H}-3^{\mathrm{Gal}}\right), 4.89(\mathrm{dd}, J=9.4 \mathrm{~Hz}, J=8.0 \mathrm{~Hz}, 2 \mathrm{H}$, $\left.\mathrm{H}-2^{\mathrm{Glc}}\right), 4.69\left(\mathrm{dd}, J=13.0 \mathrm{~Hz}, J=6.9 \mathrm{~Hz}, 2 \mathrm{H}, \mathrm{H}^{\text {allyl }}\right), 4.57$ $\left(\mathrm{dd}, J=13.1 \mathrm{~Hz}, J=5.7 \mathrm{~Hz}, 2 \mathrm{H}, \mathrm{H}^{\text {allyl }}\right), 4.52-4.50(\mathrm{~m}, 4 \mathrm{H}$, H-1 $\left.{ }^{\mathrm{Glc}} \mathrm{H}-6^{\mathrm{Glc}}\right), 4.48$ (d, $\left.J=7.9 \mathrm{~Hz}, 2 \mathrm{H}, \mathrm{H}-1^{\mathrm{Gal}}\right), 4.35$ (d, $J=$ $\left.5.9 \mathrm{~Hz}, 4 \mathrm{H}, \mathrm{H}^{\text {benzyl }}\right), 4.31\left(\mathrm{~d}, J=6.2 \mathrm{~Hz}, 4 \mathrm{H}, \mathrm{H}^{\text {allyl }}\right), 4.14-4.11$ (m, $\left.2 \mathrm{H}, \mathrm{H}-6^{\mathrm{Gal}}\right), 4.09-4.06$ (m, $\left.4 \mathrm{H}, \mathrm{H}-6^{\prime \mathrm{Glc}}, \mathrm{H}-6^{\prime \mathrm{Gal}}\right), 3.87$ (bt, $\left.J=6.8 \mathrm{~Hz}, 2 \mathrm{H}, \mathrm{H}-5^{\mathrm{Gal}}\right), 3.79\left(\mathrm{t}, J=9.5 \mathrm{~Hz}, 2 \mathrm{H}, \mathrm{H}-4^{\mathrm{Glc}}\right)$, $3.61-3.59\left(\mathrm{~m}, 2 \mathrm{H}, \mathrm{H}-5^{\mathrm{Glc}}\right), 2.15\left(\mathrm{~s}, 6 \mathrm{H}, \mathrm{C}(\mathrm{O}) \mathrm{CH}_{3}\right), 2.11(\mathrm{~s}, 6$ $\left.\mathrm{H}, \mathrm{C}(\mathrm{O}) \mathrm{CH}_{3}\right), 2.06\left(\mathrm{~s}, 6 \mathrm{H}, \mathrm{C}(\mathrm{O}) \mathrm{CH}_{3}\right), 2.04\left(\mathrm{~s}, 6 \mathrm{H}, \mathrm{C}(\mathrm{O}) \mathrm{CH}_{3}\right)$, $2.04\left(\mathrm{~s}, 6 \mathrm{H}, \mathrm{C}(\mathrm{O}) \mathrm{CH}_{3}\right), 2.02\left(\mathrm{~s}, 6 \mathrm{H}, \mathrm{C}(\mathrm{O}) \mathrm{CH}_{3}\right), 1.96(\mathrm{~s}, 6 \mathrm{H}$, $\left.\mathrm{C}(\mathrm{O}) \mathrm{CH}_{3}\right) .{ }^{13} \mathrm{C} \mathrm{NMR}\left(150 \mathrm{MHz}, \mathrm{CDCl}_{3}\right): \delta=170.4,170.3$, 170.1, 170.0, 169.8, 169.7, $169.1\left(C(\mathrm{O}) \mathrm{CH}_{3}\right), 156.2(\mathrm{OC}(\mathrm{O}) \mathrm{N})$, 137.1, 129.1 (Ar), 128.9, $128.5\left(\mathrm{CH}^{\text {olefin }}\right), 128.5,126.6(\mathrm{Ar})$, $101.1\left(\mathrm{C}-1^{\mathrm{Gal}}\right), 99.0\left(\mathrm{C}-1^{\mathrm{Glc}}\right), 76.3\left(\mathrm{C}-4^{\mathrm{Glc}}\right), 72.9\left(\mathrm{C}-3^{\mathrm{Glc}}\right), 72.6$ $\left(\mathrm{C}-5^{\mathrm{Glc}}\right), 71.6\left(\mathrm{C}-2^{\mathrm{Glc}}\right), 71.0\left(\mathrm{C}-3^{\mathrm{Gal}}\right), 70.7\left(\mathrm{C}-5^{\mathrm{Gal}}\right), 69.1\left(\mathrm{C}-2^{\mathrm{Gal}}\right)$, $66.6\left(\mathrm{C}-4^{\mathrm{Gal}}\right), 64.3\left(\mathrm{CH}_{2}{ }^{\text {allyl }}\right), 62.0\left(\mathrm{C}-6^{\mathrm{Glc}}\right), 60.8\left(\mathrm{C}-6^{\mathrm{Gal}}\right), 60.5$ $\left(\mathrm{CH}_{2}{ }^{\text {allyl }}\right), 44.9\left(\mathrm{CH}_{2}{ }^{\text {benzyl }}\right), 20.9-20.5\left(\mathrm{C}(\mathrm{O}) \mathrm{CH}_{3}\right)$. MALDI-MS: calcd $m / z, 1623.5\left[\mathrm{M}+\mathrm{Na}^{+}\right], 1639.5\left[\mathrm{M}+\mathrm{K}^{+}\right]$, found 1623.6, 1639.6. Anal. calcd for $\mathrm{C}_{70} \mathrm{H}_{92} \mathrm{~N}_{2} \mathrm{O}_{40}$ : C 52.50, H 5.79, N 1.75, found: C 51.92, H 5.81, N 1.84 .

$N, N^{\prime}$-Bis-(4- $(\beta$-D-galactopyranosyl-( $1 \rightarrow 4)-\beta$-D-glucopyranosyloxy)-(Z)-but-2-enyloxycarbonyl)- $m$-xylylenediamine (G). According to GP 2, Ac-G (130 mg, $0.081 \mathrm{mmol})$ was deacetylated with $0.5 \mathrm{M} \mathrm{NaOMe}$ solution $(0.5 \mathrm{~mL})$ in $\mathrm{MeOH}(2 \mathrm{~mL})$ to give $\mathbf{G}(81 \mathrm{mg}, 98 \%)$ as a white solid. ${ }^{1} \mathrm{H}$ NMR $(600 \mathrm{MHz}$, $\left.\mathrm{D}_{2} \mathrm{O}\right): \delta=7.29-7.27$ (m, $\left.1 \mathrm{H}, \mathrm{Ar}\right), 7.14-7.12$ (m, $\left.3 \mathrm{H}, \mathrm{Ar}\right)$, 5.73-5.71 (m, $\left.4 \mathrm{H}, \mathrm{H}^{\text {vinyl }}\right), 4.60-4.54\left(\mathrm{~m}, 4 \mathrm{H}, \mathrm{H}^{\text {allyl }}\right), 4.38-4.28$ $\left(\mathrm{m}, 8 \mathrm{H}, \mathrm{H}-1^{\mathrm{Glc}}, \mathrm{H}-1^{\mathrm{Gal}}, \mathrm{H}^{\text {allyl }}\right), 4.20\left(\mathrm{~s}, 4 \mathrm{H}, \mathrm{H}^{\text {benzyl }}\right), 3.84-3.82$ (m, $4 \mathrm{H}, \mathrm{H}-4^{\mathrm{Gal}}$, H-6 $\left.{ }^{\mathrm{Glc}}\right), 3.70-3.60\left(\mathrm{~m}, 8 \mathrm{H}, \mathrm{H}-5^{\mathrm{Gal}}\right.$, H-6 ${ }^{\prime \mathrm{Glc}}$, H-6 $\left.{ }^{\mathrm{Gal}}, \mathrm{H}-6^{\mathrm{Gal}}\right), 3.57-3.48$ (m, $\left.6 \mathrm{H}, \mathrm{H}-3^{\mathrm{Glc}}, \mathrm{H}-3^{\mathrm{Gal}}, \mathrm{H}-4^{\mathrm{Glc}}\right)$, $3.45-3.42\left(\mathrm{~m}, 4 \mathrm{H}, \mathrm{H}-2^{\mathrm{Gal}}, \mathrm{H}-5^{\mathrm{Glc}}\right), 3.20(\mathrm{t}, J=8.3 \mathrm{~Hz}, 2 \mathrm{H}$, $\left.\mathrm{H}-2^{\mathrm{Glc}}\right) .{ }^{13} \mathrm{C} \mathrm{NMR}\left(150 \mathrm{MHz}, \mathrm{D}_{2} \mathrm{O}\right): \delta=158.4(\mathrm{OC}(\mathrm{O}) \mathrm{N})$, 139.2, $129.0(\mathrm{Ar}), 128.9,128.5\left(\mathrm{CH}^{\text {olefin }}\right), 125.9,125.3(\mathrm{Ar})$, $102.9\left(\mathrm{C}-1^{\mathrm{Gal}}\right), 100.9\left(\mathrm{C}-1^{\mathrm{Glc}}\right), 78.3\left(\mathrm{C}-4^{\mathrm{Glc}}\right), 75.4\left(\mathrm{C}-5^{\mathrm{Gal}}\right), 74.8$ $\left(\mathrm{C}-5^{\mathrm{Glc}}\right), 74.4\left(\mathrm{C}-3^{\mathrm{Glc}}\right), 72.8\left(\mathrm{C}-3^{\mathrm{Gal}}\right), 72.6\left(\mathrm{C}-2^{\mathrm{Glc}}\right), 71.0\left(\mathrm{C}-2^{\mathrm{Gal}}\right)$, $68.6\left(\mathrm{C}-4^{\mathrm{Gal}}\right), 64.8\left(\mathrm{CH}_{2}{ }^{\text {allyl }}\right), 61.0\left(\mathrm{C}-6^{\mathrm{Gal}}\right), 61.0\left(\mathrm{CH}_{2}{ }^{\text {allyl }}\right), 60.0$ $\left(\mathrm{C}-6^{\mathrm{Glc}}\right), 43.9\left(\mathrm{CH}_{2}^{\mathrm{Bn}}\right)$. MALDI-MS: calcd $\mathrm{m} / \mathrm{z}$ 1035.4 [M + $\left.\mathrm{Na}^{+}\right]$, found 1035.4 .

$N, N^{\prime}$-Bis-(4-(2,3,4,6-tetra- $O$-acetyl- $\beta$-D-galactopyranosyl$(1 \rightarrow 4)-2,3,6$-tri- $O$-acetyl- $\beta$-D-glucopyranosyloxy)-( $Z$ )-but-2enyloxycarbonyl)-p-xylylenediamine (Ac-H). According to GP $1,7(157 \mathrm{mg}, 180 \mathrm{mmol})$ and $\alpha, \alpha^{\prime}$-diamino- $p$-xylene 10 (12 $\mathrm{mg}, 0.088 \mathrm{mmol})$ were reacted in $\mathrm{CH}_{2} \mathrm{Cl}_{2}(3 \mathrm{~mL})$. Purification by $\mathrm{FC}$ (petroleum ether/ethyl acetate $1: 2 \rightarrow 1: 3$ ) gave Ac-H (130 mg, 92\%) as a white foam. $R_{\mathrm{f}}=0.10$ (petroleum ether/ ethyl acetate 1:2). ${ }^{1} \mathrm{H} \mathrm{NMR}\left(600 \mathrm{MHz}, \mathrm{CDCl}_{3}\right): \delta=7.27$ (s, $4 \mathrm{H}, \mathrm{Ar}), 5.75-5.64\left(\mathrm{~m}, 4 \mathrm{H}, \mathrm{H}^{\text {vinyl }}\right), 5.35(\mathrm{~d}, J=2.9 \mathrm{~Hz}, 2 \mathrm{H}$, $\left.\mathrm{H}-4^{\mathrm{Gal}}\right), 5.17\left(\mathrm{t}, J=9.3 \mathrm{~Hz}, 2 \mathrm{H}, \mathrm{H}-3^{\mathrm{Glc}}\right), 5.10(\mathrm{dd}, J=10.4$ $\left.\mathrm{Hz}, J=7.9 \mathrm{~Hz}, 2 \mathrm{H}, \mathrm{H}-2^{\mathrm{Gal}}\right), 4.96(\mathrm{dd}, J=10.4 \mathrm{~Hz}, J=3.5$ $\left.\mathrm{Hz}, 2 \mathrm{H}, \mathrm{H}-3^{\mathrm{Gal}}\right), 4.89\left(\mathrm{dd}, J=9.4 \mathrm{~Hz}, J=8.0 \mathrm{~Hz}, 2 \mathrm{H}, \mathrm{H}-2^{\mathrm{Glc}}\right)$, $4.68\left(\mathrm{dd}, J=12.6 \mathrm{~Hz}, J=7.1 \mathrm{~Hz}, 2 \mathrm{H}, \mathrm{H}^{\text {allyl }}\right), 4.57(\mathrm{dd}, J=$ $\left.13.1 \mathrm{~Hz}, J=5.8 \mathrm{~Hz}, 2 \mathrm{H}, \mathrm{H}^{\mathrm{allyl}}\right), 4.51-4.48\left(\mathrm{~m}, 6 \mathrm{H}, \mathrm{H}-1^{\mathrm{Glc}}\right.$, $\left.\mathrm{H}-1^{\mathrm{Gal}}, \mathrm{H}-6^{\mathrm{Glc}}\right), 4.35\left(\mathrm{~d}, J=5.9 \mathrm{~Hz}, 4 \mathrm{H}, \mathrm{H}^{\text {benzyl }}\right), 4.32(\mathrm{~d}, J=$ $\left.6.3 \mathrm{~Hz}, 4 \mathrm{H}, \mathrm{H}^{\text {allyl }}\right), 4.15-4.12\left(\mathrm{~m}, 2 \mathrm{H}, \mathrm{H}-6^{\mathrm{Gal}}\right), 4.10-4.07(\mathrm{~m}$, $4 \mathrm{H}, \mathrm{H}-6^{\prime \mathrm{Glc}}, \mathrm{H}-6^{\prime \mathrm{Gal}}$ ), 3.87 (bt, $\left.J=6.7 \mathrm{~Hz}, 2 \mathrm{H}, \mathrm{H}-5^{\mathrm{Gal}}\right), 3.79$ $\left(\mathrm{t}, J=9.5 \mathrm{~Hz}, 2 \mathrm{H}, \mathrm{H}-4^{\mathrm{Glc}}\right), 3.62-3.60\left(\mathrm{~m}, 2 \mathrm{H}, \mathrm{H}-5^{\mathrm{Glc}}\right), 2.15$ $\left(\mathrm{s}, 6 \mathrm{H}, \mathrm{C}(\mathrm{O}) \mathrm{CH}_{3}\right), 2.11\left(\mathrm{~s}, 6 \mathrm{H}, \mathrm{C}(\mathrm{O}) \mathrm{CH}_{3}\right), 2.06(\mathrm{~s}, 6 \mathrm{H}$, $\left.\mathrm{C}(\mathrm{O}) \mathrm{CH}_{3}\right), 2.05\left(\mathrm{~s}, 6 \mathrm{H}, \mathrm{C}(\mathrm{O}) \mathrm{CH}_{3}\right), 2.04\left(\mathrm{~s}, 6 \mathrm{H}, \mathrm{C}(\mathrm{O}) \mathrm{CH}_{3}\right)$, $2.03\left(\mathrm{~s}, 6 \mathrm{H}, \mathrm{C}(\mathrm{O}) \mathrm{CH}_{3}\right), 1.97\left(\mathrm{~s}, 6 \mathrm{H}, \mathrm{C}(\mathrm{O}) \mathrm{CH}_{3}\right) .{ }^{13} \mathrm{C} \mathrm{NMR}(150$ $\left.\mathrm{MHz}, \mathrm{CDCl}_{3}\right): \delta=170.3,170.3,170.1,170.0,169.7,169.6$, $169.0\left(\mathrm{C}(\mathrm{O}) \mathrm{CH}_{3}\right), 156.7(\mathrm{OC}(\mathrm{O}) \mathrm{N}), 136.9(\mathrm{Ar}), 128.8,128.5$ $\left(\mathrm{CH}^{\text {olefin }}\right), 127.7(\mathrm{Ar}), 101.1\left(\mathrm{C}-1^{\mathrm{Gal}}\right), 98.9\left(\mathrm{C}-1^{\mathrm{Glc}}\right), 76.3(\mathrm{C}-$ $\left.4^{\mathrm{Glc}}\right), 72.9\left(\mathrm{C}-3^{\mathrm{Glc}}\right), 72.6\left(\mathrm{C}-5^{\mathrm{Glc}}\right), 71.6\left(\mathrm{C}-2^{\mathrm{Glc}}\right), 71.0\left(\mathrm{C}-3^{\mathrm{Gal}}\right)$, $70.7\left(\mathrm{C}-5^{\mathrm{Gal}}\right), 69.1\left(\mathrm{C}-2^{\mathrm{Gal}}\right), 66.6\left(\mathrm{C}-4^{\mathrm{Gal}}\right), 64.7\left(\mathrm{CH}_{2}{ }^{\text {allyl }}\right), 62.0$ $\left(\mathrm{C}-6^{\mathrm{Glc}}\right), 60.8\left(\mathrm{C}-6^{\mathrm{Gal}}\right), 60.5\left(\mathrm{CH}_{2}{ }^{\text {allyl }}\right), 44.3\left(\mathrm{CH}_{2}{ }^{\text {benzyl }}\right), 20.8-20.5$ 
$\left(\mathrm{C}(\mathrm{O}) \mathrm{CH}_{3}\right)$. MALDI-MS: calcd $m / z, 1623.5\left[\mathrm{M}+\mathrm{Na}^{+}\right], 1639.5$ $\left[\mathrm{M}+\mathrm{K}^{+}\right]$, found $1623.4,1639.4$. Anal. calcd for $\mathrm{C}_{70} \mathrm{H}_{92} \mathrm{~N}_{2} \mathrm{O}_{40}$ : C 52.50, H 5.79, N 1.75, found: C 52.21, H 5.72, N 1.72 .

$N, N^{\prime}$-Bis-(4-( $\beta$-D-galactopyranosyl-( $\left.1 \rightarrow 4\right)$ - $\beta$-D-glucopyranosyloxy)-(Z)-but-2-enyloxycarbonyl)- $p$-xylylenediamine $(\mathbf{H})$. According to GP 2, Ac-H (125 mg, $0.078 \mathrm{mmol})$ was deacetylated with $0.5 \mathrm{M} \mathrm{NaOMe}$ solution $(0.5 \mathrm{~mL})$ in $\mathrm{MeOH}(2 \mathrm{~mL})$ to give $\mathbf{H}(76 \mathrm{mg}, 96 \%)$ as a white solid. ${ }^{1} \mathrm{H}$ NMR $(600 \mathrm{MHz}$, $\left.\mathrm{D}_{2} \mathrm{O}\right): \delta=7.21(\mathrm{~s}, 4 \mathrm{H}, \mathrm{Ar}), 5.74-5.72\left(\mathrm{~m}, 4 \mathrm{H}, \mathrm{H}^{\text {vinyl }}\right)$, $4.60-4.53\left(\mathrm{~m}, 4 \mathrm{H}, \mathrm{H}^{\text {allyl }}\right), 4.39-4.29\left(\mathrm{~m}, 8 \mathrm{H}, \mathrm{H}^{-1}{ }^{\mathrm{Glc}}, \mathrm{H}-1^{\mathrm{Gal}}\right.$, $\left.\mathrm{H}^{\text {allyl }}\right), 4.20$ (s, $\left.4 \mathrm{H}, \mathrm{H}^{\mathrm{benzyl}}\right), 3.85-3.83\left(\mathrm{~m}, 4 \mathrm{H}, \mathrm{H}-4^{\mathrm{Gal}}, \mathrm{H}-6^{\mathrm{Glc}}\right)$, $3.71-3.66\left(\mathrm{~m}, 6 \mathrm{H}, \mathrm{H}-6^{\prime \mathrm{Glc}}, \mathrm{H}-6^{\mathrm{Gal}}, \mathrm{H}-6^{\prime \mathrm{Gal}}\right), 3.65-3.61(\mathrm{~m}, 2$ $\left.\mathrm{H}, \mathrm{H}-5^{\mathrm{Gal}}\right), 3.58-3.49$ (m, $\left.6 \mathrm{H}, \mathrm{H}-3^{\mathrm{Glc}}, \mathrm{H}-3^{\mathrm{Gal}}, \mathrm{H}-4^{\mathrm{Glc}}\right), 3.46-3.43$ $\left(\mathrm{m}, 4 \mathrm{H}, \mathrm{H}-2^{\mathrm{Gal}}, \mathrm{H}-5^{\mathrm{Glc}}\right), 3.21\left(\mathrm{t}, J=8.5 \mathrm{~Hz}, 2 \mathrm{H}, \mathrm{H}-2^{\mathrm{Glc}}\right) .{ }^{13} \mathrm{C}$ NMR (150 MHz, $\left.\mathrm{D}_{2} \mathrm{O}\right): \delta=158.4(\mathrm{OC}(\mathrm{O}) \mathrm{N}), 135.4(\mathrm{Ar}), 128.9$, $128.5\left(\mathrm{CH}^{\text {olefin }}\right), 127.9(\mathrm{Ar}), 102.9\left(\mathrm{C}-1^{\mathrm{Gal}}\right), 100.9\left(\mathrm{C}-1^{\mathrm{Glc}}\right), 78.3$ $\left(\mathrm{C}-4^{\mathrm{Glc}}\right), 75.4\left(\mathrm{C}-5^{\mathrm{Gal}}\right), 74.8,74.4,72.8,72.6,71.0,68.6$, (C$\left.2^{\mathrm{Glc}}, \mathrm{C}-2^{\mathrm{Gal}}, \mathrm{C}-3^{\mathrm{Gal}}, \mathrm{C}-3^{\mathrm{Glc}}, \mathrm{C}-4^{\mathrm{Gal}}, \mathrm{C}-5^{\mathrm{Glc}}\right), 64.7\left(\mathrm{CH}_{2}{ }^{\mathrm{allyl}}\right), 61.0$ $\left(\mathrm{C}^{-} 6^{\mathrm{Gal}}\right), 61.0\left(\mathrm{CH}_{2}^{\mathrm{allyl}}\right), 60.0\left(\mathrm{C}-6^{\mathrm{Glc}}\right), 43.8\left(\mathrm{CH}_{2}{ }^{\mathrm{Bn}}\right)$. MALDIMS: calcd $m / z$ 1035.4 [M $\left.+\mathrm{Na}^{+}\right]$, found 1034.9.

$N, N^{\prime}$-Bis-(4-(2,3,4,6-tetra- $O$-acetyl- $\beta$-D-galactopyranosyl$(1 \rightarrow 4)-2,3,6$-tri- $O$-acetyl- $\beta$-D-glucopyranosyloxy)-( $Z$ )-but-2enyloxycarbonyl)-4,7,10-trioxa-1,13-tridecanediamine (AcI). According to GP 1,7 (140 $\mathrm{mg}, 0.178 \mathrm{mmol}$ ) and 4,7,10trioxa-1,13-tridecanediamine $12(16 \mu \mathrm{L}, 0.073 \mathrm{mmol})$ were reacted in $\mathrm{CH}_{2} \mathrm{Cl}_{2}(3 \mathrm{~mL})$. Purification by $\mathrm{FC}$ (petroleum ether/ ethyl acetate $1: 3$, then ethyl acetate) gave Ac-I (120 mg, 98\%) as a white solid. $R_{\mathrm{f}}=0.27$ (ethyl acetate). ${ }^{1} \mathrm{H}$ NMR $(600 \mathrm{MHz}$, $\left.\mathrm{CDCl}_{3}\right): \delta=5.72-5.62\left(\mathrm{~m}, 4 \mathrm{H}, \mathrm{H}^{\text {vinyl }}\right), 5.35(\mathrm{dd}, J=3.4 \mathrm{~Hz}$, $\left.J=0.8 \mathrm{~Hz}, 2 \mathrm{H}, \mathrm{H}-4^{\mathrm{Gal}}\right), 5.18\left(\mathrm{t}, J=9.3 \mathrm{~Hz}, 2 \mathrm{H}, \mathrm{H}-3^{\mathrm{Glc}}\right), 5.10$ (dd, $\left.J=10.4 \mathrm{~Hz}, J=7.9 \mathrm{~Hz}, 2 \mathrm{H}, \mathrm{H}-2^{\mathrm{Gal}}\right), 4.95$ (dd, $J=10.4$ $\left.\mathrm{Hz}, J=3.5 \mathrm{~Hz}, 2 \mathrm{H}, \mathrm{H}-3^{\mathrm{Gal}}\right), 4.89(\mathrm{dd}, J=9.5 \mathrm{~Hz}, J=8.0 \mathrm{~Hz}$, $\left.2 \mathrm{H}, \mathrm{H}-2^{\mathrm{Glc}}\right), 4.63-4.47$ (m, $\left.10 \mathrm{H}, \mathrm{H}-1^{\mathrm{Glc}}, \mathrm{H}-1^{\mathrm{Gal}}, \mathrm{H}-6^{\mathrm{Glc}}, \mathrm{H}^{\mathrm{allyl}}\right)$, 4.33-4.26 (m, $\left.4 \mathrm{H}, \mathrm{H}^{\text {allyl }}\right), 4.15-4.12\left(\mathrm{~m}, 2 \mathrm{H}, \mathrm{H}-6^{\mathrm{Gal}}\right)$, 4.13-4.06 (m, 4 H, H-6 ${ }^{\text {Glc }}$, H-6 $^{\prime \text { Gal }}$ ), 3.87 (bt, $J=6.8$ Hz, 2 H, $\left.\mathrm{H}-5^{\mathrm{Gal}}\right), 3.79\left(\mathrm{t}, J=9.5 \mathrm{~Hz}, 2 \mathrm{H}, \mathrm{H}-4^{\mathrm{Glc}}\right), 3.65-3.59(\mathrm{~m}, 10 \mathrm{H}$, $\left.\mathrm{H}-5^{\mathrm{Glc}}, \mathrm{OCH}_{2} \mathrm{CH}_{2}, \mathrm{OCH}_{2} \mathrm{CH}_{2}\right), 3.55(\mathrm{t}, J=5.8 \mathrm{~Hz}, 4 \mathrm{H}$, $\mathrm{OCH}_{2} \mathrm{CH}_{2} \mathrm{CH}_{2}$ ), 3.29-3.26 (m, $\left.4 \mathrm{H}, \mathrm{CH}_{2} \mathrm{CH}_{2} \mathrm{NH}\right), 2.15$ (s, 6 $\left.\mathrm{H}, \mathrm{C}(\mathrm{O}) \mathrm{CH}_{3}\right), 2.12$ (s, $\left.6 \mathrm{H}, \mathrm{C}(\mathrm{O}) \mathrm{CH}_{3}\right), 2.06\left(\mathrm{~s}, 6 \mathrm{H}, \mathrm{C}(\mathrm{O}) \mathrm{CH}_{3}\right)$, $2.05\left(\mathrm{~s}, 6 \mathrm{H}, \mathrm{C}(\mathrm{O}) \mathrm{CH}_{3}\right), 2.04\left(\mathrm{~s}, 12 \mathrm{H}, \mathrm{C}(\mathrm{O}) \mathrm{CH}_{3}\right), 1.96(\mathrm{~s}, 6 \mathrm{H}$, $\left.\mathrm{C}(\mathrm{O}) \mathrm{CH}_{3}\right), 1.79-1.75\left(\mathrm{~m}, 4 \mathrm{H}, \mathrm{CH}_{2} \mathrm{CH}_{2} \mathrm{CH}_{2}\right) .{ }^{13} \mathrm{C}$ NMR (150 $\left.\mathrm{MHz}, \mathrm{CDCl}_{3}\right): \delta=170.4,170.3,170.1,170.0,169.8,169.7$, $169.1\left(\mathrm{C}(\mathrm{O}) \mathrm{CH}_{3}\right), 156.2(\mathrm{OC}(\mathrm{O}) \mathrm{N}), 128.8,128.5\left(\mathrm{CH}^{\text {olefin }}\right), 101.1$ $\left(\mathrm{C}-1^{\mathrm{Gal}}\right), 99.1\left(\mathrm{C}-1^{\mathrm{Glc}}\right), 76.3\left(\mathrm{C}-4^{\mathrm{Glc}}\right), 72.9\left(\mathrm{C}-3^{\mathrm{Glc}}\right), 72.6\left(\mathrm{C}-5^{\mathrm{Glc}}\right)$, $71.6\left(\mathrm{C}-2^{\mathrm{Glc}}\right), 71.0\left(\mathrm{C}-3^{\mathrm{Gal}}\right), 70.7\left(\mathrm{C}-5^{\mathrm{Gal}}\right), 70.5\left(\mathrm{OCH}_{2} \mathrm{CH}_{2} \mathrm{O}\right)$, $70.2\left(\mathrm{OCH}_{2} \mathrm{CH}_{2} \mathrm{O}\right), 69.6\left(\mathrm{OCH}_{2} \mathrm{CH}_{2}\right), 69.1\left(\mathrm{C}-2^{\mathrm{Gal}}\right), 66.6(\mathrm{C}-$ $\left.4^{\mathrm{Gal}}\right), 65.5\left(\mathrm{Allyl} \mathrm{CH}_{2}\right), 62.0\left(\mathrm{C}-6^{\mathrm{Glc}}\right), 60.8\left({\mathrm{C}-6^{\mathrm{Gal}}}\right), 60.2$ (Allyl $\left.\mathrm{CH}_{2}\right), 39.3\left(\mathrm{CH}_{2} \mathrm{CH}_{2} \mathrm{NH}\right), 29.4\left(\mathrm{CH}_{2} \mathrm{CH}_{2} \mathrm{CH}_{2}\right), 20.9-20.5$ $\left(\mathrm{C}(\mathrm{O}) \mathrm{CH}_{3}\right)$. MALDI-MS: calcd $m / z$ 1707.6 [M + Na $\left.{ }^{+}\right], 1723.6$ $\left[\mathrm{M}+\mathrm{K}^{+}\right]$, found 1707.2, 1723.2. Anal. calcd for $\mathrm{C}_{72} \mathrm{H}_{104} \mathrm{~N}_{2} \mathrm{O}_{43}$ : C 51.30, H 6.22, N 1.66, found: C 51.38, H 5.96, N 1.83 .

$N, N^{\prime}$-Bis-(4-( $\beta$-D-galactopyranosyl-( $\left.\rightarrow 4\right)$ - $\beta$-D-glucopyranosyloxy)-(Z)-but-2-enyloxycarbonyl)-4,7,10-trioxa-1,13-tridecanediamine (I). According to GP 2, Ac-I (114 mg, 0.068 mmol) was deacetylated with $0.5 \mathrm{M} \mathrm{NaOMe}$ solution $(0.5 \mathrm{~mL})$ in $\mathrm{MeOH}(2 \mathrm{~mL})$ to give $\mathbf{I}(73 \mathrm{mg}, 99 \%)$ as a white solid. ${ }^{1} \mathrm{H}$ NMR (600 MHz, $\left.\mathrm{D}_{2} \mathrm{O}\right): \delta=5.72$ (bs, $\left.4 \mathrm{H}, \mathrm{H}^{\text {vinyl }}\right), 4.60-4.53$ $\left(\mathrm{m}, 4 \mathrm{H}, \mathrm{H}^{\mathrm{allyl}}\right), 4.41\left(\mathrm{~d}, J=8.0 \mathrm{~Hz}, 2 \mathrm{H}, \mathrm{H}-1^{\mathrm{Glc}}\right), 4.38-4.29$ $\left(\mathrm{m}, 6 \mathrm{H}, \mathrm{H}-1^{\mathrm{Gal}}, \mathrm{H}^{\text {allyl }}\right), 3.87(\mathrm{dd}, J=12.4 \mathrm{~Hz}, J=1.5 \mathrm{~Hz}, 2 \mathrm{H}$, H-6 $\left.6^{\mathrm{Glc}}\right) 3.82\left(\mathrm{~d}, J=2.9 \mathrm{~Hz}, \mathrm{H}-4^{\mathrm{Gal}}\right), 3.73-3.61\left(\mathrm{~m}, 8 \mathrm{H}, \mathrm{H}-5^{\mathrm{Gal}}\right.$, H- $6^{\text {'Glc }}$, H-6 $\left.{ }^{\text {Gal }}, \mathrm{H}^{\prime} 6^{\text {Gal }}\right), 3.56-3.52\left(\mathrm{~m}, 14 \mathrm{H}, \mathrm{H}-3^{\mathrm{Gal}}, \mathrm{OCH}_{2} \mathrm{CH}_{2}\right.$, $\left.\mathrm{OCH}_{2} \mathrm{CH}_{2}, \mathrm{OCH}_{2} \mathrm{CH}_{2} \mathrm{O}\right), 3.49-3.42\left(\mathrm{~m}, 8 \mathrm{H}, \mathrm{H}-2^{\mathrm{Gal}}, \mathrm{H}-3^{\mathrm{Glc}}\right.$, $\left.\mathrm{H}-4^{\mathrm{Glc}}, \mathrm{H}-5^{\mathrm{Glc}}\right), 3.22\left(\mathrm{t}, J=8.4 \mathrm{~Hz}, 2 \mathrm{H}, \mathrm{H}-2^{\mathrm{Glc}}\right), 3.01(\mathrm{t}, J=$ $\left.6.2 \mathrm{~Hz}, 4 \mathrm{H}, \mathrm{CH}_{2} \mathrm{CH}_{2} \mathrm{NH}\right), 1,69(\mathrm{p}, J=6.3 \mathrm{~Hz}, 4 \mathrm{H}$, $\left.\mathrm{CH}_{2} \mathrm{CH}_{2} \mathrm{CH}_{2}\right) .{ }^{13} \mathrm{C}$ NMR $\left(150 \mathrm{MHz}, \mathrm{D}_{2} \mathrm{O}\right): \delta=158.2(\mathrm{OC}(\mathrm{O}) \mathrm{N})$, $128.8,128.6\left(\mathrm{CH}^{\text {olefin }}\right), 102.9\left(\mathrm{C}-1^{\mathrm{Gal}}\right), 101.0\left(\mathrm{C}-1^{\mathrm{Glc}}\right), 78.3(\mathrm{C}-$ $\left.4^{\mathrm{Glc}}\right), 75.4\left(\mathrm{C}-5^{\mathrm{Gal}}\right), 74.8,74.5,72.8,72.6,71.0,69.668 .6(\mathrm{C}-$
$\left.2^{\mathrm{Glc}}, \mathrm{C}-2^{\mathrm{Gal}}, \mathrm{C}-3^{\mathrm{Gal}}, \mathrm{C}-3^{\mathrm{Glc}}, \mathrm{C}-5^{\mathrm{Glc}}, \mathrm{OCH}_{2} \mathrm{CH}_{2}\right), 68.4\left(\mathrm{C}-4^{\mathrm{Gal}}\right), 68.3$ $\left(\mathrm{OCH}_{2} \mathrm{CH}_{2}\right), 64.8\left(\mathrm{CH}_{2}{ }^{\text {allyl }}\right), 61.0\left(\mathrm{C}-6^{\mathrm{Gal}}\right), 61.0\left(\mathrm{CH}_{2}{ }^{\text {allyl }}\right), 60.8$, $60.0\left(\mathrm{C}-6^{\mathrm{Glc}}\right), 37.6\left(\mathrm{CH}_{2} \mathrm{CH}_{2} \mathrm{NH}\right), 28.7\left(\mathrm{CH}_{2} \mathrm{CH}_{2} \mathrm{CH}_{2}\right)$. MALDIMS: calcd $m / z, 1119.4\left[\mathrm{M}+\mathrm{Na}^{+}\right], 1135.4\left[\mathrm{M}+\mathrm{K}^{+}\right]$, found 1119.3, 1135.3.

Tetrakis-(4-(2,3,4,6-tetra- $\boldsymbol{O}$-acetyl- $\boldsymbol{\beta}$-D-galactopyranosyl$(1 \rightarrow 4)-2,3,6$-tri- $O$-acetyl- $\beta$-D-glucopyranosyloxy)-( $Z$ )-but-2enyloxycarbonylaminomethyl)methane (Ac-J). According to GP 1, 7 (240 mg, $0.275 \mathrm{mmol}$ ) and tetra(aminomethyl)methane 15 (22) (8 mg, $0.056 \mathrm{mmol})$ were reacted in $\mathrm{CH}_{2} \mathrm{Cl}_{2}(2 \mathrm{~mL})$. Purification by FC (petroleum ether/ethyl acetate $1: 2 \rightarrow 1: 3 \rightarrow$ 1:4) gave Ac-J (70 mg, 53\%) as a white solid. $R_{\mathrm{f}}=0.20$ (petroleum ether/ethyl acetate 1:3). ${ }^{1} \mathrm{H} \mathrm{NMR}\left(600 \mathrm{MHz}, \mathrm{CDCl}_{3}\right)$ : $\delta=6.36(\mathrm{t}, J=6.6 \mathrm{~Hz}, 4 \mathrm{H}, \mathrm{NH}), 5.73-5.65\left(\mathrm{~m}, 8 \mathrm{H}, \mathrm{H}^{\mathrm{vinyl}}\right)$, $5.34\left(\mathrm{~d}, J=3.3 \mathrm{~Hz}, 4 \mathrm{H}, \mathrm{H}-4^{\mathrm{Gal}}\right), 5.18(\mathrm{~d}, J=9.3 \mathrm{~Hz}, 4 \mathrm{H}$, $\left.\mathrm{H}-3^{\mathrm{Glc}}\right), 5.09$ (dd, $\left.J=10.4 \mathrm{~Hz}, J=7.9 \mathrm{~Hz}, 4 \mathrm{H}, \mathrm{H}-2^{\mathrm{Gal}}\right), 4.95$ $\left(\mathrm{dd}, J=10.4 \mathrm{~Hz}, J=3.4 \mathrm{~Hz}, 4 \mathrm{H}, \mathrm{H}-3^{\mathrm{Gal}}\right), 4.89(\mathrm{dd}, J=9.4$ $\left.\mathrm{Hz}, J=8.0 \mathrm{~Hz}, 4 \mathrm{H}, \mathrm{H}-2^{\mathrm{Glc}}\right), 4.62-4.56\left(\mathrm{~m}, 8 \mathrm{H}, \mathrm{H}^{\mathrm{allyl}}\right)$, $4.51-4.48\left(\mathrm{~m}, 12 \mathrm{H}, \mathrm{H}-1^{\mathrm{Glc}}, \mathrm{H}-1^{\mathrm{Gal}}, \mathrm{H}-6^{\mathrm{Glc}}\right), 4.34$ (dd, $J=12.8$ $\left.\mathrm{Hz}, J=5.2 \mathrm{~Hz}, 4 \mathrm{H}, \mathrm{H}^{\text {allyl }}\right), 4.22(\mathrm{dd}, J=12.8 \mathrm{~Hz}, J=6.2 \mathrm{~Hz}$, $\left.4 \mathrm{H}, \mathrm{H}^{\text {allyl }}\right), 4.14-4.06\left(\mathrm{~m}, 12 \mathrm{H}, \mathrm{H}-6^{\prime \mathrm{Glc}}, \mathrm{H}-6^{\mathrm{Gal}}, \mathrm{H}-6^{\prime \mathrm{Gal}}\right), 3.87$ (bt, $\left.J=6.9 \mathrm{~Hz}, 4 \mathrm{H}, \mathrm{H}-5^{\mathrm{Gal}}\right), 3.80\left(\mathrm{t}, J=9.4 \mathrm{~Hz}, 4 \mathrm{H}, \mathrm{H}-4^{\mathrm{Glc}}\right)$, 3.60 (ddd, $\left.J=9.7 \mathrm{~Hz}, J=4.9 \mathrm{~Hz}, J=2.0 \mathrm{~Hz}, 4 \mathrm{H}, \mathrm{H}-5^{\mathrm{Glc}}\right)$, $2.81\left(\mathrm{~d}, J=4.2 \mathrm{~Hz}, 8 \mathrm{H}, \mathrm{CCH}_{2} \mathrm{NH}\right), 2.15\left(\mathrm{~s}, 12 \mathrm{H}, \mathrm{C}(\mathrm{O}) \mathrm{CH}_{3}\right)$, 2.12 (s, $\left.12 \mathrm{H}, \mathrm{C}(\mathrm{O}) \mathrm{CH}_{3}\right), 2.06$ (s, $\left.12 \mathrm{H}, \mathrm{C}(\mathrm{O}) \mathrm{CH}_{3}\right), 2.04$ (s, 24 $\left.\mathrm{H}, \mathrm{C}(\mathrm{O}) \mathrm{CH}_{3}\right), 2.03\left(\mathrm{~s}, 12 \mathrm{H}, \mathrm{C}(\mathrm{O}) \mathrm{CH}_{3}\right), 1.96$ (s, $12 \mathrm{H}$, $\left.\mathrm{C}(\mathrm{O}) \mathrm{CH}_{3}\right) .{ }^{13} \mathrm{C} \mathrm{NMR}\left(150 \mathrm{MHz}, \mathrm{CDCl}_{3}\right): \delta=170.3,170.3$, 170.1, 170.0, 169.7, 169.6, $169.0\left(\mathrm{C}(\mathrm{O}) \mathrm{CH}_{3}\right), 157.8(\mathrm{OC}(\mathrm{O}) \mathrm{N})$, 128.7, 128.2 ( $\left.\mathrm{CH}^{\text {olefin }}\right), 101.1\left(\mathrm{C}-1^{\mathrm{Gal}}\right), 99.4\left(\mathrm{C}-1^{\mathrm{Glc}}\right), 76.2(\mathrm{C}-$ $\left.4^{\mathrm{Glc}}\right), 72.9\left(\mathrm{C}-3^{\mathrm{Glc}}\right), 72.7\left(\mathrm{C}-5^{\mathrm{Glc}}\right), 71.6\left(\mathrm{C}-2^{\mathrm{Glc}}\right), 71.0\left(\mathrm{C}-3^{\mathrm{Gal}}\right)$, $70.7\left(\mathrm{C}-5^{\mathrm{Gal}}\right), 69.1\left(\mathrm{C}-2^{\mathrm{Gal}}\right), 66.6\left(\mathrm{C}-4^{\mathrm{Gal}}\right), 64.7\left(\mathrm{CH}_{2}{ }^{\text {allyl }}\right), 62.0$ $\left(\mathrm{C}-6^{\mathrm{Glc}}\right), 61.0\left(\mathrm{CH}_{2}{ }^{\text {allyl }}\right), 60.8\left(\mathrm{C}-6^{\mathrm{Gal}}\right), 39.8\left(\mathrm{CCH}_{2} \mathrm{NH}\right), 20.8-20.5$ $\left(\mathrm{C}(\mathrm{O}) \mathrm{CH}_{3}\right)$. MALDI-MS: calcd $m / z, 3084.0\left[\mathrm{M}+\mathrm{Na}^{+}\right], 3100.0$ $\left[\mathrm{M}+\mathrm{K}^{+}\right]$, found 3083.9, 3099.9. Anal. calcd for $\mathrm{C}_{129} \mathrm{H}_{176} \mathrm{~N}_{4} \mathrm{O}_{80}$ : C 50.59, H 5.79, N 1.83, found: C 50.77, H 5.94, N 1.79.

Tetrakis-(4-( $\boldsymbol{\beta}$-D-galactopyranosyl-( $\rightarrow 4)$ - $\boldsymbol{\beta}$-D-glucopyranosyloxy)-(Z)-but-2-enyloxycarbonylaminomethyl)methane (J). According to GP 2, Ac-J (78 mg, $0.025 \mathrm{mmol}$ ) was deacetylated with $0.5 \mathrm{M} \mathrm{NaOMe}$ solution $(0.5 \mathrm{~mL})$ in $\mathrm{MeOH}(2 \mathrm{~mL})$ to give J (48 mg, quant) as a white solid. ${ }^{1} \mathrm{H}$ NMR $\left(600 \mathrm{MHz}, \mathrm{D}_{2} \mathrm{O}\right)$ : $\delta=5.77-5.72\left(\mathrm{~m}, 8 \mathrm{H}, \mathrm{H}^{\text {vinyl }}\right), 4.61-4.56\left(\mathrm{~m}, 8 \mathrm{H}, \mathrm{H}^{\text {allyl }}\right)$, 4.43-4.30 (m, $\left.16 \mathrm{H}, \mathrm{H}-1^{\mathrm{Glc}}, \mathrm{H}-1^{\mathrm{Gal}}, \mathrm{H}^{\text {allyl }}\right), 3.88(\mathrm{~d}, J=8.3$ $\left.\mathrm{Hz}, 4 \mathrm{H}, \mathrm{H}-6^{\mathrm{Glc}}\right), 3.83\left(\mathrm{~d}, J=3.0 \mathrm{~Hz}, 4 \mathrm{H}, \mathrm{H}-4^{\mathrm{Gal}}\right), 3.73-3.62$ (m, $\left.16 \mathrm{H}, \mathrm{H}-5^{\mathrm{Gal}}, \mathrm{H}^{\prime} 6^{\text {(Glc }}, \mathrm{H}-6^{\mathrm{Gal}}, \mathrm{H}-6^{\prime \mathrm{Gal}}\right), 3.58-3.53(\mathrm{~m}, 12 \mathrm{H}$, H-3 $\left.3^{\mathrm{Glc}}, \mathrm{H}-3^{\mathrm{Gal}}, \mathrm{H}-4^{\mathrm{Glc}}\right), 3.49-3.43$ (m, $\left.8 \mathrm{H}, \mathrm{H}-2^{\mathrm{Gal}}, \mathrm{H}-5^{\mathrm{Glc}}\right), 3.23$ $\left(\mathrm{t}, J=8.3 \mathrm{~Hz}, 4 \mathrm{H}, \mathrm{H}-2^{\mathrm{Glc}}\right), 2.95$ (bs, $\left.8 \mathrm{H}, \mathrm{CCH}_{2} \mathrm{NH}\right) .{ }^{13} \mathrm{C} \mathrm{NMR}$ $\left(150 \mathrm{MHz}, \mathrm{D}_{2} \mathrm{O}\right): \delta=158.3(\mathrm{OC}(\mathrm{O}) \mathrm{N}), 128.8,128.5\left(\mathrm{CH}^{\text {olefin }}\right)$, $102.9\left(\mathrm{C}-1^{\mathrm{Gal}}\right), 100.9\left(\mathrm{C}-1^{\mathrm{Glc}}\right), 78.4\left(\mathrm{C}-4^{\mathrm{Glc}}\right), 75.4\left(\mathrm{C}-5^{\mathrm{Gal}}\right), 74.8$ $\left(\mathrm{C}-5^{\mathrm{Glc}}\right), 74.4\left(\mathrm{C}-3^{\mathrm{Glc}}\right), 72.8\left(\mathrm{C}-3^{\mathrm{Gal}}\right), 72.5\left(\mathrm{C}-2^{\mathrm{Glc}}\right), 71.0\left(\mathrm{C}-2^{\mathrm{Gal}}\right)$, $68.5\left(\mathrm{C}-4^{\mathrm{Gal}}\right), 64.7\left(\mathrm{CH}_{2}{ }^{\text {allyl }}\right), 61.1\left(\mathrm{CH}_{2}{ }^{\text {allyl }}\right), 61.0\left(\mathrm{C}-6^{\mathrm{Gal}}\right), 60.0$ $\left(\mathrm{C}-6^{\mathrm{Glc}}\right), 38.8\left(\mathrm{CCH}_{2} \mathrm{NH}\right)$. MALDI-MS: calcd $\mathrm{m} / \mathrm{z}$ 1907.7 [M $+\mathrm{Na}^{+}$], found 1908.4 .

Lectins and (Neo)glycoproteins. Purification of VAA and of the galectins (human galectins- $1,-3$, and -4 as well as rat galectin-5) started from extracts of dried leaves and bacteria harboring the respective expression vector. One-step isolation used lactosylated Sepharose 4B, which was prepared after activation by divinyl sulfone and elution with $0.2 \mathrm{M}$ lactose (23). The purity of the proteins was tested by one- and twodimensional gel electrophoresis on $10 \%$ running gels and mass spectrometry by nanoESI-MS/MS on a QTOF instrument Q-Tof2 (Waters Micromass, Manchester, UK) (24). Their quaternary structure was analyzed on a Superose 12 HR 10/30 column (GE Healthcare, Munich, Germany), and lectin activity was tested in 2-fold dilutions by hemagglutination with trypsinized, glutaraldehyde-fixed rabbit erythrocytes (25-27). Biotinylation with the $N$-hydroxysuccinimide ester derivative 
of biotin (Sigma, Munich, Germany) under activity-preserving conditions followed by mass spectrometric product analysis to quantify label incorporation was performed as described (24). Proteolytic truncation of human galectin-3 required $300 \mu \mathrm{g}$ collagenase D from Clostridium histolyticum (Roche Diagnostics, Mannheim, Germany) in Tris-buffered saline with $10 \mathrm{mM}$ $\mathrm{CaCl}_{2}$ at $\mathrm{pH} 7$ for $2 \mathrm{~h}$ at $37{ }^{\circ} \mathrm{C}$ and $1 \mathrm{mg}$ lectin as substrate (24). The neoglycoprotein with average ligand density of 28 units attached as $p$-isothiocyanatophenyl derivatives was based on bovine serum albumin as carrier; the glycoproteins serum amyloid $\mathrm{P}$ component, asialofetuin, and $\alpha_{1}$-acid glycoprotein were prepared as outlined $(28-30)$.

Inhibition Assays. Adsorption of (neo)glycoproteins to the surface of microtiter plate wells from phosphate-buffered saline $(50 \mu \mathrm{L})$ at $4{ }^{\circ} \mathrm{C}$ overnight established the ligand-bearing matrix. Residual sites for binding proteins were saturated with bovine serum albumin free of contaminating glycoproteins (Biomol, Hamburg, Germany; $100 \mu \mathrm{L}, 1 \% \mathrm{w} / \mathrm{v})$ for $1 \mathrm{~h}$ at $37^{\circ} \mathrm{C}$. The incubation with lectin-containing solution in the absence and presence of lactose and the glycocompounds lasted $1 \mathrm{~h}$ at 37 ${ }^{\circ} \mathrm{C}$, and the extent of bound lectin was determined after thorough washing steps with aliquots of the indicator conjugate streptavidin-peroxidase $\left(0.5 \mu \mathrm{g} \mathrm{mL}^{-1}\right.$; Sigma, Munich, Germany) and then with $o$-phenylenediamine $\left(1 \mathrm{mg} \mathrm{mL}{ }^{-1}\right) / \mathrm{H}_{2} \mathrm{O}_{2}(1 \mu \mathrm{L}$ $\mathrm{mL}^{-1}$ ) as chromogenic substrates (31). Cell assays were performed with the human B-lymphoblastoid line Croco II, the T-lymphoblast line MOLT-4 (T-ALL), the human pancreatic carcinoma line Capan-1, with reconstituted expression of the tumor suppressor $\mathrm{p} 16^{\mathrm{INK} 4 \mathrm{a}}$, which enhances galectin-binding capacity linked to susceptibility to anoikis (32; kindly provided by K. M. Detjen, Berlin, Germany), and the colon adenocarcinoma line SW480 in Dulbecco's phosphate-buffered saline (9.2 $\mathrm{mM} \mathrm{Na}_{2} \mathrm{HPO}_{4}, 1.5 \mathrm{mM} \mathrm{KH} \mathrm{PO}_{4}, 137 \mathrm{mM} \mathrm{NaCl}$, and 2.7 $\mathrm{mM} \mathrm{KCl}$ at $\mathrm{pH}$ 7.4) using standard conditions with lectin incubation for $30 \mathrm{~min}$ at $4{ }^{\circ} \mathrm{C}$ to minimize uptake and streptavidin/R-phycoerythrin as fluorescent indicator (1:40; Sigma, Munich, Germany). FACScan analysis and processing of data from fluorescence detection yielded the percentage of positive cells and the mean fluorescence intensity $(15,32)$. Cell proliferation in the absence/presence of test compound in aliquots of cell suspension was monitored after $48 \mathrm{~h}$ by using the blue chromogen MTT (5 mg mL ${ }^{-1}$; 3-(4,5-dimethyl-thiozol2-yl)-2,5-diphenyltetrazolium bromide) (33).

\section{RESULTS AND DISCUSSION}

Synthesis of the Glycocompounds. A convergent strategy with lactose derivatives activated as $p$-nitrophenyl carbonates was set up, taking advantage of (a) the fast reaction of $p$-nitrophenyl carbonates with amines, (b) the high yields of resulting carbamates, and (c) the versatile nature of the reaction with a variety of amino-substituted scaffolds $(34,35)$. To delineate any influence of sugar spacing on lectin binding, we synthesized two series of ligands with the carbamate either directly connected to the anomeric center ( $O$-glycosyl carbamates $\mathbf{A}-\mathbf{F}$ ) or separated from the pyranose ring by a butene diol linker $(\mathbf{G}-\mathbf{J})$. The synthesis of $O$-glycosyl carbamates by addition of anomerically unprotected carbohydrates to isocyanates is, with few exceptions (36), not stereoselective (37-39) and requires extensive product purification and identification, especially if several carbohydrate moieties are attached in one step. Activated glycosyl carbonates and 1-imidazolylcarbonyl glycosides, on the other hand, are excellent precursors of $O$-glycosyl carbamates-provided they are available as pure isomers-because they react under retention of configuration at the anomeric center. However, the preparation of glycosyl carbonates and 1-imidazolylcarbonyl glycosides from anomerically unprotected carbohydrates usually leads to $\alpha / \beta$ mixtures,
Scheme 1. Synthesis of Lactosyl Carbonate 3
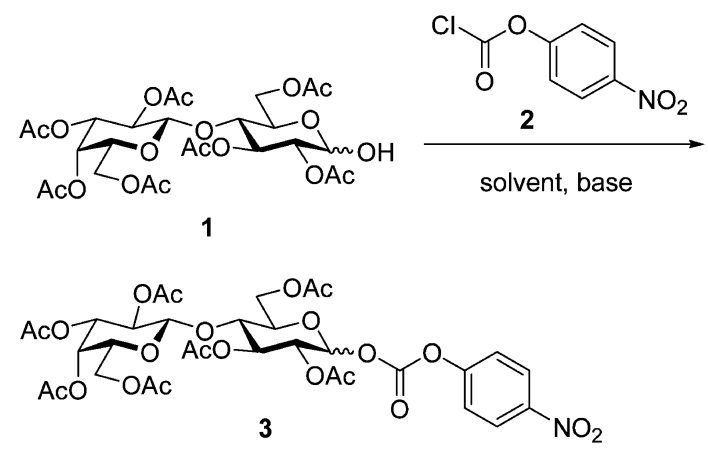

Table 1. Synthesis of lactosyl carbonate 3 under various reaction conditions according to Scheme 1

\begin{tabular}{|c|c|c|c|}
\hline solvent & base & $\alpha / \beta$ ratio $^{a}$ & yield $(\%)^{b}$ \\
\hline \multirow[t]{5}{*}{ toluene } & $\mathrm{K}_{2} \mathrm{CO}_{3}$ & $1: 2$ & 80 \\
\hline & $\mathrm{NaH}$ & $1: 1$ & 60 \\
\hline & $\mathrm{Et}_{3} \mathrm{~N}$ & $1: 1$ & 70 \\
\hline & pyridine & $1: 4$ & 80 \\
\hline & 2,6-lutidine & $1: 1$ & 85 \\
\hline \multirow{6}{*}{$\mathrm{CH}_{2} \mathrm{Cl}_{2}$} & $\mathrm{~K}_{2} \mathrm{CO}_{3}$ & n.d. ${ }^{e}$ & $<10$ \\
\hline & $\mathrm{NaH}$ & $1: 1.5$ & 80 \\
\hline & $\mathrm{Et}_{3} \mathrm{~N}$ & $1: 1$ & 80 \\
\hline & pyridine & $2: 1$ & 80 \\
\hline & DMAP & $2: 1$ & 80 \\
\hline & 2,6-lutidine & $1: 4$ & 90 \\
\hline \multirow[t]{5}{*}{ THF } & $\mathrm{K}_{2} \mathrm{CO}_{3}$ & n.d. & $<10$ \\
\hline & $\mathrm{Et}_{3} \mathrm{~N}$ & $1: 2.5$ & 80 \\
\hline & pyridine & $1: 1$ & 80 \\
\hline & DMAP & $2.5: 1$ & 80 \\
\hline & 2,6-lutidine & $1: 7$ & 30 \\
\hline \multirow[t]{6}{*}{$\mathrm{CH}_{3} \mathrm{CN}$} & $\mathrm{K}_{2} \mathrm{CO}_{3}$ & $1: 1$ & 90 \\
\hline & $\mathrm{Et}_{3} \mathrm{~N}$ & $1.5: 1$ & 90 \\
\hline & pyridine & $3: 1$ & 90 \\
\hline & $\mathrm{KO} t-\mathrm{Bu}$ & $1: 2.5$ & 35 \\
\hline & DMAP & $>19: 1$ & $95^{c}$ \\
\hline & 2,6-lutidine & $1:>10$ & $50^{d}$ \\
\hline
\end{tabular}

${ }^{a}$ Determined by ${ }^{1} \mathrm{H}$ NMR spectroscopy of crude product. ${ }^{b}$ Determined by ${ }^{1} \mathrm{H}$ NMR spectroscopy of crude product unless otherwise stated. ${ }^{c}$ Yield of isolated $\alpha-3 .{ }^{d}$ Yield of isolated $\beta-3 .{ }^{e}$ n.d. $=$ not determined.

too $(18,40-45)$. Leenders et al. reported high $\beta$-selectivity by hydrolysis of an intermediate anomeric silyl ether and immediate condensation of the resulting $\beta$-hydroxy group with succinimidyl chloroformate in an overall yield of $38 \%$ (46). When we applied this strategy to lactosyl carbonates, we also experienced a low overall yield (30-40\%). Therefore, we searched for conditions that gain fast and easy access to pure isomers of activated lactosyl carbonates to answer the first question given in the Introduction.

Scheme 1 and Table 1 summarize our results for the stereoselective preparation of lactosyl carbonate 3. From anomeric $O$-alkylation reactions, it is well-established that solvent and base have a tremendous influence on the selectivity at the anomeric center $(47,48)$. To explore the effect of these parameters on stereoselective $O$-acylation, we reacted anomerically deprotected lactose $\mathbf{1}$ (19) and $p$-nitrophenyl chloroformate 2 in different base/solvent combinations. With $\mathrm{K}_{2} \mathrm{CO}_{3}, \mathrm{NaH}$, $\mathrm{Et}_{3} \mathrm{~N}$, and pyridine, only modest degrees of selectivity were observed regardless of the solvent. Similar results had been reported with $\mathrm{CH}_{2} \mathrm{Cl}_{2} /$ pyridine $(\alpha / \beta=2 / 1,72 \%)$ and dimethoxyethane/ $\mathrm{NaH}(\alpha / \beta=1 / 1,55 \%)$ (18). In acetonitrile, however, 4-(dimethylamino)pyridine (DMAP) led to a remarkable $\alpha / \beta$ selectivity of $>19: 1$, and it was possible to isolate $\alpha-3$ in a yield of $95 \%$. In contrast, the sterically hindered base 2,6-lutidine gave an $\alpha / \beta$-mixture of $1:>10$, from which $\beta$-3 could be purified in a yield of $50 \%$. Attempts to improve the yield with 
Scheme 2. Synthesis of Activated Carbonate 7

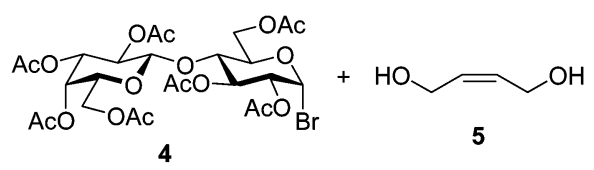

$\mathrm{Ag}_{2} \mathrm{CO}_{3}, \mathrm{I}_{2}$, $\mathrm{CaSO}_{4} \cdot 0.5 \mathrm{H}_{2} \mathrm{O}$ $61 \%$

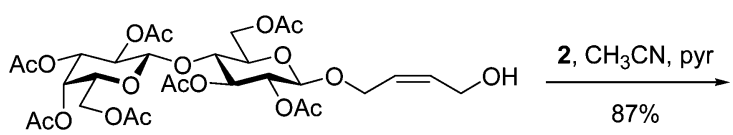

6

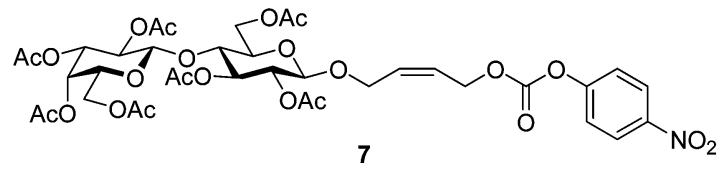

conservation of the $\beta$-selectivity by prolonging reaction times, however, were unsuccessful. We also observed that the concentration of the reaction mixture is crucial for product generation. Increasing the concentration from $0.03 \mathrm{M}$ (the concentration at which all reactions had been carried out) to $0.4 \mathrm{M}$ gave quantitative turnover, but with complete loss of selectivity $(\alpha / \beta=1 / 1)$. At lower concentrations $(0.003 \mathrm{M})$ no products were found.

The synthesis of spacer-separated carbonate 7 is depicted in Scheme 2. Acetobromolactose $4(20,21)$ and excess (Z)butenediol 5 were reacted under Koenigs-Knorr conditions to give the $\beta$-glycoside $\mathbf{6}$. Treatment with chloroformate $\mathbf{2}$ and pyridine in acetonitrile resulted in $p$-nitrophenyl carbonate $\mathbf{7}$ with $87 \%$ yield. The activated carbonates $\beta$-3 and 7 were coupled to a series of amines shown in Figure 1 to give the peracetylated lactosides Ac-A-Ac-J. These were deacetylated to the mono- to tetravalent lactose derivatives $\mathbf{A}-\mathbf{J}$ in a straightforward manner (Schemes 3 and 4), completing the synthesis. These compounds were next tested for their potency relative to lactose to inhibit the binding of labeled lectins to the (neo)glycoproteins.

Solid-Phase Inhibition Assays. Commonly, solid-phase inhibition assays are performed with a single type of matrix. To address the issue of whether the inhibitory activity of glycoclusters depends on local density of glycans in the (neo)glycoprotein matrix, we employed four types of matrices. The (neo)glycoproteins (LacBSA, SAP, ASF, and AGP, respectively) were adsorbed to the surface of plastic wells of microtiter plates. In each experimental series, the binding of the lectins to the (neo)glycoproteins was saturable and inhib-
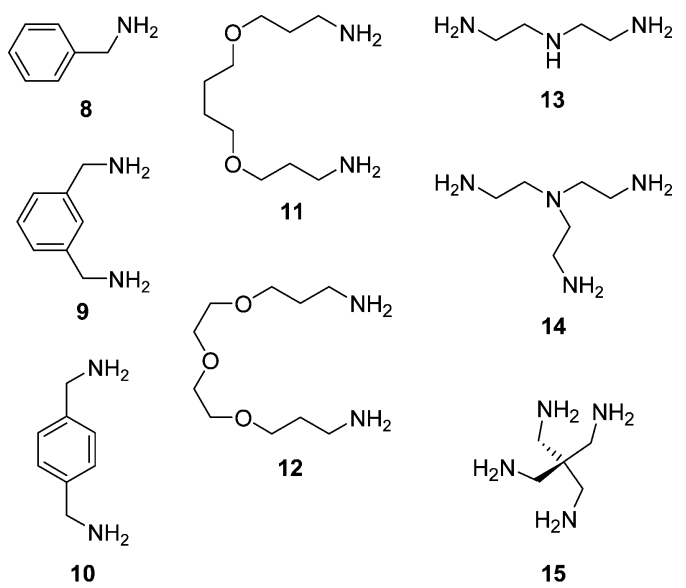

Figure 1. Amines used for preparation of $\mathbf{A}-\mathbf{J}$. itable by blocking the carbohydrate-binding site of the lectins. Their concentration was adjusted to yield signal intensity in the linear range in each case. To assess the inhibitory profiles lectin incubation was carried out in the presence of different concentrations of lactose and the synthesized lactose derivatives $\mathbf{A}-\mathbf{J}$, respectively. Figure 2 shows examples for inhibition of the binding of biotinylated VAA to AGP and human galectin-4 to LacBSA, respectively, by lactose and lactose derivatives B, D, and F. From these inhibition curves, we determined the concentration of inhibitor leading to inhibition of bound lectin of $50 \%\left(\mathrm{IC}_{50}\right)$. All $\mathrm{IC}_{50}$ values of multivalent ligands were calculated per lactose moiety contained; i.e., they were valencycorrected, leading to lower inhibitory potencies of some compounds (for example, trivalent $\mathbf{F}$, Figure 2) compared to free lactose. Relative inhibitory potencies compared to free lactose (set to 1) were plotted for each type of matrix, test substance, and lectin (Figure 3A-D). Only data for inhibitors with values above 1 are given.

The inhibition tests revealed that conjugation of lactose to an aglycon by carbamate formation can increase inhibitory potency. Some selectivity of the bivalent lactose derivatives for certain galectins could be detected. The highest relative inhibitory potency (65 per lactose moiety), e.g., was observed for inhibition of binding of galectin- 1 to the LacBSA surface by bivalent $\mathbf{E}$. The insertion of the spacer (direct comparison for the pairs $\mathbf{B} / \mathbf{G}$ and $\mathbf{D} / \mathbf{I}$ ) had favorable consequences only rarely. On average, these glycoclusters were more active than lysinebased compounds and surpass the activity of Tris- or aspartateglycine-based compounds with 6-aminohexyl spacers in several cases $(31,49)$.

Comparison of the different (neo)glycoprotein matrices revealed interesting insight into the dependence of the inhibitory activity of the lactose clusters on the local density of glycans in the matrix. For example, relative inhibition was generally lowered with increased degree of glycan branching, except for the chimera-type galectin-3 (Figure 3A-D). Since this lectin is a substrate for proteolytic processing by matrix metalloproteinases-3/-9 in vivo with impact for its activity in biosignaling $(50,51)$, we tested the truncated version along with full-length galectin-3. Conspicuous selectivity for full-length galectin-3 but not its proteolytically processed derivative was observed for several ligands (B, C, E, F) with short spacers when the degree of glycan branching on the matrix was high (Figure 3D). This feature resembles the activity of 1,3,5-triiodobenzene-based inhibitors with rigidified 2-propynyl lactoside with its 7.6-fold enhancement relative to lactose and of an octavalent poly(amidoamine) starburst glycodendrimer $(52,53)$. Under this special condition, even the monovalent compound A showed high activity with remarkable selectivity for galectin-3 (Figure 3D). As detailed comparison among the four panels A-D reveals, relative potency is a factor of ligand display on the matrix (see $\mathbf{E}$ in Figure $3 \mathrm{~A}-\mathrm{D}$ as instructive example). Inhibitory capacity should thus not be regarded as an absolute measure. Its emerging context-dependent nature confers some uncertainty to predictions for the impact on binding under physiological conditions, i.e., to cell surfaces. It is thus an obligatory step to determine whether the lactose derivatives can interfere with the binding of lectins to cells, using established tumor cells as model.

Cell-Binding Inhibition Assays. In these assays, biotinylated lectins were incubated with cells of different lines. The extent of binding of lectins to cells was measured by using fluorescently labeled streptavidin as second-step reagent. As described in the preceding part, concentration dependence of lectin binding was first determined to plot the linear range and plateau levels in each combination. Then, sugar specificity and constant reactivity of cells were ascertained in each case. An example for the carbohydrate dependence of lectin binding is given in Figure 
Scheme 3. Synthesis of Lactosyl Carbamates $A-F^{a}$
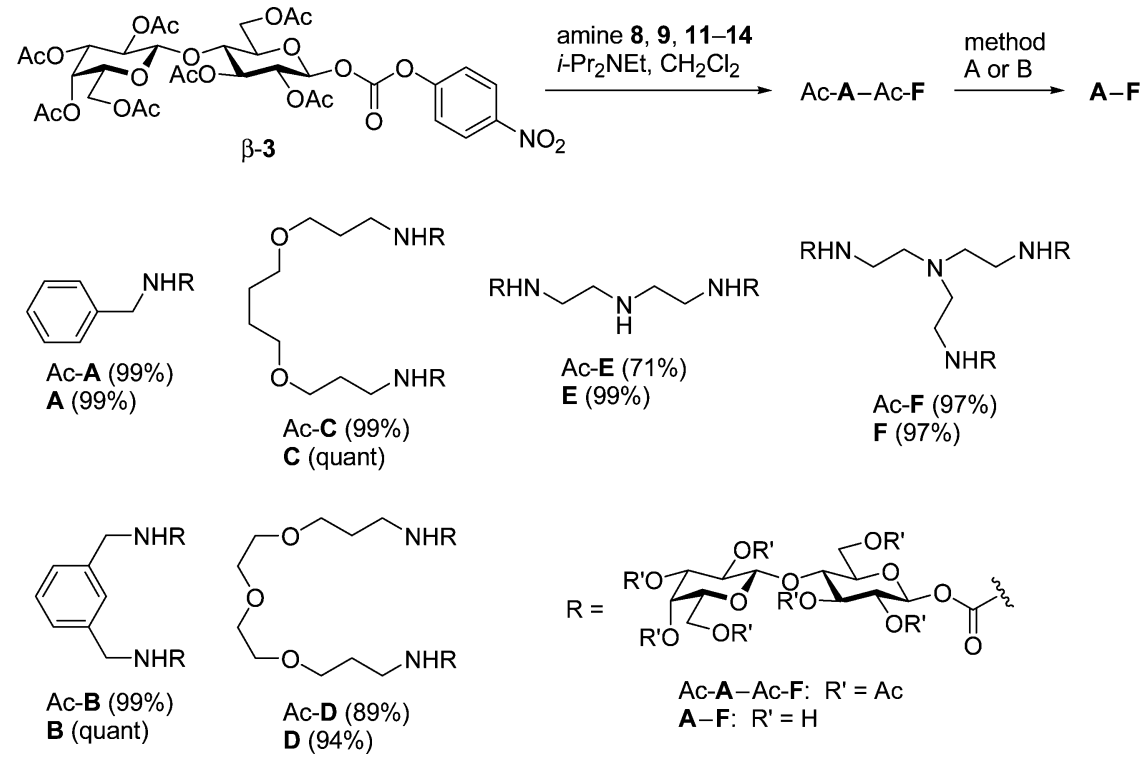

${ }^{a}$ Method A: NaOMe, $\mathrm{MeOH}$ (used for A-D). Method B: EtNMe, $\mathrm{MeOH}$ (used for E, F).

Scheme 4. Synthesis of Lactosyl Carbamates G-J
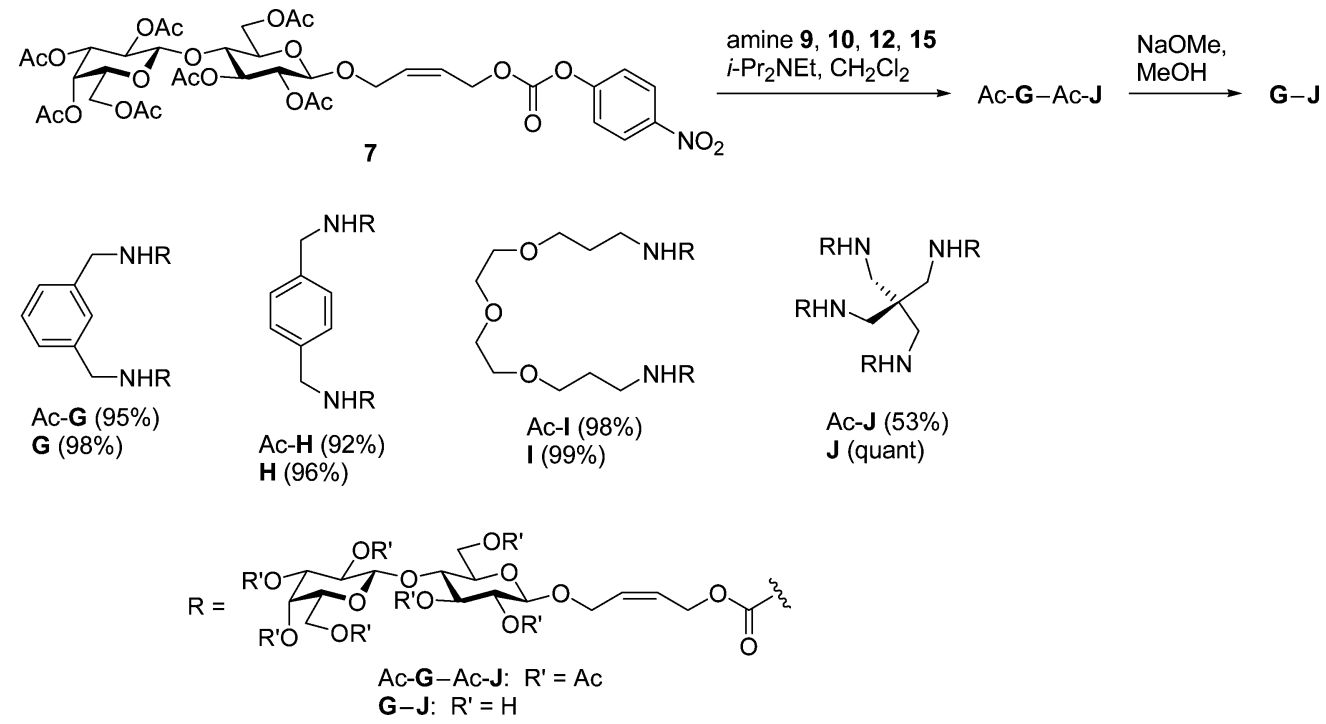

4. To preclude an impact of any variability in the cells' reactivity due to length of culture time during the passage, comparative measurements were performed with aliquots of cell batches in the same series. The obtained data, expressed in percentage of positive cells that show fluorescence above the control and mean fluorescence intensity $(F)$, confirms that the test substances can
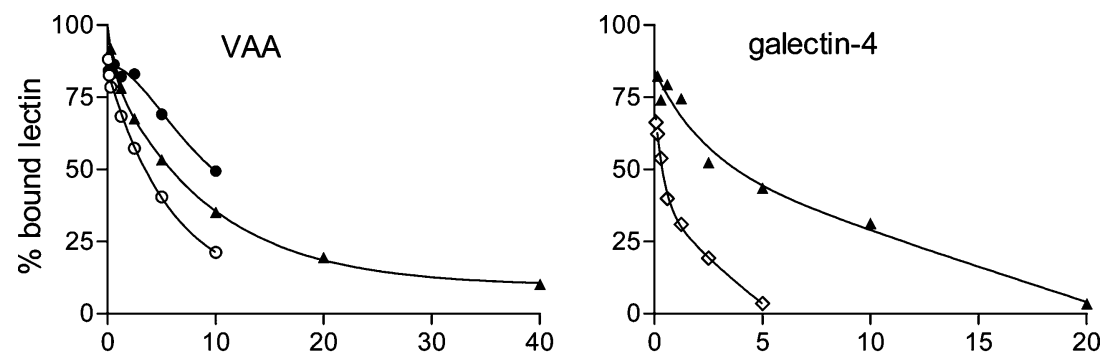

inhibitor concentration ( $\mathrm{mM})$

Figure 2. Inhibition of binding of biotinylated VAA $\left(7.5 \mu \mathrm{g} \mathrm{mL} \mathrm{L}^{-1}\right.$; left) and human galectin-4 $\left(5 \mu \mathrm{g} \mathrm{mL}^{-1}\right.$; right) to glycans of a (neo)glycoproteinpresenting matrix by a glycocompound and free lactose for comparison. The matrix presenting the lectin ligands was AGP $(0.5 \mu \mathrm{g} / \mathrm{well}$; left $)$ and the neoglycoprotein LacBSA $(0.25 \mu \mathrm{g} /$ well; right $)$. Lactose $(\mathbf{\Delta})$ was used as control, and the bivalent compounds $\mathbf{D}(\bigcirc)$ and $\mathbf{B}(\diamond)$ and the trivalent compound $\mathbf{F}(\bullet)$ as inhibitors. The concentration of inhibitor is calculated with respect to its lactose contents present in the inhibition assay to normalize data. 


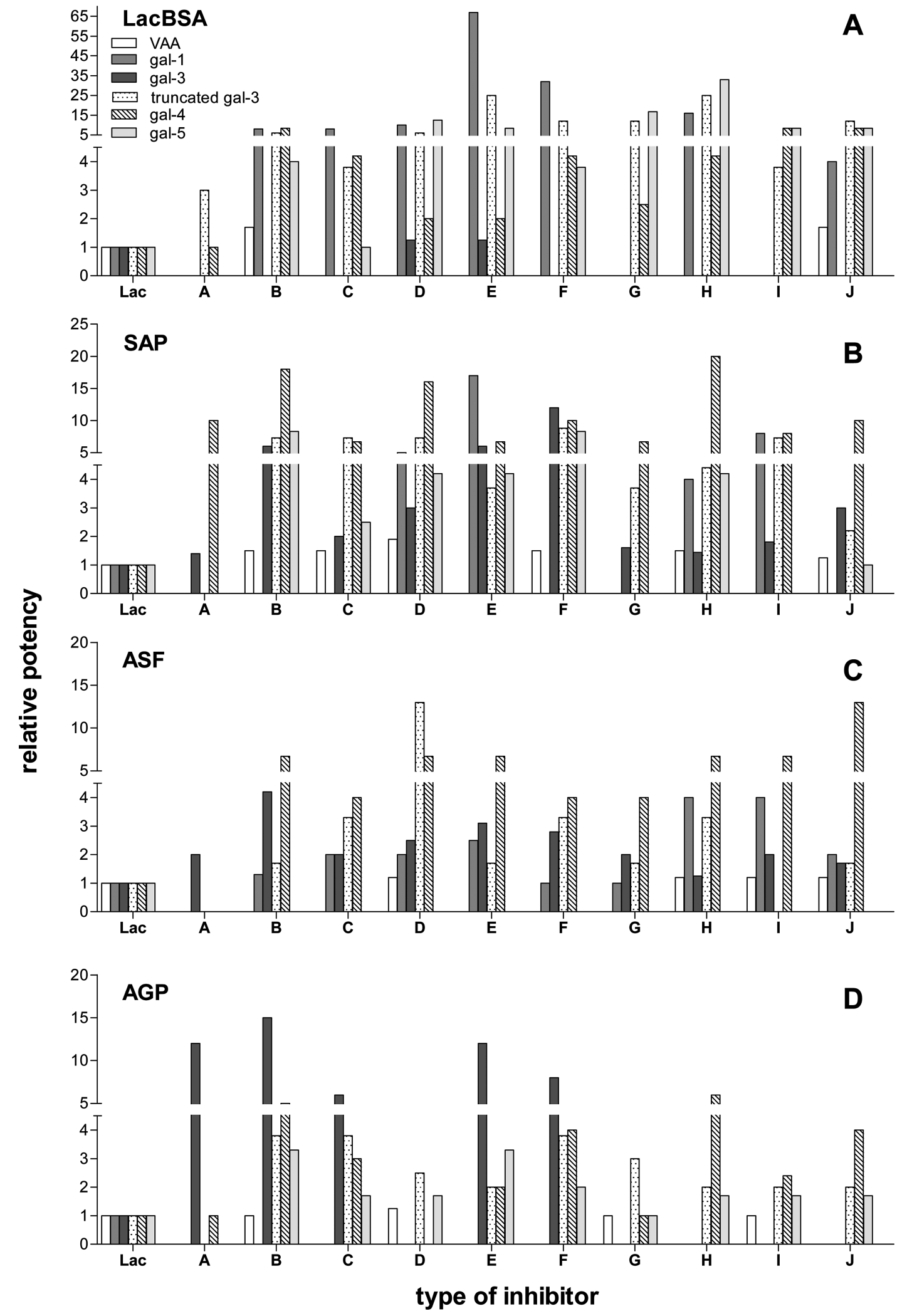

Figure 3. Relative potency of the panel of the synthetic lactose-containing compounds $\mathbf{A}-\mathbf{J}$ (for structures, see Schemes 3 and 4 ; designations of lectins are given in the top panel) as inhibitor of lectin binding. The $\mathrm{IC}_{50}$ values are based on the lactose concentration with free lactose as standard (set to 1) and they were determined in each case by systematic inhibition assays (for an example, see Figure 2). Experiments were repeated up to six times; the standard deviation did not exceed $11 \%$. All cases better than free lactose are given. The optimal conditions were as follows: (A) 0.25 $\mu \mathrm{g} /$ well neoglycoprotein (lactosylated bovine serum albumin: LacBSA) and $0.5 \mu \mathrm{g} \mathrm{mL}^{-1} \mathrm{VAA}, 30 \mu \mathrm{g} \mathrm{mL} \mathrm{galectin}^{-1}, 15 \mu \mathrm{g} \mathrm{mL} \mathrm{galectin}^{-1} 3$ (both versions), $5 \mu \mathrm{g} \mathrm{mL}^{-1}$ galectin- 4 , and $35 \mu \mathrm{g} \mathrm{mL}{ }^{-1}$ galectin-5; (B) $0.5 \mu \mathrm{g} /$ well serum amyloid $\mathrm{P}$ component (SAP) and $2 \mu \mathrm{g} \mathrm{mL}^{-1} \mathrm{VAA}^{-2} 2.5$ $\mu \mathrm{g} \mathrm{mL}^{-1}$ galectin-1, $5 \mu \mathrm{g} \mathrm{mL} \mathrm{g}^{-1}$ full-length galectin-3, $30 \mu \mathrm{g} \mathrm{mL}^{-1}$ truncated galectin-3, $5 \mu \mathrm{g} \mathrm{mL}^{-1}$ galectin-4, and $15 \mu \mathrm{g} \mathrm{mL}-1$ galectin-5; (C) 0.25 $\mu \mathrm{g} /$ well asialofetuin (ASF) and $0.5 \mu \mathrm{g} \mathrm{mL}{ }^{-1}$ VAA, $5 \mu \mathrm{g} \mathrm{mL}{ }^{-1}$ galectin-1, full-length galectin-3 and galectin- $4,30 \mu \mathrm{g} \mathrm{mL}{ }^{-1}$ truncated galectin-3, and $10 \mu \mathrm{g} \mathrm{mL}^{-1}$ galectin-5; (D) $0.5 \mu \mathrm{g} /$ well $\alpha_{1}$-acid glycoprotein (AGP) and $7.5 \mu \mathrm{g} \mathrm{mL}^{-1}$ VAA, $30 \mu \mathrm{g} \mathrm{mL} \mathrm{galectin}^{-1}, 10 \mu \mathrm{g} \mathrm{mL} \mathrm{gu}^{-1}$ full-length galectin-3, $60 \mu \mathrm{g} \mathrm{mL}^{-1}$ truncated galectin- $3,20 \mu \mathrm{g} \mathrm{mL}^{-1}$ galectin- 4 , and $25 \mu \mathrm{g} \mathrm{mL}{ }^{-1}$ galectin-5. 


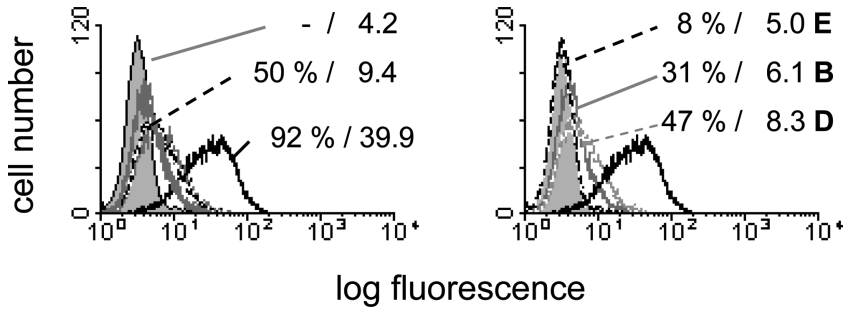

Figure 4. Semilogarithmic representation of the fluorescent surface staining of T-lymphoblast cells MOLT-4 (T-ALL) by labeled full-length galectin-3 $\left(10 \mu \mathrm{g} \mathrm{mL}^{-1}\right)$. The control value representing staining by the second-step reagent in the absence of lectin is given as the shaded area; the peak for lectin binding in the absence of any inhibitor as the black line. Quantitative data on the percentage of positive cells that show fluorescence above the control and mean fluorescence intensity are given. The left diagram illustrates the inhibition curves obtained by increasing concentrations of lactose of $1 \mathrm{mM}, 2 \mathrm{mM}, 4 \mathrm{mM}, 8 \mathrm{mM}$, and $10 \mathrm{mM}$. Given values are for the control (background staining without lectin), $2 \mathrm{mM}$ lactose, and maximal lectin binding without inhibitor. Right diagram: inhibition curves obtained by glycocompounds $\mathbf{E}, \mathbf{B}$, and $\mathbf{D}$ at a concentration of $2 \mathrm{mM}$ of lactose residues (i.e., a concentration of bivalent inhibitors of $1 \mathrm{mM}$ ).

act as inhibitors of lectin binding to cells. As shown in Figure 4 , compound $\mathbf{E}$ at a concentration of $2 \mathrm{mM}$ of lactose residues (i.e., a concentration of bivalent $\mathbf{E}$ of $1 \mathrm{mM}$ ) reduces binding of galectin-3 to the MOLT-4 T-lymphoblast cells from $92 \%(F$ 39.9 ) to $8 \%$ ( $F$ 5.0). In comparison, a $2 \mathrm{mM}$ solution of free lactose leads to a reduction to $50 \%$ ( $F$ 9.4). This compound distinguishes the full-length lectin from its truncated derivative and is only rather weakly reactive with galectins- 1 and -5 . In general, none of the lactose clusters surpasses lactose as inhibitor for galectin-1. Compound $\mathbf{D}$, at a concentration of $2 \mathrm{mM}$ in lactose moieties reduces binding of truncated galectin-3 to MOLT-4 T-lymphoblasts from $53 \%(F 9.0)$ to $28 \%(F 9.0)$ and binding of galectin-5 to the colon adenocarcinoma line SW480 from $89 \%$ ( $F 50.8$ ) to $60 \%(F 16.7)$. A $2 \mathrm{mM}$ solution of lactose correspondingly leads to a reduction to $32 \%(F 7.6)$ and $69 \%$ ( $F$ 20.2), respectively. Binding of galectin-4 to the $\mathrm{p} 16^{\mathrm{INK} 4 \mathrm{a}}$ expressing pancreatic carcinoma line Capan-1 is impaired best by the bivalent compound $\mathbf{B}$, a strongly active reagent in the solid-phase assays, with a reduction from $60 \%(F 47.0)$ to $16 \%$ $(F 7.6)$ at a concentration of lactose residues of $4 \mathrm{mM}$. Here, even a $20 \mathrm{mM}$ lactose solution results in a reduction to only $44 \%$ ( $F$ 24.5). To examine the influence of cell type, we tested galectin-3 binding also with pancreatic carcinoma cells. In this system, compound $\mathbf{F}$ was the best inhibitor with a nearly 4 -fold enhancement relative to lactose. Similar results on influence of cell type were obtained with the plant toxin, with compound D yielding the best results at a nearly 2-fold increase (not shown).

Having delineated the activity of the lactose derivatives in lectin binding to tumor cells, any further consideration for potential applications will crucially depend on their lack of cytotoxicity. To answer this last question, we monitored cell proliferation over a period of $48 \mathrm{~h}$ in the presence of lactose as control and lactose clusters selected to represent the scaffolds all at the same concentration of sugar in parallel. Compounds D, F, G, and I did not influence the growth of SW480 colon adenocarcinoma cells at a concentration of lactose residues of $2 \mathrm{mM}$; compound $\mathbf{F}$ was also tested on Capan-1 pancreatic carcinoma cells at $5 \mathrm{mM}$ without influence on proliferation.

\section{CONCLUSIONS}

In summary, we investigated inhibition of binding of adhesion/growth-regulatory galectins and a plant toxin to a series of immobilized (neo)glycoproteins and to tumor cells by monoto tetravalent lactose derivatives. Our experiments enabled us to answer the five questions given at the end of the Introduction:
(1) Synthetically, we developed conditions to stereoselectively produce activated lactosyl carbonates from the anomerically unprotected disaccharide. These derivatives have general application for the attachment of lactosyl residues to aminosubstituted scaffolds yielding lactosyl carbamates. (2) In systematic solid-phase screening, bioactivity was found to increase by more than 1 order of magnitude relative to free lactose (valence-corrected values) for galectins. (3) Individual scaffold structure was more important than valency of lactose in the glycocompounds, and introduction of butene diol to extend the spacer's length led to enhancements only rarely. However, the inhibitory activity showed selectivity for lectin type (plant toxin vs galectins) and among galectins. In addition, the nature of the matrix glycans ranging from bi- to tetraantennary $\mathrm{N}$-glycans and including the neoglycoprotein LacBSA also had a strong impact on inhibitory potency and selectivity. Interestingly, rather low activity was noted with the AGP matrix having the highest degree of branching except for the chimera-type galectin-3, an effector in cardiac dysfunction (54). This is why test series should routinely include cell assays to gauge potential for lectin blocking in a physiological context. (4) Strong inhibition of cell binding was detected for galectins-3 and -4 with distinct lactose-bearing compounds, and (5) we could show that representative examples of our compounds are not cytotoxic, emphasizing the suitability of carbamate-linked lactose derivatives in a lectin blocking approach.

Evidently, it is a reasonable long-term aim to tailor scaffolds adorned with lectin ligands for the ability to distinguish lectin groups or even members of a family based on reactivity. Due to arising evidence for functional antagonism among lectins, e.g., for galectins- 1 and -3 in tumor growth regulation (50), such a discriminatory capacity is desirable. However, the impact of glycan branching revealed herein precludes immediate extrapolations from data in a single system. The measured relative reduction in inhibitory potency in cell assays could be compensated by tailoring the glycan part to the lectin. Extended structures such as histo-blood group $\mathrm{ABH}$ epitopes or other natural ligands will enhance affinity and selectivity $(9,11,55-57)$.

\section{ACKNOWLEDGMENT}

We gratefully acknowledge the generous financial support by the research initiative LMUexcellent, the Deutsche Forschungsgemeinschaft (FOR 434 "Oligosaccharide and DNA Chips - Analysis of Secondary Gene Products"), the Verein zur Förderung des biologisch-technologischen Fortschritts in der Medizin e.V. (Heidelberg, Germany), and an EC Marie Curie Research Training Network grant (contract no. MCRTN-200519561), the inspiring discussions with Drs. B. Friday and S. Namirha, the helpful advice and remarkable diligence of the reviewers as well as the expert technical assistance by B. Hofer and L. Mantel.

\section{LITERATURE CITED}

(1) Gabius, H.-J., Ed. (2009) The Sugar Code. Fundamentals of Glycosciences, Wiley-VCH, Weinheim.

(2) Gabius, H.-J., Siebert, H.-C., André, S., Jiménez-Barbero, J., and Rüdiger, H. (2004) Chemical biology of the sugar code. ChemBioChem 5, 740-764.

(3) Yamazaki, N., Kojima, S., Bovin, N. V., André, S., Gabius, S., and Gabius, H.-J. (2000) Endogenous lectins as targets for drug delivery. Adv. Drug Delivery Rev. 43, 225-244.

(4) Roy, R. (2003) A decade of glycodendrimer chemistry. Trends Glycosci. Glycotechnol. 15, 291-310.

(5) Rorive, S., Belot, N., Decaestecker, C., Lefranc, F., Gordower, L., Micik, S., Maurage, C.-A., Kaltner, H., Ruchoux, M.-M., Danguy, A., Gabius, H.-J., Salmon, I., Kiss, R., and Camby, I. 
(2001) Galectin-1 is highly expressed in human gliomas with relevance for modulation of invasion of tumor astrocytes into the brain parenchyma. Glia 33, 241-255.

(6) Nagy, N., Legendre, H., Engels, O., André, S., Kaltner, H., Wasano, K., Zick, Y., Pector, J.-C., Decaestecker, C., Gabius, H.-J., Salmon, I., and Kiss, R. (2003) Refined prognostic evaluation in colon carcinoma using immunohistochemical galectin fingerprinting. Cancer 97, 1849-1858.

(7) Langbein, S., Brade, J., Badawi, J. K., Hatzinger, M., Kaltner, H., Lensch, M., Specht, K., André, S., Brinck, U., Alken, P., and Gabius, H.-J. (2007) Gene-expression signature of adhesion/ growth-regulatory tissue lectins (galectins) in transitional cell cancer and its prognostic relevance. Histopathology 91, 681690.

(8) Dam, T. K., Gabius, H.-J., André, S., Kaltner, H., Lensch, M., and Brewer, C. F. (2005) Galectins bind to the multivalent glycoprotein asialofetuin with enhanced affinities and a gradient of decreasing binding constants. Biochemistry 44, 12564-12571.

(9) Wu, A. M., Singh, T., Wu, J. H., Lensch, M., André, S., and Gabius, H.-J. (2006) Interaction profile of galectin-5 with free saccharides and mammalian glycoproteins: probing its fine specificity and the effect of naturally clustered ligand presentation. Glycobiology 16, 524-537.

(10) André, S., Kožár, T., Schuberth, R., Unverzagt, C., Kojima, S., and Gabius, H.-J. (2007) Substitutions in the N-glycan core as regulators of biorecognition: the case of core-fucose and bisecting GlcNAc moieties. Biochemistry 46, 6984-6995.

(11) Siebert, H.-C., André, S., Lu, S.-Y., Frank, M., Kaltner, H., van Kuik, A., Korchagina, E. Y., Bovin, N. V., Tajkhorshid, E., Kaptein, R., Vliegenthart, J. F. G., von der Lieth, C.-W., JiménezBarbero, J., Kopitz, J., and Gabius, H.-J. (2003) Unique conformer selection of human growth-regulatory lectin galectin-1 for ganglioside $\mathrm{GM}_{1}$ versus bacterial toxins. Biochemistry 42 , 14762-14773.

(12) Wu, A. M., Singh, T., Liu, J.-H., Krzeminski, M., Russwurm, R., Siebert, H.-C., Bonvin, A. M. J. J., André, S., and Gabius, H.-J. (2007) Activity-structure correlations in divergent lectin evolution: fine specificity of chicken galectin CG-14 and computational analysis of flexible ligand docking for CG-14 and the closely related CG-16. Glycobiology 17, 165-184.

(13) Jiménez, M., André, S., Siebert, H.-C., Gabius, H.-J., and D. Solís, D. (2006) AB-type lectin (toxin/agglutinin) from mistletoe: differences in affinity of the two galactoside-binding Trp/Tyrsites and regulation of their functionality by monomer/dimer equilibrium. Glycobiology 16, 926-937.

(14) Tsujishita, H., Hiramatsu, Y., Kondo, N., Ohmoto, H., Kondo, H., Kiso, M., and Hasegawa, A. (1997) Selectin-ligand interactions revealed by molecular dynamics simulation in solution. J. Med. Chem. 40, 362-369.

(15) André, S., Sansone, F., Kaltner, H., Casnati, A., Kopitz, J., Gabius, H.-J., and Ungaro, R. (2008) Calix[n]arene-based glycoclusters: bioactivity of thiourea-linked galactose/lactose moieties as inhibitors of binding of medically relevant lectins to a glycoprotein and cell-surface glycoconjugates and selectivity among human adhesion/growth-regulatory galectins. ChemBioChem 9, 1649-1661.

(16) Liu, J., Begley, D., Mitchell, D. D., Verlinde, C. L. M. J., Varani, G., and Fan, E. (2008) Multivalent drug design and inhibition of cholera toxin by specific and transient protein-ligand interactions. Chem. Biol. Drug Des. 71, 408-419.

(17) André, S., Kaltner, H., Lensch, M., Russwurm, R., Siebert, H.-C., Fallsehr, C., Tajkhorshid, E., Heck, A. J. R., von Knebel Doeberitz, M., Gabius, H.-J., and Kopitz, J. (2005) Determination of structural and functional overlap/divergence of five prototype galectins by analysis of the growth-regulatory interaction with ganglioside $\mathrm{GM}_{1}$ in silico and in vitro on human neuroblastoma cells. Int. J. Cancer 114, 46-57.

(18) Azoulay, M., Escriou, V., Florent, J.-C., and Monneret, C. (2001) Synthesis of new galactosyl and lactosyl carbamatecontaining glycolipids. J. Carbohydr. Chem. 20, 841-853.
(19) Renaudet, O., and Dumy, P. (2001) Expedient synthesis of aminooxylated carbohydrates for chemoselective access of glycoconjugates. Tetrahedron Lett. 42, 7575-7578.

(20) Dale, J. K. (1916) Preparation of bromoacetylglucose and certain other bromoacetyl sugars. J. Am. Chem. Soc. 38, 21872188.

(21) Hudson, C. S., and Kunz, A. (1925) Relations between rotatory power and structure in the sugar group. X. The chloro-, bromoand iodo-acetyl derivatives of lactose. J. Am. Chem. Soc. 47, 2052-2055.

(22) Feldman, K. S., and Masters, K. M. (1999) Facile preparation of tetra(2-aminoethyl)methane and tetra(3-aminopropyl)methane: novel tetravalent monomers for materials synthesis. J. Org. Chem. 64, 8945-8947.

(23) Gabius, H.-J. (1990) Influence of type of linkage and spacer on the interaction of $\beta$-galactoside-binding proteins with immobilized affinity ligands. Anal. Biochem. 189, 91-94.

(24) Kübler, D., Hung, C.-W., Dam, T. K., Kopitz, J., André, S., Kaltner, H., Lohr, M., Manning, J. C., He, L., Wang, H., Middelberg, A., Brewer, C. F., Reed, J., Lehmann, W.-D., and Gabius, H.-J. (2008) Phosphorylated human galectin-3: facile large-scale preparation of active lectin and detection of structural changes by CD spectroscopy. Biochim. Biophys. Acta 1780, 716722.

(25) Gabius, H.-J., Engelhardt, R., Cramer, F., Bätge, R., and Nagel, G. A. (1985) Pattern of endogenous lectins in a human epithelial tumor. Cancer Res. 45, 253-257.

(26) Jiménez, M., Sáiz, J. L., André, S., Gabius, H.-J., and Solís, D. (2005) Monomer/dimer equilibrium of the AB-type lectin from mistletoe enables combination of toxin/agglutinin activities in one protein: analysis of native and citraconylated proteins by ultracentrifugation/gel filtration and cell biological consequences of dimer destabilization. Glycobiology 15, 1386-1395.

(27) Lensch, M., Lohr, M., Russwurm, R., Vidal, M., Kaltner, H., André, S., and Gabius, H.-J. (2006) Unique sequence and expression profiles of rat galectins-5 and -9 as a result of speciesspecific gene divergence. Int. J. Biochem. Cell Biol. 38, 17411758.

(28) Gabius, H.-J., Bodanowitz, S., and Schauer, A. (1988) Endogenous sugar-binding proteins in human breast tissue and benign and malignant breast lesions. Cancer 61, 1125-1131.

(29) Shiyan, S. D., and Bovin, N. V. (1997) Carbohydrate composition and immunomodulatory activity of different glycoforms of $\alpha_{1}$-acid glycoprotein. Glycoconj. J. 14, 631-638.

(30) André, S., Kaltner, H., Furuike, T., Nishimura, S.-I., and Gabius, H.-J. (2004) Persubstituted cyclodextrin-based glycoclusters as inhibitors of protein-carbohydrate recognition using purified plant and mammalian lectins and wild-type and lectingene-transfected tumor cells as targets. Bioconjugate Chem. 15, 87-98.

(31) André, S., Frisch, B., Kaltner, H., Desouza, D. L., Schuber, F., and Gabius, H.-J. (2000) Lectin-mediated drug targeting: selection of valency, sugar type (Gal/Lac), and spacer length for cluster glycosides as parameters to distinguish ligand binding to C-type asialoglycoprotein receptors and galectins. Pharm. Res. 17, 985-990.

(32) André, S., Sanchez-Ruderisch, H., Nakagawa, H., Buchholz, M., Kopitz, J., Forberich, P., Kemmner, W., Böck, C., Deguchi, K., Detjen, K. M., Wiedenmann, B., von Knebel-Doeberitz, M., Gress, T. M., Nishimura, S.-I., Rosewicz, S., and Gabius, H.-J. (2007) Tumor suppressor p16 ${ }^{\mathrm{INK} 4 \mathrm{a}}$ - modulator of glycomic profile and galectin-1 expression to increase susceptibility to carbohydrate-dependent induction of anoikis in pancreatic carcinoma cells. FEBS J. 274, 3233-3256.

(33) Gabius, H.-J., Darro, F., Remmelink, M., André, S., Kopitz, J., Danguy, A., Gabius, S., Salmon, I., and Kiss, R. (2001) Evidence for stimulation of tumor proliferation in cell lines and histotypic cultures by clinically relevant low doses of the galactoside-binding mistletoe lectin, a component of proprietary extracts. Cancer Invest. 19, 114-126. 
(34) Wittmann, V., and Seeberger, S. (2000) Combinatorial solidphase synthesis of multivalent cyclic neoglycopeptides. Angew. Chem., Int. Ed. 39, 4348-4352.

(35) Wittmann, V., and Seeberger, S. (2004) Spatial screening of cyclic neoglycopeptides: identification of polyvalent wheat-germ agglutinin ligands. Angew. Chem., Int. Ed. 43, 900-903.

(36) Leenders, R. G. G., Ruytenbeek, R., Damen, E. W. P., and Scheeren, H. W. (1996) Highly diastereoselective synthesis of anomeric $\beta$-O-glycopyranosyl carbamates from isocyanates. Synthesis 1309-1312.

(37) Kunz, H., and Zimmer, J. (1993) Glycoside synthesis via electrophile-induced activation of $\mathrm{N}$-allyl carbamates. Tetrahedron Lett. 34, 2907-2910.

(38) Gum, A. G., Kappes-Roth, T., and Waldmann, H. (2000) Enzyme-labile protecting groups in peptide synthesis: development of glucose- and galactose-derived urethanes. Chem.-Eur. J. 6, 3714-3721.

(39) Knoben, H.-P., Schlüter, U., and Redlich, H. (2004) Synthesis of N-unsubstituted, mono- and disubstituted carbohydrate-1-Ocarbamates and their behaviour in glycoside syntheses. Carbohydr. Res. 339, 2821-2833.

(40) Ford, M. J., and Ley, S. V. (1990) A simple, one-pot, glycosidation procedure via 1-O-(1-imidazolylcarbonyl)glycoses and zinc bromide. Synlett 255-256.

(41) Iimori, T., Shibazaki, T., and Ikegami, S. (1996) A novel intramolecular decarboxylative glycosidation via mixed carbonate. Tetrahedron Lett. 37, 2267-2270.

(42) Scheffler, G., and Schmidt, R. R. (1997) Decarboxylative glycosidation reaction - intramolecular versus intermolecular reaction course. Tetrahedron Lett. 38, 2943-2946.

(43) Azumaya, I., Niwa, T., Kotani, M., Iimori, T., and Ikegami, S. (1999) An efficient synthesis of mixed $\beta$-carbonates of acylprotected sugars and their decarboxylative glycosidation promoted by trimethylsilyl trifluoromethanesulfonate. Tetrahedron Lett. 40, 4683-4686.

(44) Fernández, C., Nieto, O., Fontenla, J. A., Rivas, E., de Ceballos, M. L., and Fernández-Mayoralas, A. (2003) Synthesis of glycosyl derivatives as dopamine prodrugs: interaction with glucose carrier glut-1. Org. Biomol. Chem. 1, 767-771.

(45) Cai, T. B., Lu, D., Tang, X., Zhang, Y., Landerholm, M., and Wang, P. G. (2005) New glycosidase activated nitric oxide donors: glycose and 3-morphorlinosydnonimine conjugates. $J$. Org. Chem. 70, 3518-3524.

(46) Leenders, R. G. G., Scheeren, H. W., Houba, P. H. J., Boven, E., and Haisma, H. J. (1995) Synthesis and evaluation of novel daunomycin-phosphate, -sulfate, $-\beta$-glucuronide and $-\beta$-glucoside prodrugs for application in ADEPT. Bioorg. Med. Chem. Lett. 5, 2975-2980.

(47) Schmidt, R. R. (1996) The anomeric $O$-alkylation and the trichloroacetimidate method - versatile strategies for glycoside bond formation. Modern Methods in Carbohydrate Synthesis (Khan, S. H., and O'Neill, R. A., Eds.) pp 20-54, Harwood Academic Publishers, Amsterdam.

(48) Tamura, J. (2000) Glycosylation methods: alkylations of reducing sugars. Carbohydrates in Chemistry and Biology (Ernst, B., Hart, G. W., and Sinaÿ, P., Eds.) pp 177-193, Wiley-VCH, Weinheim.

(49) Lee, R. T., Gabius, H.-J., and Lee, Y. C. (1992) Ligand binding characteristics of the major mistletoe lectin. J. Biol. Chem. 267, 23722-23727.

(50) Kopitz, J., von Reitzenstein, C., André, S., Kaltner, H., Uhl, J., Ehemann, V., Cantz, M., and Gabius, H.-J. (2001) Negative regulation of neuroblastoma cell growth by carbohydratedependent surface binding of galectin- 1 and functional divergence from galectin-3. J. Biol. Chem. 276, 35917-35923.

(51) Lohr, M., Kaltner, H., Lensch, M., André, S., Sinowatz, F., and Gabius, H.-J. (2008) Cell-type-specific expression of murine multifunctional galectin-3 and its association with follicular atresia/luteolysis in contrast to pro-apoptotic galectins-1 and -7. Histochem. Cell Biol. 130, 567-581.

(52) André, S., Ortega, P. J. C., Perez, M. A., Roy, R., and Gabius, H.-J. (1999) Lactose-containing starburst dendrimers: influence of dendrimer generation and binding-site orientation of receptors (plant/animal lectins and immunoglobulins) on binding properties. Glycobiology 9, 1253-1261.

(53) André, S., Liu, B., Gabius, H.-J., and Roy, R. (2003) First demonstration of differential inhibition of lectin binding by synthetic tri- and tetravalent glycoclusters from cross-coupling of rigidified 2-propynyl lactoside. Org. Biomol. Chem. 1, 39093916.

(54) Liu, Y.-H., D’Ambrosio, M., Liao, T.-D., Peng, H., Rhaleb, N.-E., Sharma, U., André, S., Gabius, H.-J., and Carretero, O. A. (2009) N-acetyl-seryl-aspartyl-lysyl-proline prevents cardiac remodeling and dysfunction induced by galectin-3, a mammalian adhesion/growth-regulatory lectin. Am. J. Physiol. Heart Circ. Physiol. 296, H404-H412.

(55) Wu, A. M., Wu, J. H., Liu, J.-H., Singh, T., André, S., Kaltner, H., and Gabius, H.-J. (2004) Effects of polyvalency of glycotopes and natural modifications of human blood group ABH/Lewis sugars at the $\mathrm{Gal} \beta 1$-terminated core saccharides on the binding of domain I of recombinant tandem-repeat-type galectin-4 from rat gastrointestinal tract (G4-N). Biochimie 86, 317-326.

(56) André, S., Kojima, S., Prahl, I., Lensch, M., Unverzagt, C., and Gabius, H.-J. (2005) Introduction of extended LEC14-type branching into core-fucosylated biantennary N-glycan. FEBS J. 272, 1986-1998.

(57) Gabius, H.-J. (2008) Glycans: bioactive signals decoded by lectins. Biochem. Soc. Trans. 36, 1491-1496.

BC900152W 